PNNL-13290

\title{
Medical Isotope Production in the Fast Flux Test Facility and the High Flux Isotope Reactor and Isotope Production Software Users Guides
}

M. A. Garland

August 2000

Prepared for

The U.S. Department of Energy

under Contract DE-AC06-76RLO 1830

Pacific Northwest National Laboratory

Richland, Washington 99352 



\section{DISCLAIMER}

This report was prepared as an account of work sponsored by an agency of the United States Government. Neither the United States Government nor any agency thereof, nor any of their employees, make any warranty, express or implied, or assumes any legal liability or responsibility for the accuracy, completeness, or usefulness of any information, apparatus, product, or process disclosed, or represents that its use would not infringe privately owned rights. Reference herein to any specific commercial product, process, or service by trade name, trademark, manufacturer, or otherwise does not necessarily constitute or imply its endorsement, recommendation, or favoring by the United States Government or any agency thereof. The views and opinions of authors expressed herein do not necessarily state or reflect those of the United States Government or any agency thereof. 


\section{DISCLAIMER}

Portions of this document may be illegible in electronic image products. Images are produced from the best available original document. 


\section{Summary}

This report was prepared as input for the report Isotope Production at the Hanford Site in Richland, Washington (Pacific Northwest National Laboratory 1999) to provide a perspective on the relative medical isotope production capabilities of the Fast Flux Test Facility (FFTF) at the Hanford Site in Richland, Washington and the High Flux Isotope Reactor (HFIR) at the Oak Ridge National Laboratory in Oak Ridge, Tennessee. It will also serve to meet the University of Maryland Department of Nuclear Engineering technical paper requirement for a Master of Science degree for M. A. Garland.

Isotope production at various reactor facilities depends on many factors such as neutron flux spectra, target isotope energy-dependent cross sections, and target volumes. This report uses representative data for both reactors to generate medical isotope production data that can be used to compare the capabilities of the two reactors. Production capability for FFTF is evaluated for representative locations throughout the reactor core, whereas the calculations for HFIR are limited to selected core locations where the neutron flux is highest.

For the purposes of this report, twenty-three isotopes are evaluated. These isotopes are among the thirty-one that are the most likely candidates for production should FFTF be restarted and are also isotopes for which HFIR production has been calculated.

The following table summarizes the data generated for this report:

FFTF-HFIR Isotope Production Comparison

\begin{tabular}{|c|c|c|c|c|c|c|c|}
\hline \multirow{2}{*}{$\begin{array}{l}\text { Product } \\
\text { Isotope }\end{array}$} & \multicolumn{2}{|c|}{$\begin{array}{l}\text { Product Activity } \\
\text { (Ci) }\end{array}$} & \multirow{2}{*}{$\begin{array}{c}\text { Production } \\
\text { Ratio } \\
\text { (FFTF/HFIR) }\end{array}$} & \multicolumn{2}{|c|}{$\begin{array}{c}\text { Target Volume } \\
\left(\mathrm{cm}^{3}\right)\end{array}$} & \multirow{2}{*}{$\begin{array}{c}\text { Volume } \\
\text { Ratio } \\
\text { (FFTF/HFIR) }\end{array}$} & \multirow{2}{*}{$\begin{array}{l}\text { FFTF Advantage } \\
\text { (Prod. Ratio x } \\
\text { Vol. Ratio) }\end{array}$} \\
\hline & FFTF & HFIR & & FFTF & HFIR & & \\
\hline Ac-227 & $8.5 E+01$ & $4.3 E+01$ & 2.0 & 38500 & 386 & 99.7 & 197 \\
\hline Cd-109 & $1.2 E+04$ & $4.7 E+03$ & 2.6 & 38500 & 386 & 99.7 & 255 \\
\hline $\mathrm{Cu}-64$ & $7.5 \mathrm{E}+00$ & $1.1 \mathrm{E}+01$ & 0.7 & 72 & 12.8 & 5.6 & 3.8 \\
\hline $\mathrm{Cu}-67$ & $2.9 \mathrm{E}+00$ & $4.1 \mathrm{E}+00$ & 0.7 & 72 & 12.8 & 5.6 & 4.0 \\
\hline Ho-166 & $9.1 \mathrm{E}+01$ & $1.2 \mathrm{E}+03$ & 0.1 & 72 & 12.8 & 5.6 & 0.4 \\
\hline $\mathrm{I}-131$ & $4.3 \mathrm{E}+02$ & $5.5 \mathrm{E}+03$ & 0.1 & 72 & 12.8 & 5.6 & 0.4 \\
\hline Ir-192 & $8.2 E+06$ & $7.9 \mathrm{E}+06$ & 1.0 & 77100 & 386 & 200 & 207 \\
\hline Mo-99 & $1.0 \mathrm{E}+02$ & $2.3 E+02$ & 0.4 & 72 & 12.8 & 5.6 & 2.4 \\
\hline Os-194 & $3.1 \mathrm{E}+01$ & $4.0 \mathrm{E}+03$ & 0.0 & 77100 & 386 & 200 & 1.5 \\
\hline P-32 & $5.5 \mathrm{E}+01$ & $7.8 \mathrm{E}+01$ & 0.7 & 72 & 12.8 & 5.6 & 4.0 \\
\hline $\mathrm{P}-33$ & $4.6 \mathrm{E}+01$ & $3.0 \mathrm{E}+02$ & 0.2 & 77100 & 386 & 200 & 30.6 \\
\hline $\mathrm{Pd}-103$ & $1.6 \mathrm{E}+03$ & $2.4 \mathrm{E}+04$ & 0.1 & 77100 & 386 & 200 & 13.3 \\
\hline Pt-195m & $6.5 E+01$ & $1.9 \mathrm{E}+02$ & 0.3 & 72 & 12.8 & 5.6 & 1.9 \\
\hline $\mathrm{Re}-186$ & $1.3 \mathrm{E}+04$ & $1.1 \mathrm{E}+05$ & 0.1 & 72 & 12.8 & 5.6 & 0.7 \\
\hline $\mathrm{Sc}-47$ & $5.7 \mathrm{E}+01$ & $1.4 \mathrm{E}+02$ & 0.4 & 72 & 12.8 & 5.6 & 2.3 \\
\hline $\mathrm{Se}-75$ & $4.4 \mathrm{E}+02$ & $1.3 \mathrm{E}+03$ & 0.3 & 38500 & 386 & 99.7 & 33.8 \\
\hline Sm-145 & $4.3 \mathrm{E}+01$ & $1.5 \mathrm{E}+02$ & 0.3 & 38500 & 386 & 99.7 & 28.6 \\
\hline $\mathrm{Sm}-153$ & $3.1 \mathrm{E}+01$ & $3.0 \mathrm{E}+02$ & 0.1 & 72 & 12.8 & 5.6 & 0.6 \\
\hline Sr-89 & $9.8 \mathrm{E}+01$ & $5.3 \mathrm{E}+02$ & 0.2 & 38500 & 386 & 99.7 & 18.4 \\
\hline Th-228 & $5.0 \mathrm{E}+02$ & $1.9 \mathrm{E}+03$ & 0.3 & 38500 & 386 & 99.7 & 26.2 \\
\hline Th-229 & $5.9 \mathrm{E}-02$ & $2.4 \mathrm{E}-01$ & 0.2 & 38500 & 386 & 99.7 & 24.5 \\
\hline W-188 & $6.2 \mathrm{E}+04$ & $1.3 \mathrm{E}+06$ & 0.0 & 38500 & 386 & 99.7 & 4.8 \\
\hline $\mathrm{Xe}-127$ & $7.5 \mathrm{E}+01$ & $7.4 \mathrm{E}+02$ & 0.1 & 77100 & 386 & 200 & 20.2 \\
\hline
\end{tabular}


Both FFTF and HFIR can produce significant quantities of medical isotopes. This fact is extremely important in light of the need for a reliable source of isotopes for use in medicine. Research and clinical applications require a continuous supply of isotopes to satisfactorily complete investigations and provide for the treatment of patients in a timely manner. No one reactor can meet this requirement due to routine shutdowns for maintenance and refueling. Such shutdowns interrupt the steady supply of short-lived isotopes. It is therefore beneficial, if not absolutely necessary, to have multiple sources of medical isotopes. With FFTF and HFIR capable of efficient production of isotopes that are not easily produced in conventional thermal reactors, the Department of Energy has the opportunity to provide needed isotopes in a coordinated manner that satisfies the needs of the medical community.

Flux spectra in both reactors are favorable for the production of many medical isotopes that require epithermal, fast, and high energy neutrons. Neutrons of these energies are not available in appreciable quantities in typical light water reactors and as such, FFTF and HFIR offer distinct advantages over most other reactors for the production of certain isotopes.

Selective HFIR positions analyzed in this report have a much higher thermal flux than any of the FFTF core locations studied, as would be expected since HFIR is a water-cooled reactor while FFTF is a sodium-cooled reactor. Interestingly, however, the HFIR positions have substantially higher epithermal fluxes than FFTF positions and one HFIR position has a substantial fast and high energy flux compared with FFTF. Such phenomena should not be exceptionally surprising since HFIR was designed to provide a very high flux in the central region of the reactor, i.e., the flux trap. Thus, even with both reactors operating at similar power levels, HFIR should be expected to have higher flux levels in the high flux region than FFTF, which is a more homogeneous reactor.

In addition to the higher flux levels achieved by the design of HFIR there are other factors that reduce FFTF flux levels with respect to HFIR. There is a substantial "flux degradation" associated with operation of FFTF at $100 \mathrm{MW}$ with a Pu-238 mission. Obviously, the change from $400 \mathrm{MW}$ to $100 \mathrm{MW}$ operation will reduce the flux. Also, the $100 \mathrm{MW}$ flux spectra were generated assuming a Pu-238 mission. Production of $\mathrm{Pu}-238$ requires significant hydriding (moderation of the neutron flux) and this also affects the overall flux spectrum. These two effects result in lower total fluxes and a softer (slower) neutron spectrum than prior FFTF experience.

More favorable flux spectra for FFTF than those used in this report can be achieved in two ways. The degree of hydriding should be optimized in assemblies producing isotopes that have targets with large neutron absorption cross sections in the epithermal region. This report used a generic target vehicle design that had two rows of yttrium hydride (moderator) pins surrounding the target pins; other designs that tailor the flux to take advantage of high neutron capture resonance peaks of individual targets would result in increased isotope production. Also, core locations should be selected for target assemblies that have the highest available flux. This report used one row 4 location to calculate all short-lived isotope production data and one row 6 location to calculate all long-lived isotope production data. Placing target assemblies in rows closer to the core centerline would increase total flux, and investigating optimal position within rows (e.g., positions not in close proximity to $\mathrm{Pu}-238$ production assemblies) would identify locations with higher fluxes and more favorable flux spectra.

Production ratios (see the table above) calculated without target self-shielding corrections mostly favor HFIR (i.e., the ratio is typically $<1$ ). The reasons for this are primarily due to flux spectra as discussed above. On the other hand, volume ratios favor FFTF due to larger volumes of the irradiation vehicles and the higher number of irradiation locations available. 
When production and volume data are considered simultaneously, FFTF typically has higher overall production capabilities because the volume advantage overcomes the production disadvantage. The fact that some isotopes (Ho-166, I-131, Re-186, and Sm-153, all of which have substantial production in the epithermal region) are more favorably produced in HFIR reemphasizes the importance of judicious placement of target vehicles and flux tailoring to compensate for the "flux degradation" mentioned above. Also, the low advantage ratios for isotopes produced in the fast and high energy range (e.g., $\mathrm{Cu}-64, \mathrm{Cu}-67, \mathrm{P}-32$, Pt-195m) highlights the importance of placing target assemblies in regions of high flux that are minimally affected by moderation for the production of $\mathrm{Pu}-238$.

The above discussion identifies significant neutronic effects that should be taken into account when core locations are allocated for isotope production. If isotope production is relegated to outer rows that are in close proximity to Pu-238 targets, the degradation in the total flux and the neutron spectrum will significantly impact production capabilities. Further, the degradation in flux levels highlights the importance of flux tailoring to optimize isotope production (i.e., to get the most benefit from the neutrons available). Finally, resumption of FFTF operation at $400 \mathrm{MW}$ would provide tremendous advantages for the production of substantial quantities of isotopes.

It should be noted that target masses used in this report represent $20 \%$ of the projected U.S. demand for each isotope (Pacific Northwest National Laboratory June 1999). Sufficient volume exists in FFTF for targets of such size; however, HFIR volume is not sufficient to accommodate the full mass of some of these targets. 


\section{Acknowledgements}

These calculations were performed under the guidance of Robert E. Schenter, Ph.D., Staff Scientist, Deputy Site Manager, Hanford Radioisotopes Program, Pacific Northwest National Laboratory.

This research was performed under appointment to the U.S. Department of Energy Nuclear Engineering and Health Physics Fellowship Program sponsored by DOE's Office of Nuclear Energy, Science and Technology. 


\section{Contents}

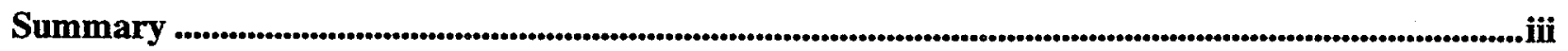

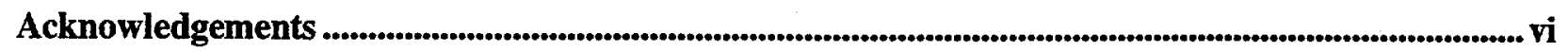

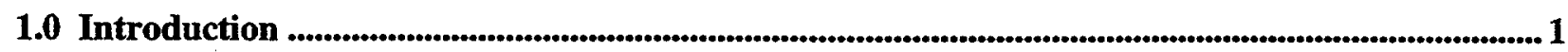

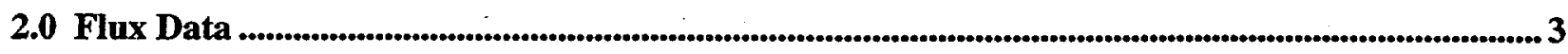

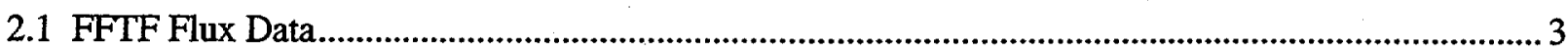

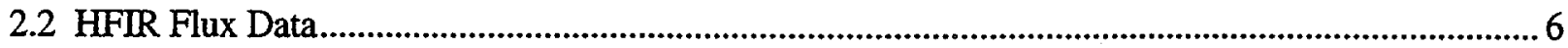

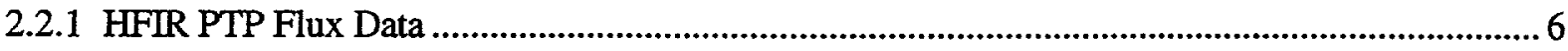

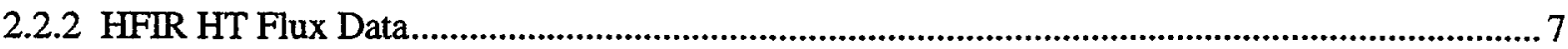

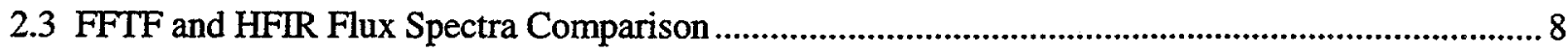

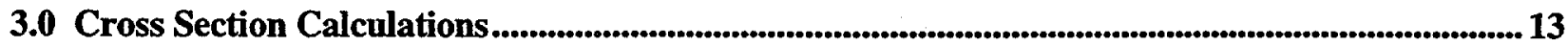

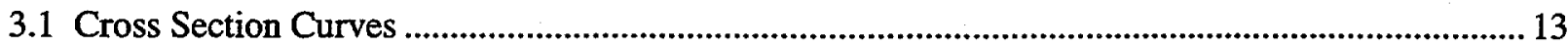

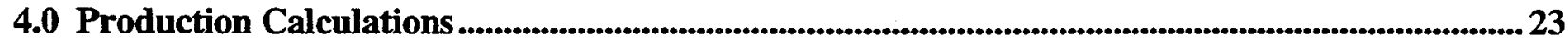

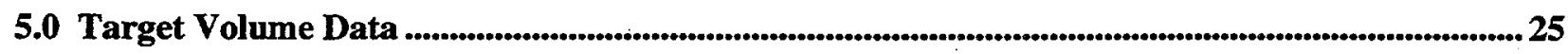

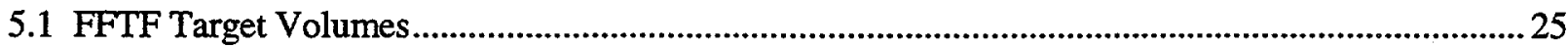

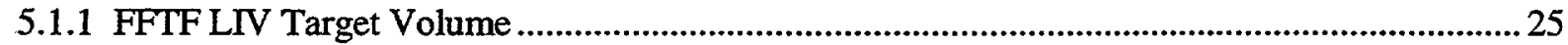

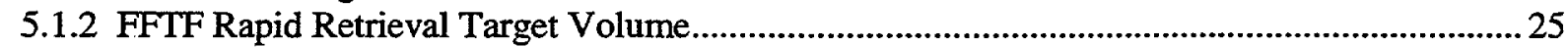

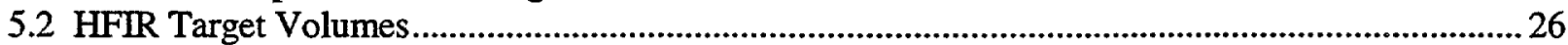

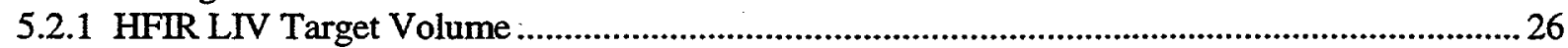

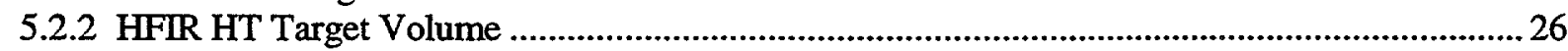

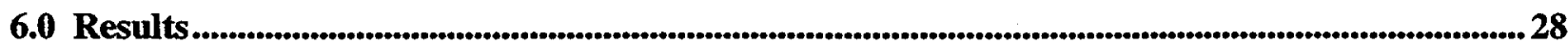

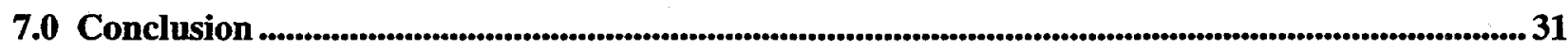

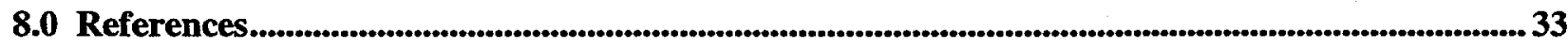

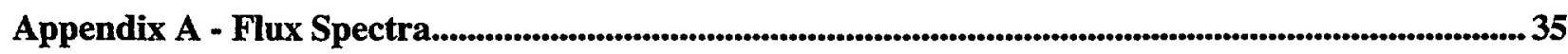

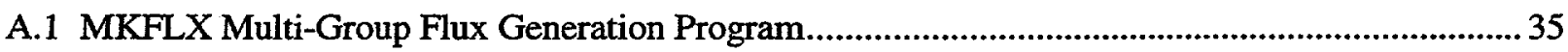

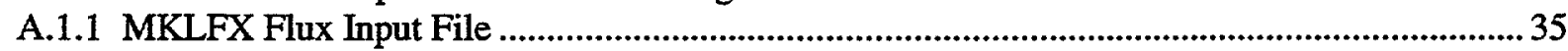

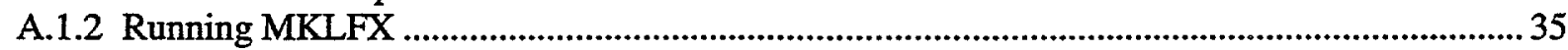

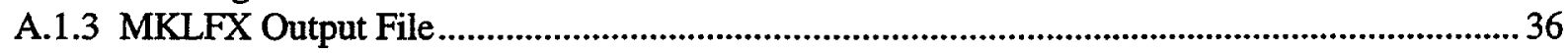

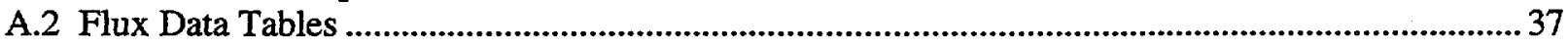

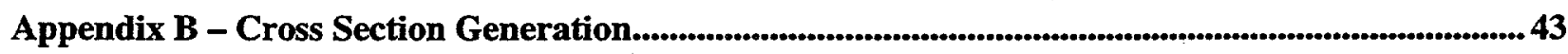

B.1 BW One-Group Cross Section Generation Program .................................................................... 43

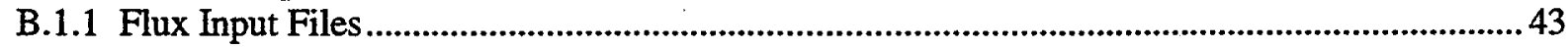

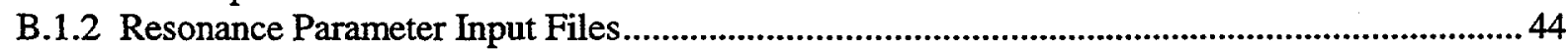

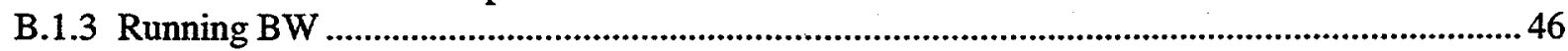

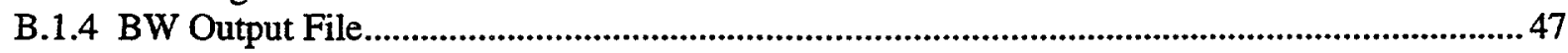




\section{Contents}

Appendix C - Isotope Production Calculations .............................................................................51

C.1 CHAIN Isotope Production Calculation Program ...................................................................51

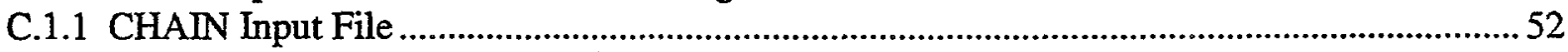

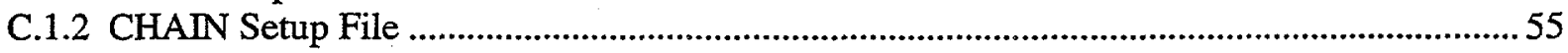

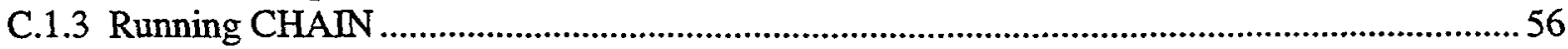

C.1.4 CHAIN Output Files........................................................................................................ 57

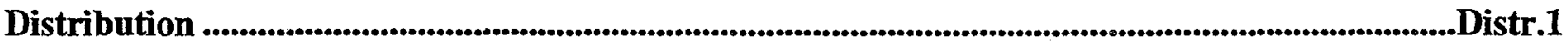




\section{Figures}

Figure 1 Core Map for Multiple FFTF Missions.....................................................................

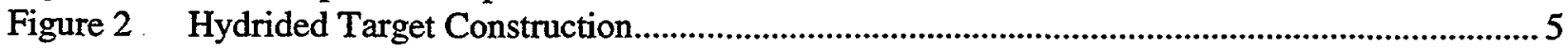

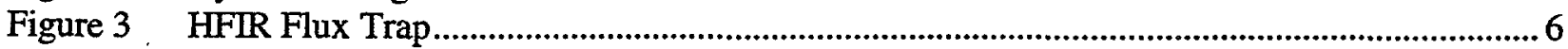

Figure 4 FFTF and HFIR Flux Spectra Comparison ................................................................. 11

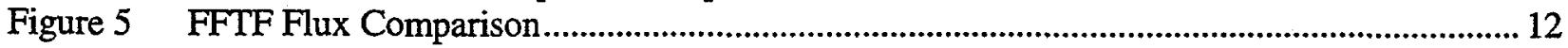

Figure 6 Ho-166, Ir-192, Re-186 Production Cross Sections......................................................... 16

Figure 7 Se-75, Sm-153, W-188 Production Cross Sections............................................................ 17

Figure 8 Ac-227, Th-228, Th-229 Production Cross Sections ........................................................ 18

Figure 9 Cd-109, Os-194, Pd-103, Xe-127 Production Cross Sections ............................................. 19

Figure 10 I-131, Sm-145, Sr-89, Mo-99 Production Cross Sections...................................................20 20

Figure 11 P-32, P-33, Sc-47, Cu-64, Cu-67, Pt-195m Production Cross Sections..................................21

Figure 12 Optimum Production of Reactor-Produced Medical Isotopes ................................................ 22

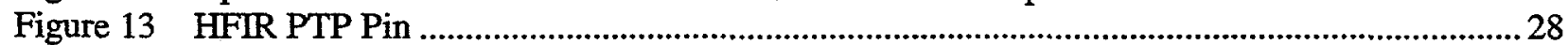

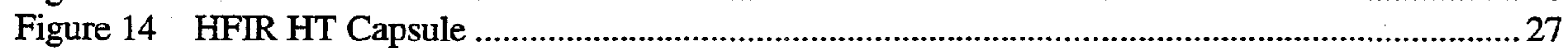

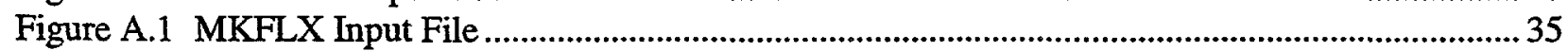

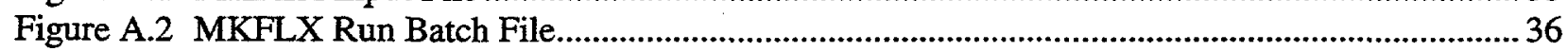

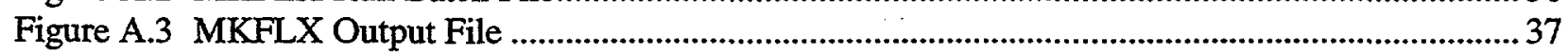

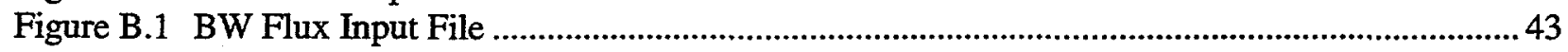

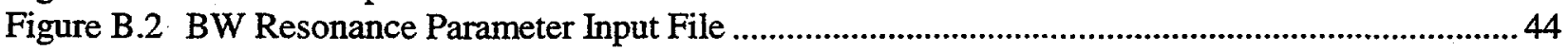

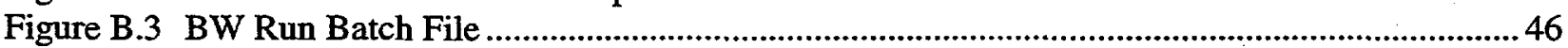

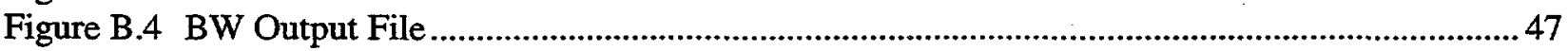

Figure C.1 W188 Production CHAIN Block Diagram …................................................................ 51

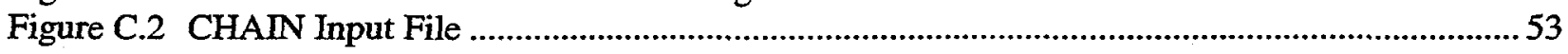

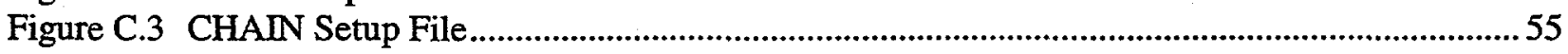

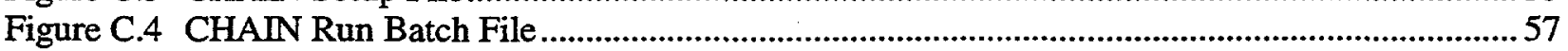

Figure C.5 CHAIN Production Summary Output File....................................................................5

Figure C.6 CHAIN Product Isotope Production Versus Time Output File..............................................59

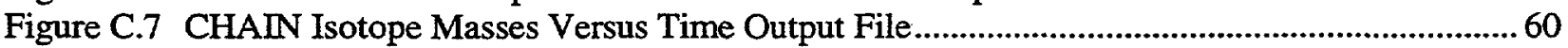

Figure C.8 CHAIN Isotope Activities Versus Time Output File .............................................................. 60

\section{Tables}

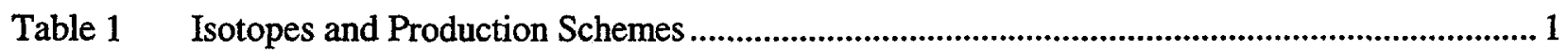

Table 2 Core Locations Used for Isotope Production Calculations ........................................................ 8

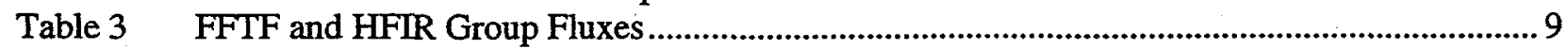

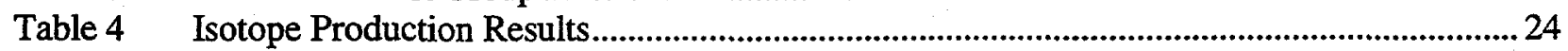

Table $5 \quad$ FFTF-HFIR Isotope Production Comparison ......................................................................28

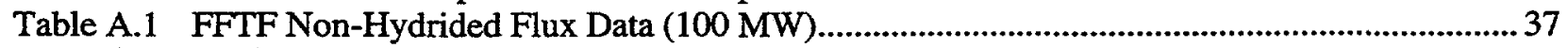

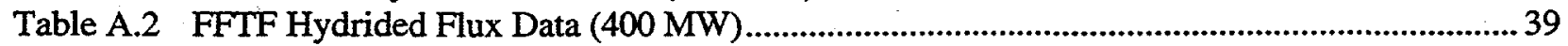

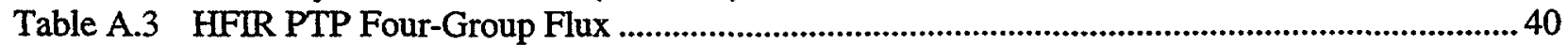

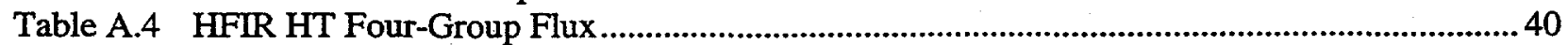

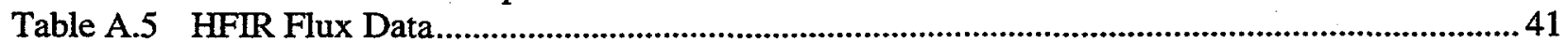




\subsection{Introduction}

This report was prepared as input for the report Isotope Production at the Hanford Site in Richland, Washington (Pacific Northwest National Laboratory 1999) to provide a perspective on the relative medical isotope production capabilities of the Fast Flux Test Facility (FFTF) at the Hanford Site in Richland, Washington and the High Flux Isotope Reactor (HFIR) at the Oak Ridge National Laboratory in Oak Ridge, Tennessee. It will also serve to meet the University of Maryland Department of Nuclear Engineering technical paper requirement for a Master of Science degree for M. A. Garland.

Appendices are also provided that serve as users guides for the three unpublished Fortran programs that are used to perform isotope production calculations. These users guides are intended to facilitate production calculations by students and interns at the Pacific Northwest National Laboratory. Guides have been provided for the following programs:

- MKFLX generates multi-group flux spectra for use in one-group cross section generation (BW) and isotope production calculation (CHAIN)

- BW generates one-group cross sections for isotopes in a particular reactor environment

- CHAIN calculates isotope production in a particular reactor environment.

Isotope production at various reactor facilities depends on many factors such as neutron flux spectra, target isotope energy-dependent cross sections, and target volumes. This report uses representative data for both reactors to generate medical isotope production data that can be used to compare the capabilities of the two reactors.

Medical isotope production values rely on neutron flux data, neutron cross section calculations, production and decay calculations, and target volume calculations. These aspects are presented in Sections $2.0,3.0,4.0$, and 5.0, respectively, with the overall determination of production capabilities presented in Section 6.0.

For the purposes of this report, twenty-three isotopes are evaluated (Table 1). These isotopes are among the thirty-one that are the most likely candidates for production should FFTF be restarted and are also isotopes for which sufficient data is available such that HFIR production can be calculated.

Table 1 Isotopes and Production Schemes

\begin{tabular}{|c|c|c|}
\hline Product Isotope & Half-Life & Production Scheme \\
\hline Ac-227 & 21.77 years & $\mathrm{Ra}-226(\mathrm{n}, \gamma) \mathrm{Ra}-227\left(\beta^{-}\right) \mathrm{Ac}-227$ \\
\hline $\mathrm{Cd}-109$ & 462.0 days & $\mathrm{Cd}-108(\mathrm{n}, \gamma) \mathrm{Cd}-109$ \\
\hline $\mathrm{Cu}-64$ & 12.70 hours & $\mathrm{Zn}-64(n, p) \mathrm{Cu}-64$ \\
\hline $\mathrm{Cu}-67$ & 2.58 days & $\mathrm{Zn}-67(\mathrm{n}, \mathrm{p}) \mathrm{Cu}-67$ \\
\hline Ho-166 & 1.12 days & Ho-165 (n,y) Ho-166 \\
\hline $\mathrm{I}-131$ & 8.02 days & $\mathrm{Te}-130(\mathrm{n}, \gamma) \mathrm{Te}-131\left(\beta^{\circ}\right) \mathrm{I}-131$ \\
\hline Ir-192 & 73.83 days & Ir-191 (n,y) Ir-192 \\
\hline Mo-99 & 2.75 days & Mo-98 $(\mathrm{n}, \gamma)$ Mo-99 \\
\hline Os-194 & 6.0 years & 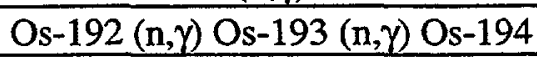 \\
\hline $\mathrm{P}-32$ & 14.28 days & $S-32(n, p)$ P-32 \\
\hline
\end{tabular}




\begin{tabular}{|c|c|c|}
\hline Product Isotope & Half-Life & Production Scheme \\
\hline $\mathrm{P}-33$ & 25.3 days & $\mathrm{S}-33(\mathrm{n}, \mathrm{p}) \mathrm{P}-33$ \\
\hline Pd-103 & 16.99 days & $\mathrm{Pd}-102(n, \gamma) \mathrm{Pd}-103$ \\
\hline Pt-195m & 4.02 days & Pt-195 (n,n') Pt-195m \\
\hline $\operatorname{Re}-186$ & 3.72 days & $\operatorname{Re}-185(n, \gamma) \operatorname{Re}-186$ \\
\hline Sc-47 & 3.35 days & $\mathrm{Ti}-47(\mathrm{n}, \mathrm{p}) \mathrm{Sc}-47$ \\
\hline Se-75 & 119.8 days & $\mathrm{Se}-74(\mathrm{n}, \gamma) \mathrm{Se}-75$ \\
\hline Sm-145 & 340 days & $\mathrm{Sm}-144(\mathrm{n}, \gamma) \mathrm{Sm}-145$ \\
\hline Sm-153 & 1.93 days & $\mathrm{Sm}-152(\mathrm{n}, \gamma) \mathrm{Sm}-153$ \\
\hline $\mathrm{Sr}-89$ & 50.52 days & $\mathrm{Sr}-88(\mathrm{n}, \gamma) \mathrm{Sr}-89$ \\
\hline Th-228 & 1.91 years & Ra-226 $(\mathrm{n}, \gamma)$ Ra-227 ( $\left.\beta^{-}\right)$Ac-227 $(\mathrm{n}, \gamma)$ Ac-228 $\left(\beta^{-}\right)$Th-228 \\
\hline Th-229 & 7300 years & $\mathrm{Ra}-226 \Rightarrow \mathrm{Th}-228(\mathrm{n}, \gamma)$ Th-229 \\
\hline W-188 & 69.4 days & 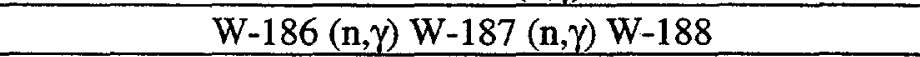 \\
\hline $\mathrm{Xe}-127$ & 36.4 days & $\mathrm{Xe}-126(\mathrm{n}, \gamma) \mathrm{Xe}-127$ \\
\hline
\end{tabular}




\subsection{Flux Data}

Flux data for each reactor position to be evaluated were obtained to provide input for one-group cross section calculations (see Section 3.0) and isotope production calculations (see Section 4.0). One-group cross section calculations require 58-group and total flux data and isotope production calculations require total flux data.

In order to provide a meaningful comparison between the two reactors it was necessary to obtain similar flux data. Existing flux data for FFTF was based on $400 \mathrm{MW}$ operation (rather than the planned $100 \mathrm{MW}$ operation) and represented flux values averaged over the height of the target for each core location. Existing data for HFIR was based on $100 \mathrm{MW}$ operation (rather than the current $85 \mathrm{MW}$ operation) and represented peak flux values at the midplane of various target locations. For this report, flux data was generated based on current power levels and averaged over the length of each target.

\subsection{FFTF Flux Data}

FFTF flux spectra were obtained for non-hydrided ${ }^{(a)}$ and hydrided ${ }^{\text {(b) }}$ targets. "Hydriding" refers to a technique used to tailor the neutron flux to optimize isotope production. FFTF is a liquid metal-cooled reactor with a fast flux spectrum (relative to water-cooled thermal reactors). Since certain isotopes are more optimally produced with thermal and epithermal neutrons, it is advantageous to soften the neutron spectrum (i.e., slow down the neutrons) in the vicinity of the isotopes' target material. In FFTF, this is accomplished by using a hydride material (typically yttrium hydride).

Both the non-hydrided and hydrided spectra were obtained as 58-group output of MCNP (Briesmeister 1997) calculations.

Non-hydrided spectra were obtained for six different core locations (see Figure 1):

1. 1202 row 2 , averaged over a target length of 49.4 "

2. 1406 row 4 , averaged over a target length of 49.4 "

3. 3406 row 4 , averaged over a target length of 49.4 "

4. 2610 row 6 , averaged over a target length of 49.4 "

5. 3610 row 6 , averaged over a target length of 49.4 "

6. $1607,1608,1609,2607,2608,2609,3607,3608,3609$ row six "corner" assemblies (three clusters of three long-lived isotope production assemblies shown in Figure 1), averaged over a target length of 36 " and over all nine assemblies

These spectra were generated assuming a $100 \mathrm{MW}$, plutonium-238 production core. The raw data is presented in Table A.1.

(a) Wootan, DW. "100 MW Spectra for MOTA Type Assemblies," email to R.E. Schenter, June 24, 1999.

(b) Wootan, DW. "100 MW In-Core Hydride Spectra," email to R.E. Schenter, July 14, 1999. 


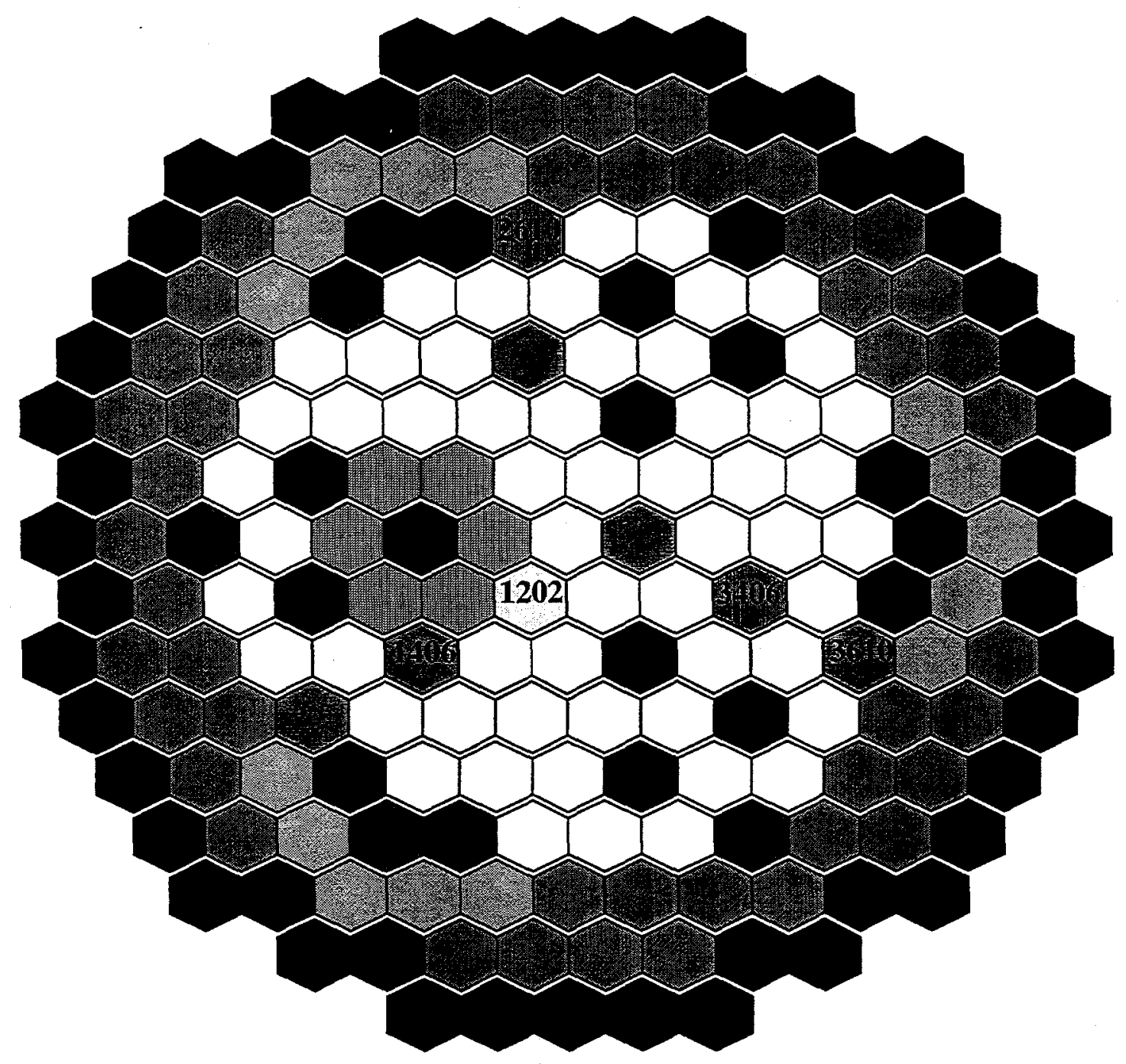

3 Short-Lived Isotope Production

$\bigcirc$ Gaseous Isotope Production

Fully Instrumented, In-Core Test

Long-Lived Isotope Production

Cobalt-60 Production
0 Plutonium-238 Production

Fuel Tests

Safety Rods/Control Rods

$\bigcirc$ Driver Fuel Assemblies

Reflectors

Figure 1 Core Map for Multiple FFTF Missions 
Hydrided spectra were obtained for five different core locations:

1. 1202 row 2 , averaged over a target length of $36 ", \mathrm{YH} / \mathrm{inconel} /$ tungsten target assembly

2. 1406 row 4, averaged over a target length of 36 ", YH/inconel/tungsten target assembly

3. 3406 row 4, averaged over a target length of 36", YH/inconel/tungsten target assembly

4. 2610 row 6 , averaged over a target length of 36 ", $\mathrm{YH} /$ inconel/tungsten target assembly

5. 3610 row 6 , averaged over a target length of 36 ", $\mathrm{YH} / \mathrm{YH} / \mathrm{YH}$ target assembly

These spectra were generated assuming a $400 \mathrm{MW}$, plutonium-238 production core. The raw data is presented in Table A.2. Since that data was based on operation at $400 \mathrm{MW}$, all flux values were corrected for $100 \mathrm{MW}$ operation by multiplication by 0.25 prior to their use in cross section calculations (Section 3.0 ) and isotope production calculations (Section 4.0).

Since isotope production target pins are typically 49.4", the flux should be averaged over that range rather than just the active fuel region (36"). The author of the data reported that a factor of 1.18 is a reasonable approximation of the relationship between the two average fluxes. Therefore, all flux values were corrected for 49.4 " target irradiation by division by 1.18 prior to their use in cross section calculations (Section 3.0) and isotope production calculations (Section 4.0).

In the list of hydrided spectra, assumed target vehicle materials were specified. As shown in Figure 2 , targets are comprised of four concentric essentially cylindrical regions. Typical construction consists of the target material in the center tube surrounded by two rows each of yttrium hydride (YH) pins, inconel (a form of stainless steel) pins, and tungsten (W) pins. The flux spectrum for core location 3610 was based on surrounding the target with six rows of yttrium hydride pins rather than using inconel and tungsten for the outer rows. This provides the ability to analyze the effects on isotope production of changing the degree of hydriding since more yttrium hydride in a target will produce a softer neutron energy spectrum.

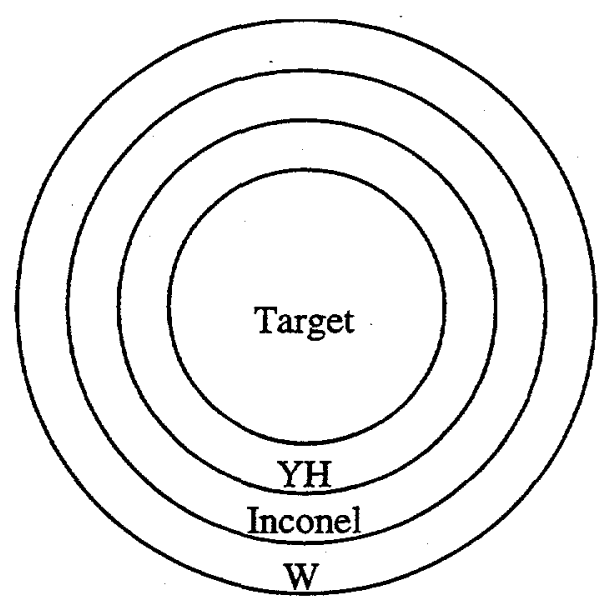

Figure 2 Hydrided Target Construction 


\subsection{HFIR Flux Data}

To provide a meaningful comparison between FFTF and HFIR it was necessary to obtain average flux data for HFIR. This data was not directly available so several sources of data were used to generate it.

Flux spectra were developed for two HFIR positions: the peripheral target positions (PTP) and the hydraulic tube (HT). These positions are located in the HFIR central flux trap (see Figure 3). Peripheral target positions are used to produce long-lived isotopes while the hydraulic tube is used to produce shortlived isotopes.

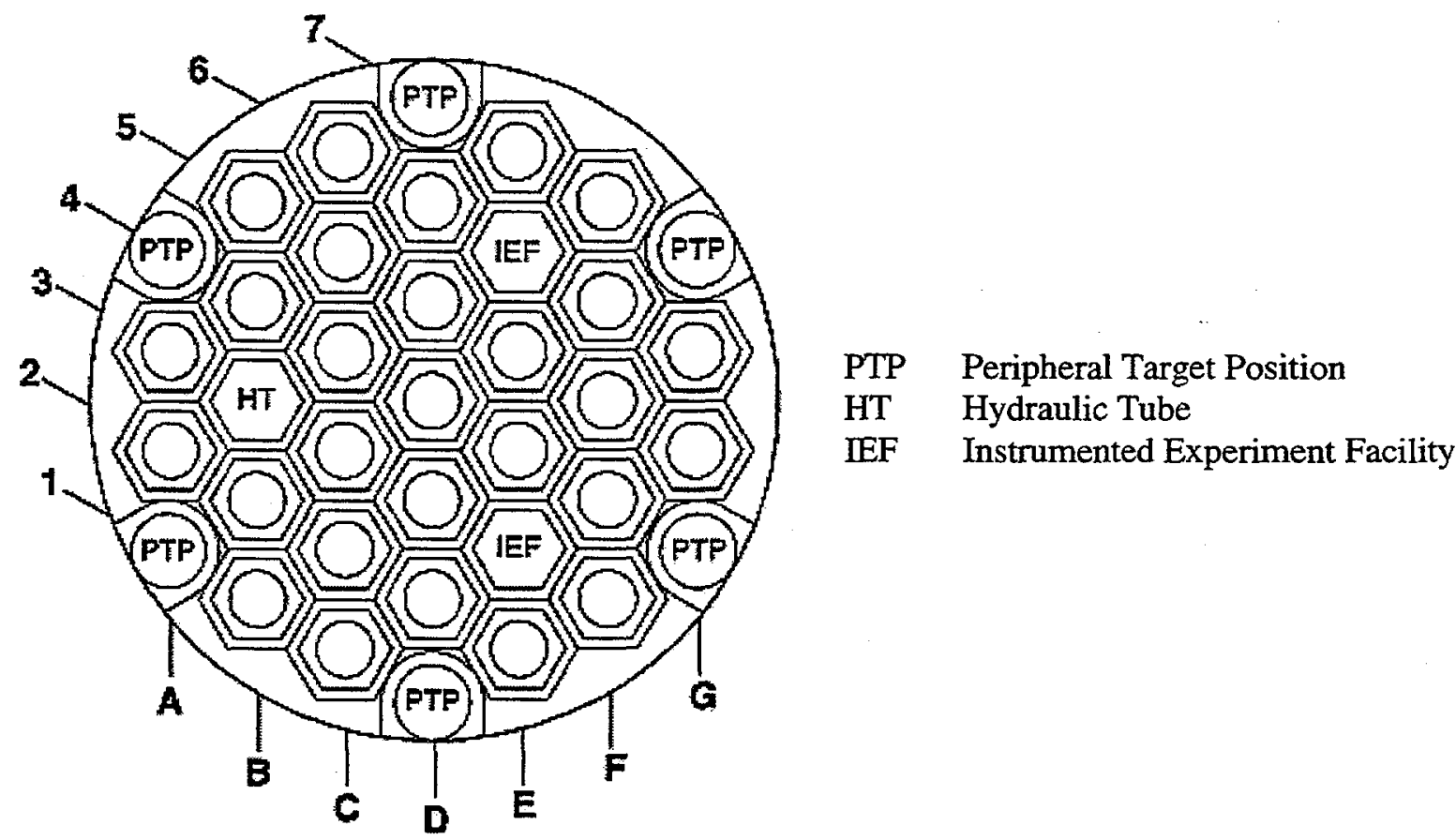

Figure 3 HFIR Flux Trap

A 58-group flux spectrum is required to calculate one-group cross sections (Section 3.0). This multi-group spectrum can be generated from a four-group flux using the program MKFLX (see Appendix A.1).

\subsubsection{HFIR PTP Flux Data}

A four-group average flux (Schenter 1990, Table 1) was used as the basis for the peripheral target positions. This data represented HFIR operation at $100 \mathrm{MW}$ - to correct for operation at $85 \mathrm{MW}$, all values were multiplied by 0.85 (see Table A.3). The $85 \mathrm{MW}$ data in Table A.3 was used as the input for MKFLX; Table A.5 presents the resulting 58-group flux spectrum for a PTP. 


\subsubsection{HFIR HT Flux Data}

A four-group average flux was not available for the hydraulic tube; however, using data from several sources, an estimation of a four-group flux was generated.

HFIR peak flux data were found in previous MKFLX data sets and this data showed that the high energy fluxes $(0.8-16 \mathrm{MeV})$ were $7.58 \mathrm{E}+14$ and $1.7 \mathrm{E}+14 \mathrm{n} / \mathrm{cm}^{2}-\mathrm{s}$ for the PTP and HT positions, respectively. This results in a ratio of $\mathrm{HT}_{\text {high energy }} / \mathrm{PTP}_{\text {high energy }}=1.7 / 7.58=0.22$. It was assumed that this ratio also applies to the high energy average flux and that it applies to the average fast flux $(5.0 \mathrm{keV}-0.8$ $\mathrm{MeV}$ ) as well (the previous MKFLX data combined the epithermal and fast fluxes into a single group so direct calculation of a fast flux conversion factor was not possible). As shown in Table A.4, this conversion factor was applied to the PTP average flux data from Table A.3 to obtain the fast and high energy group fluxes for the HT.

Conversion factors for the thermal and epithermal fluxes were based on data obtained from Oak Ridge National Laboratory ${ }^{(a)}$ (this data set only included thermal and epithermal fluxes or it would have been used to derive the fast and high energy fluxes that were calculated above). The data obtained represented peak (midplane) fluxes on a per megawatt basis. These values were multiplied by 100 to obtain $100 \mathrm{MW}$ fluxes. The peak values were converted to values averaged over the HFIR target length of 20 inches by integrating the equation for position-dependent flux ${ }^{(a)}$ :

$$
\begin{aligned}
\phi(x) & =\phi_{\text {peak }} \cos \left[\left(\frac{x}{14.5}\right)\left(\frac{\pi}{2}\right)\right] \\
\phi_{a v} & =\frac{1}{x} \int \phi(x) d x \\
& =\frac{1}{20} \int_{-10}^{10} \phi_{\text {peak }} \cos \left[\left(\frac{x}{14.5}\right)\left(\frac{\pi}{2}\right)\right] d x \\
& =\frac{1}{20} \phi_{\text {peak }} \int_{-10}^{10} \cos 0.108 x d x \\
& \left.=\frac{1}{20}\left(\frac{1}{0.108}\right) \sin 0.108 x\right]_{-10}^{10} \phi_{\text {peak }} \\
& =0.816 \phi_{\text {peak }}
\end{aligned}
$$

Applying the $100 \mathrm{MW}$ and peak-to-average correction factors to the ORNL data, the thermal fluxes $(<0.25 \mathrm{eV})$ for the PTP and the HT positions were $17.4 \mathrm{E}+14$ and $19.4 \mathrm{E}+14 \mathrm{n} / \mathrm{cm}^{2}-\mathrm{s}$, respectively. This results in a ratio of $\mathrm{HT}_{\text {thermal }} / \mathrm{PTP}_{\text {thermal }}=19.4 / 17.3=1.12$. As shown in Table A.4, this conversion factor

(a) Alexander, CW. "Fluxes," email to R.E. Schenter, June 22, 1999. 
was applied to the PTP average flux data from Table A.3 to obtain the thermal energy group flux for the HT.

Epithermal flux $(0.25 \mathrm{eV}-5.0 \mathrm{keV})$ data from ORNL was provided in terms of flux per unit lethargy. It was thus necessary to convert this data by multiplying by the epithermal group lethargy as well as by applying the $100 \mathrm{MW}$ and peak-to-average correction factors discussed previously. This was accomplished using the following equation:

$$
\text { Epithermal Flux }=\frac{\text { Epithermal Flux }}{\text { Unit Lethargy }} \ln \left(\frac{5000}{0.25}\right)(0.816)(100)
$$

Applying this equation to the ORNL data, the epithermal fluxes for the PTP and the HT positions were $9.4 \mathrm{E}+14$ and $8.8 \mathrm{E}+14 \mathrm{n} / \mathrm{cm}^{2}-\mathrm{s}$, respectively. This results in a ratio of $\mathrm{HT}_{\text {epitherma }} / \mathrm{PTP}_{\text {epithermal }}=8.8 / 9.4$ $=0.94$. As shown in Table A.4, this conversion factor was applied to the PTP average flux data from Table A.3 to obtain the epithermal energy group flux for the HT.

The four-group HT data in Table A.4 was used as the input for MKFLX; Table A.5 presents the resulting 58-group flux spectrum for the HT.

\subsection{FFTF and HFIR Flux Spectra Comparison}

Figure 4 presents a comparison of the FFTF and HFIR flux spectra used in this report's calculations of isotope production. The displayed spectra are those used in isotope production calculations in Section 4.0. Table 2 summarizes the use of each spectrum.

Table 2 Core Locations Used for Isotope Production Calculations

\begin{tabular}{|c|l|c|}
\hline Core Position & \multicolumn{1}{|c|}{ Purpose } & Symbol \\
\hline $1202-$ Hyd & production of I-125 & gas line \\
\hline 3406 & production of short-lived isotopes in rapid retrieval systems & R3 \\
\hline $3406-$ Hyd & hydrided production of short-lived isotopes in rapid retrieval systems & R3-H \\
\hline 2610 & production of long-lived isotopes in long-term irradiation vehicles & LIV \\
\hline $2610-$ Hyd & hydrided production of long-lived isotopes in long-term irradiation vehicles & LIV-H \\
\hline PTP & production of long-lived isotopes in long-term irradiation vehicles & PTP \\
\hline HT & production of short-lived isotopes in rapid retrieval systems & HT \\
\hline
\end{tabular}

As seen in Figure 4, the two HFIR positions have a much higher thermal flux than the FFTF positions. This was to be expected since HFIR is a water-cooled reactor, whereas FFTF is a sodiumcooled reactor. Interestingly, however, both HFIR positions have substantially higher epithermal fluxes than FFTF positions and the HFIR PTP has a substantial fast and high energy flux compared with FFTF. Such phenomena should not be exceptionally surprising since HFIR was designed to provide a very high flux in the central region of the reactor, i.e., the flux trap. Thus, even with both reactors operating at 
similar power levels, HFIR should be expected to have higher flux levels in the high flux region than FFTF which is a more homogeneous reactor.

A quantitative comparison of these group fluxes is presented in Table 3. This data was obtained from cross section calculation output (the BW code) as described in Section 3.0.

Table 3 FFTF and HFIR Group Fluxes

\begin{tabular}{|c|c|c|c|c|c|}
\hline \multirow[b]{2}{*}{$\begin{array}{c}\text { Core } \\
\text { Position }\end{array}$} & \multicolumn{5}{|c|}{ Group Flux (n/cm ${ }^{2}$-sec) } \\
\hline & $\begin{array}{c}\text { Thermal } \\
(0-0.252 \mathrm{eV})\end{array}$ & $\begin{array}{c}\text { Epithermal } \\
(0.252 \mathrm{eV}-5.54 \mathrm{keV})\end{array}$ & $\begin{array}{c}\text { Fast } \\
(5.54 \mathrm{keV}-0.833 \mathrm{MeV})\end{array}$ & $\begin{array}{c}\text { High Energy } \\
(0.833-15.0 \mathrm{MeV})\end{array}$ & Total \\
\hline 1202-Hyd & $1.61 \mathrm{E} 13$ & $3.99 \mathrm{E} 14$ & $7.83 \mathrm{E} 14$ & $1.12 \mathrm{E} 14$ & $1.31 \mathrm{E} 15$ \\
\hline 3406 & $9.00 \mathrm{E}-02$ & $8.84 \mathrm{E} 13$ & $7.98 \mathrm{E} 14$ & $1.19 \mathrm{E} 14$ & $1.01 \mathrm{E} 15$ \\
\hline 3406-Hyd & $1.67 \mathrm{E} 13$ & $2.75 \mathrm{E} 14$ & $5.89 \mathrm{E} 14$ & $8.74 \mathrm{E} 13$ & $9.68 \mathrm{E} 14$ \\
\hline 2610 & $2.51 \mathrm{E} 12$ & $9.60 \mathrm{E} 13$ & $4.44 \mathrm{E} 14$ & $6.39 \mathrm{E} 13$ & $6.06 \mathrm{E} 14$ \\
\hline 2610-Hyd & $1.01 \mathrm{E} 13$ & $2.01 \mathrm{E} 14$ & $3.27 \mathrm{E} 14$ & $5.48 \mathrm{E} 13$ & $5.92 \mathrm{E} 14$ \\
\hline 3610-Hyd & $6.50 \mathrm{E} 13$ & $1.74 \mathrm{E} 14$ & $1.85 \mathrm{E} 14$ & $4.42 \mathrm{E} 13$ & $4.68 \mathrm{E} 14$ \\
\hline PTP & $1.42 \mathrm{E} 15$ & $7.63 \mathrm{E} 14$ & $6.42 \mathrm{E} 14$ & $4.20 \mathrm{E} 14$ & $3.25 \mathrm{E} 15$ \\
\hline HT & $1.59 \mathrm{E} 15$ & $6.28 \mathrm{E} 14$ & $1.41 \mathrm{E} 14$ & $9.41 \mathrm{E} 13$ & $2.45 \mathrm{E} 15$ \\
\hline
\end{tabular}

This data seems to contradict the belief that FFTF is far more suitable for isotope production from a neutronics standpoint than other reactors. Isotopes that have substantial production in the epithermal region are generally more favorably produced in HFIR (the word generally is used since the above table shows "group" epithermal fluxes; actual production is significantly impacted by the specific flux at the energy of the resonance absorption peaks of the target isotopes which will be shown graphically in Section 3.0). More surprisingly, isotopes requiring neutrons with substantial energy (e.g., n,p reactions) are generally more favorably produced in the PTP than FFTF since the PTP has a higher total fast and high energy spectrum than any of these FFTF positions.

The explanation for this is the design of HFIR mentioned above and that there is a significant "flux degradation" associated with operation of FFTF at $100 \mathrm{MW}$ with a Pu-238 mission. Obviously, the change from $400 \mathrm{MW}$ to $100 \mathrm{MW}$ operation will reduce the flux. Also, the $100 \mathrm{MW}$ flux spectra were generated assuming a Pu-238 mission (see Section 2.1). Production of Pu-238 requires significant hydriding and this also affects the overall flux spectrum. Figure 5 demonstrates these effects. The MOTA curve was generated using a $400 \mathrm{MW}$ spectrum from 1990 , i.e., a standard FFTF core. The Row $6(400 \mathrm{MW})$ curve represents the flux spectra at the row 6 "corner" positions, i.e., 1607, 1608, 1609, $2607,2608,2609,3607,3608$, and 3609 , that have been designated as potential LIV positions. As seen, the flux in row 6 is substantially lower and softer than that for the MOTA position due to its location further on the periphery of the core and to the hydriding associated with the Pu- 238 core. Finally, the Row $6(100 \mathrm{MW})$ curve shows the added effect of reducing power from $400 \mathrm{MW}$ to $100 \mathrm{MW}$.

As will be seen in Section 4.0, production of isotopes that are most favorably produced in the epithermal region is typically greater in HFIR than FFTF. Figure 4 demonstrates the FFTF disadvantage in the epithermal region with core locations 3406 and 2610 having fluxes that are at best approximately one-half the level of the HFIR-PTP and HFIR-HT. The relatively low production in FFTF is due to the "generic" hydrided fluxes (core locations 3406 and 2610) used to perform production calculations. As discussed in Section 2.1, these flux spectra were generated with only two rows of yttrium hydride pins in 
the target vehicle. Enhanced production would be achieved by tailoring the degree of hydriding to boost the epithermal flux in the resonance absorption regions of the target material. However, overall group epithermal fluxes in FFTF rows 4 and 6 are unlikely to exceed HFIR-PTP and HFIR-HT group epithermal fluxes. This can be seen in the report Medical Isotope Production at the Fast Flux Test Facility (Pacific Northwest National Laboratory November 1997) which provides a historical comparison of FFTF $400 \mathrm{MW}$ fluxes to other reactors. In Figure 2-5 of that report, FFTF hydrided fluxes are approximately two to three times greater than HFIR-PTP fluxes in the epithermal region. The reduction in flux associated with $100 \mathrm{MW}$ operation of FFTF would result in a flux profile only moderately more beneficial for epithermal production than the spectra generated for this report.

Table 3 illustrates the effects of increased hydriding on flux distribution. The four-group flux spectrum for FFTF core location 3610 -Hyd is presented in the table to provide a comparison to the spectrum for 2610-Hyd. As identified in Section 2.1, the spectrum for 3610-Hyd was generated with six rows of yttrium hydride pins in the target vehicle as opposed to two rows for 2610 -Hyd. It can be seen that the increased moderation substantially increased the thermal flux in 3610-Hyd over that in 2610-Hyd. However, the epithermal flux in 3610-Hyd is lower than that in 2610-Hyd, indicating excessive moderation for isotopes produced in the epithermal region. This demonstrates the importance of target vehicle design to precisely moderate the neutron flux for optimal isotope production.

Table 3 also demonstrates that total flux decreases as the core locations are further from the FFTF reactor center (1202 is in row 2,3406 is in row 4, and 2610 and 3610 are in row 6). While FFTF has a fairly flat radial flux profile, this decrease is significant in isotope production calculations.

The above discussion identifies significant neutronic effects that should be taken into account when core locations are allocated for isotope production. If isotope production is relegated to outer rows that are in close proximity to $\mathrm{Pu}-238$ targets, the degradation in the total flux and the neutron spectrum will significantly impact production capabilities. Further, the degradation in flux levels highlights the importance of flux tailoring to optimize isotope production (i.e., to get the most benefit from the neutrons available). Finally, resumption of FFTF operation at $400 \mathrm{MW}$ would provide tremendous advantages for the production of substantial quantities of isotopes. 

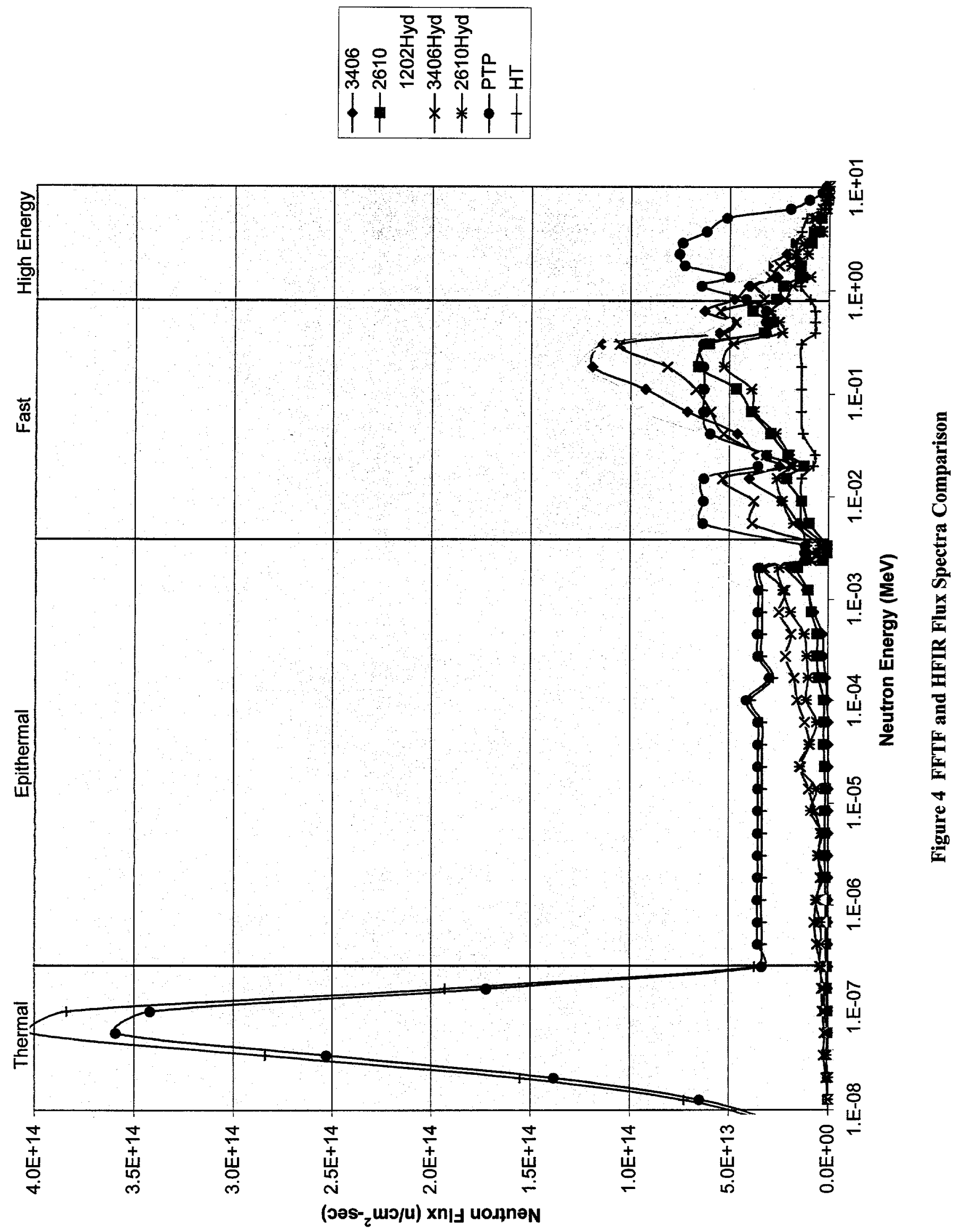

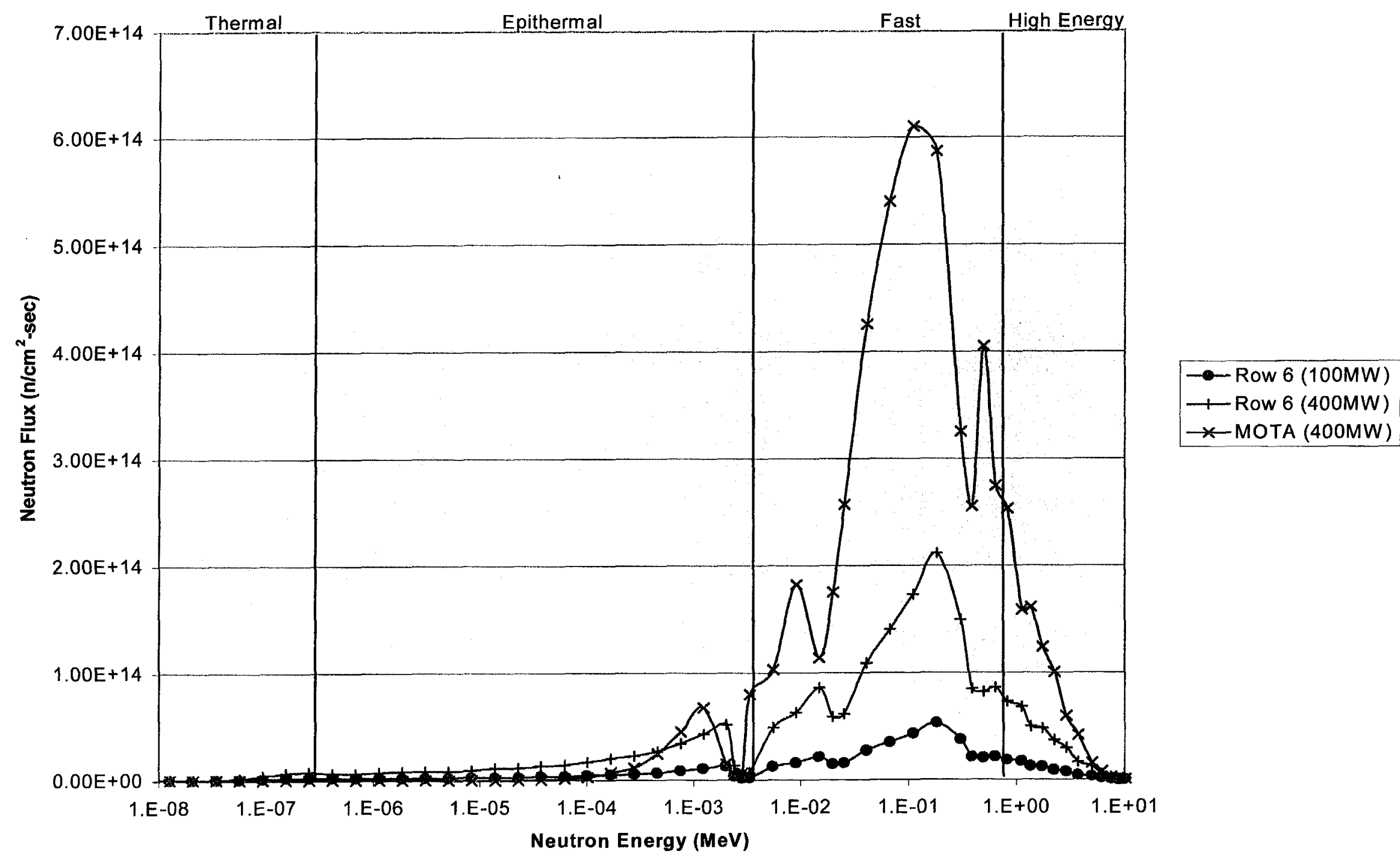

Figure 5 FFTF Flux Comparison 


\subsection{Cross Section Calculations}

One-group neutron cross sections ( $\mathrm{n}, \gamma$ and $\mathrm{n}, \mathrm{p}$ reactions) are required to calculate isotope production using the CHAIN code (see Section 4.0). These one-group cross sections are generated using the BW code (see Appendix B.1 for a detailed discussion of this code) which produces core locationspecific cross sections based on flux spectra, resonance parameter and known cross section (as a function of energy) inputs.

\subsection{Cross Section Curves}

Curves of neutron cross sections as functions of incident neutron energy can provide information on reactor environments that will lead to optimal production of isotopes. In particular, curves that show cross section peaks in the epithermal region indicate optimal production in an environment where sufficient moderation exists to lower the energy of neutrons from the fast and high energy regions to epithermal energies. Also, curves that show cross section peaks in the fast and high energy regions indicate optimal production in locations where there is little moderation. Finally, curves with peaks in the thermal region indicate optimal production in locations where the neutrons are significantly moderated; however, no isotopes in this report fall into that category since such isotopes would be more efficiently produced in thermal reactors rather than a fast reactor such as FFTF.

Figure 6 shows the absorption cross sections versus neutron energy for the target isotopes used to produce Ho-166, Ir-192, and Re-186. (These curves, and all subsequent cross section curves presented in this section, were generated from the output of the BW code.) These three isotopes are produced by a single capture $(\mathrm{n}, \gamma)$ reaction with Ho-165, Ir-191, and Re-185, respectively. Cross sections for these reactions are very large, with substantial peaks in the epithermal region. Published values for the resonance integrals of these isotopes are greater than 500 barns. Obviously, production of Ho-166, Ir192 , and $\mathrm{Re}-186$ would be optimized through hydriding to produce neutron energies tailored to the large resonances in the epithermal region. With such large cross sections, core locations with somewhat lower neutron fluxes could be used while still generating a substantial amount of product.

Figure 7 shows the absorption cross sections versus neutron energy for the target isotopes used to produce $S e-75, \mathrm{Sm}-153$, and $\mathrm{W}-188$. Se-75 and $\mathrm{Sm}-153$ are produced by a single capture $(\mathrm{n}, \gamma)$ reaction with Se-74 and Sm-152, respectively. W-188 is produced by a double capture with W-186 as the target and a W-187 intermediary. As was seen in Figure 6, these cross sections are very large, with substantial peaks in the epithermal region. Published values for the resonance integrals are again greater than around 500 barns. Production considerations for these isotopes are the same as were discussed in the preceding paragraph, with the exception of W-188. Since production of W-188 requires a double capture, it would be advantageous to place W-186 targets in high flux regions to produce significant quantities of product.

Figure 8 shows the absorption cross sections versus neutron energy for the primary isotopes involved in producing Ac-227, Th-228, and Th-229. All three isotopes are produced using a Ra-226 target. Radiative capture produces $\mathrm{Ra}-227$ which $\beta^{-}$decays to Ac-227. Radiative capture by Ac-227 produces Ac-228 which $\beta^{-}$decays to Th-228 (there are other production pathways for Th-228, but they are insignificant in comparison because of the half-lives and cross sections of the intermediaries). Finally, radiative capture by Th-228 produces Th-229 (again, there are other production pathways for Th- 
229 , but they are insignificant in comparison because of the half-lives and cross sections of the intermediaries). The cross section curves for the three main isotopes in this production scheme show fairly large cross sections with large peaks in the epithermal region. While these cross sections aren't as large as those in Figures 6 and 7, published values of the resonance integrals are on the order of $5-500$ barns. Production of these isotopes should be carried out in regions with a fairly high flux since the cross sections aren't as large as the isotopes shown in Figures 6 and 7. As with those isotopes, the flux should be tailored to match the resonance peaks to improve production. Also, since Th-228 production requires a double capture and Th-229 requires a triple capture, it would be beneficial to produce those isotopes in regions with a very high flux to achieve reasonable isotope production levels.

Figure 9 shows the absorption cross sections versus neutron energy for the target isotopes used to produce Cd-109, Os-194, Pd-103, and Xe-127. Cd-109, Pd-103, and Xe-127 are produced by a single capture $(\mathrm{n}, \gamma)$ reaction with Cd-108, Pd-102 and Xe-126, respectively. Os-194 is produced by a double capture with Os-192 as the target and an Os-193 intermediary. As was seen in Figure 8, these cross sections are fairly large, with published values of the resonance integrals on the order of $5-500$ barns. As discussed in the previous paragraph, production of these isotopes should be carried out in regions with a fairly high flux since the cross sections aren't as large as the isotopes shown in Figures 6 and 7 . Again, the flux should be tailored to match the resonance peaks to improve production. Also, since Os-194 production requires a double capture, it would be beneficial to produce that isotope in regions with a very high flux to achieve reasonable isotope production levels.

Figure 10 shows the absorption cross sections versus neutron energy for the target isotopes used to produce I-131, Sm-145, Sr-89, and Mo-99. Sm-145, Sr-89, and Mo-99 are produced by a single capture (n, $\gamma$ ) reaction Sm-144, Sr-88, and Mo-98, respectively. I-131 is produced from a Te-130 target which undergoes radiative capture to produce Te-131 which then $\beta^{-}$decays to I-131. The Mo-98 curve is similar to the curves shown in Figures 8 and 9 and so the discussion of Mo-99 production is similar to the preceding two paragraphs. However, it is seen that the Mo-98 curve has a fairly high tail in the fast and high energy regions and thus production of Mo-99 is enhanced if Mo-98 targets are placed in core locations with little moderation. Cross sections for the other three isotopes are seen to be much smaller than in previous figures-published values for these resonance integrals are less than 5 barns. With such small cross sections, these isotopes should be produced in regions with a very high flux to achieve reasonable production levels.

Figure 11 shows the cross section curves for the target isotopes used to produce $\mathrm{P}-32, \mathrm{P}-33, \mathrm{Sc}-47$, $\mathrm{Cu}-64, \mathrm{Cu}-67$, and Pt-195m. P-32, P-33, Sc-47, Cu-64, and Cu-67 are produced by (n,p) reactions of S$32, \mathrm{~S}-33, \mathrm{Ti}-47, \mathrm{Zn}-64$, and $\mathrm{Zn}-67$, respectively. Pt-195m is produced by an (n,n') reaction of Pt-195. These curves show that these reactions have very low cross sections and require high energy neutrons. As such, these isotopes should be produced in regions with very high flux and no neutron moderation.

The preceding paragraphs' discussion of isotope production considerations is summarized in Figure 12. The discussion of Figures 6 and 7 showed that Ho-166, Ir-192, Re-186, Se-75, Sm-153, and W-188 production have large cross sections with substantial peaks in the epithermal range. The discussion of Figures 8 and 9 showed that Ac-227, Th-228, Th-229, Cd-109, Os-194, Pd-103, and X-127 production have moderate cross sections with peaks in the epithermal range. The discussion of Figure 10 showed that Mo-99 production has a moderate cross section with enhanced production in the fast and high energy range. The discussion of Figure 10 also showed that $\mathrm{I}-131, \mathrm{Sm}-145$, and $\mathrm{Sr}-89$ production have small cross sections with peaks in the epithermal range. Finally, the discussion of Figure 11 showed that P-32, 
$\mathrm{P}-33, \mathrm{Sc}-47, \mathrm{Cu}-64, \mathrm{Cu}-67$, and $\mathrm{Pt}-195 \mathrm{~m}$ production have small cross sections requiring fast and high energy neutrons. This information leads to the groupings shown in Figure 12. 


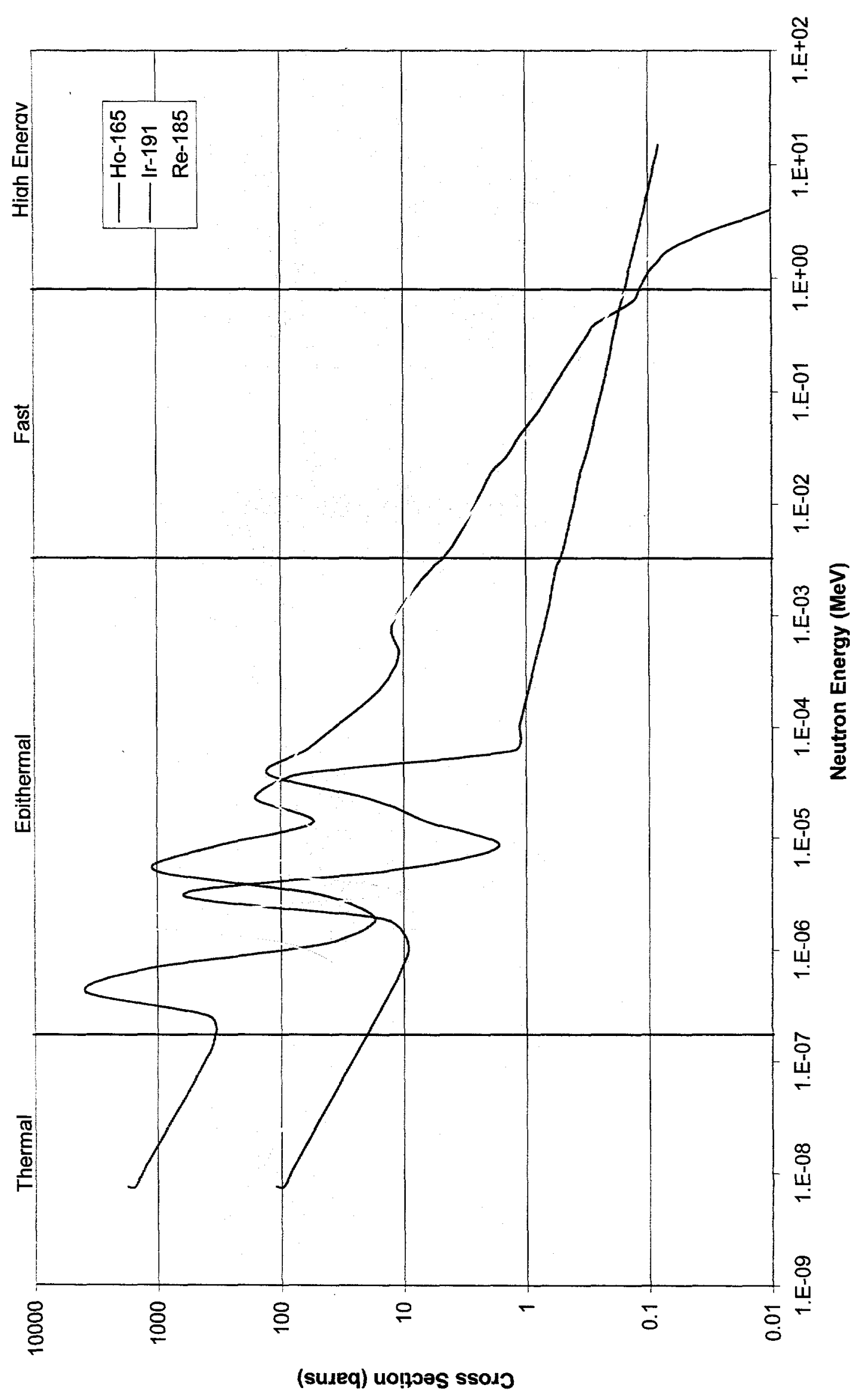

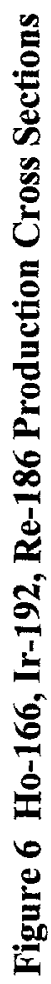




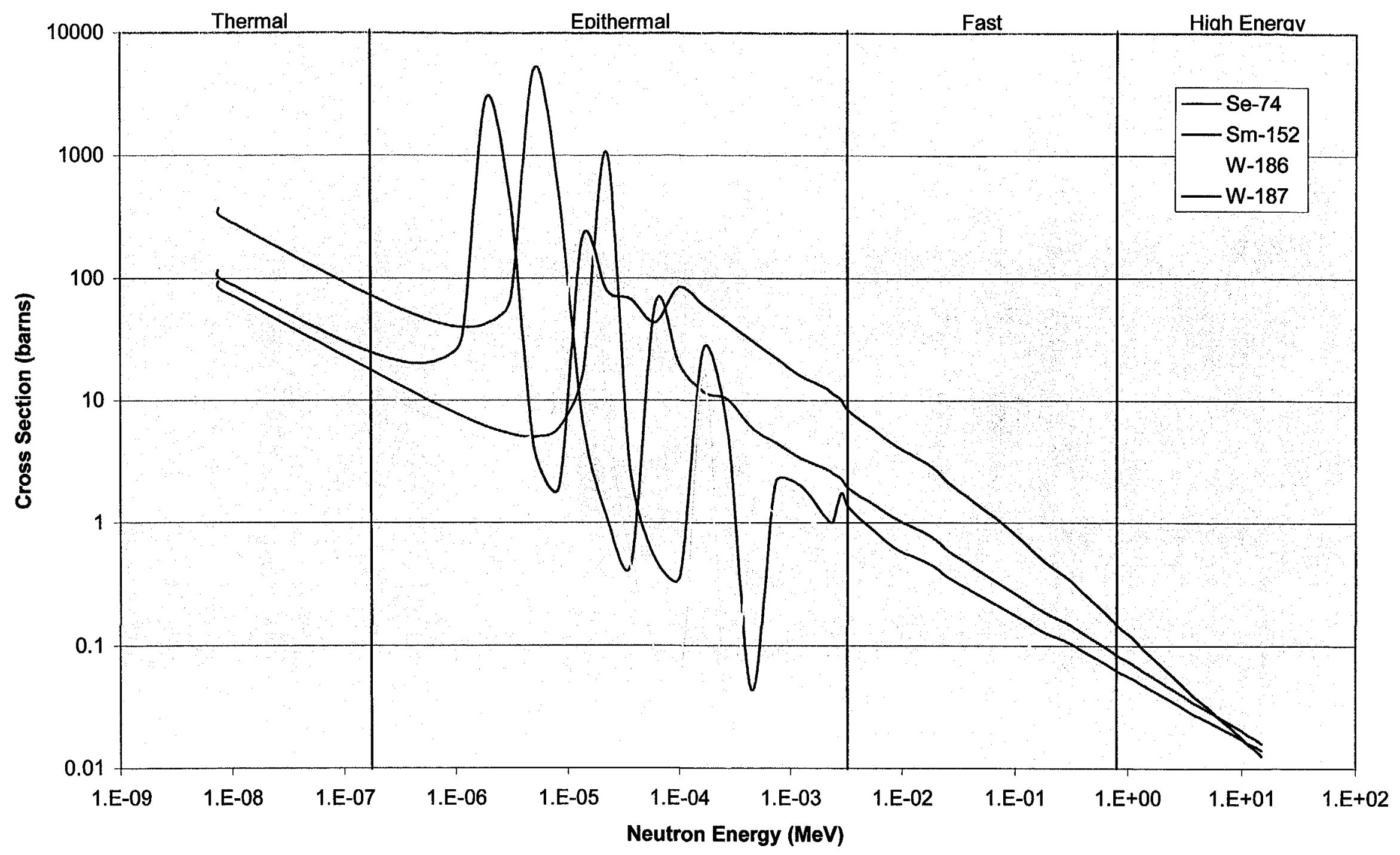

Figure 7 Se-75, Sm-153, W-188 Production Cross Sections 


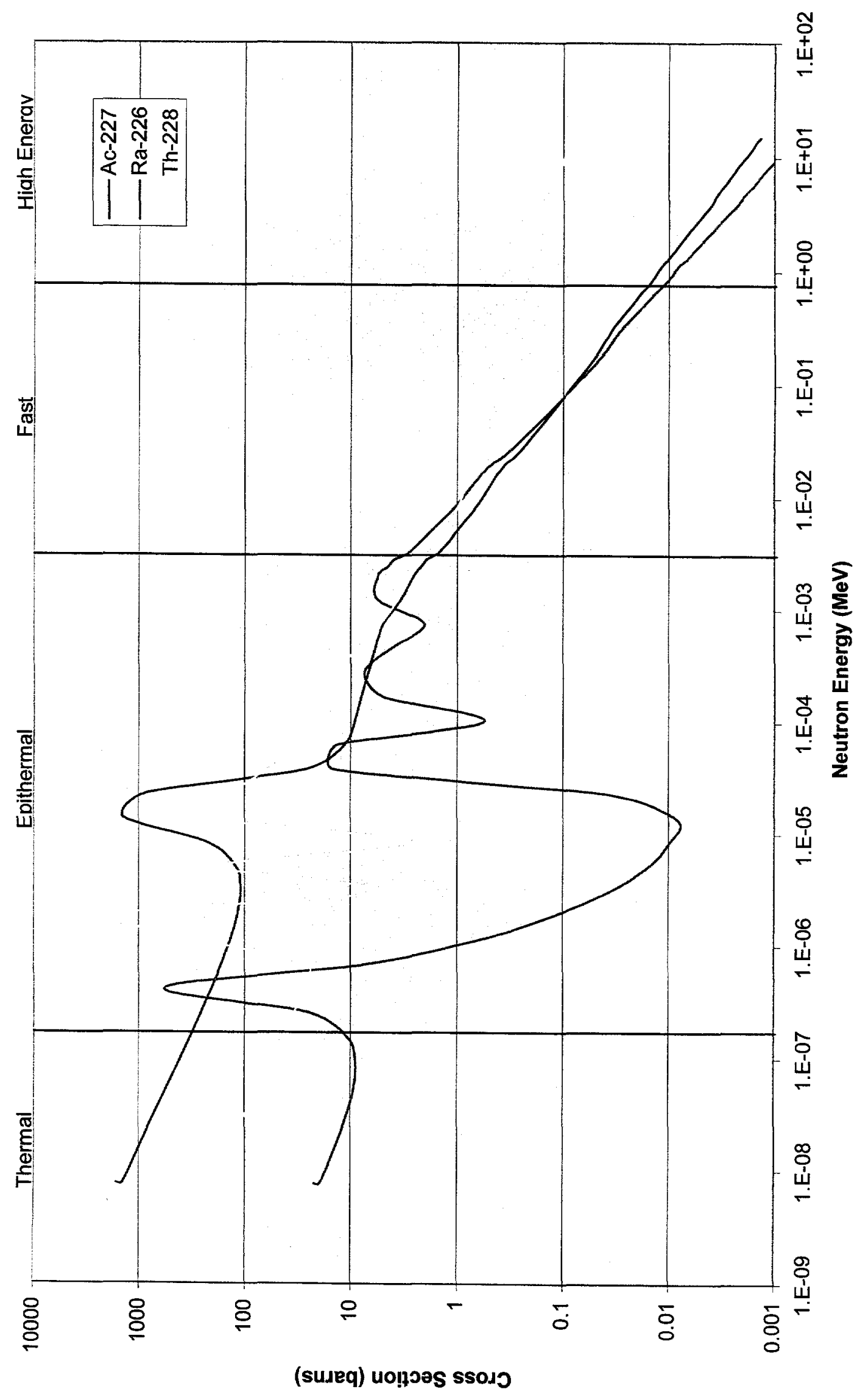




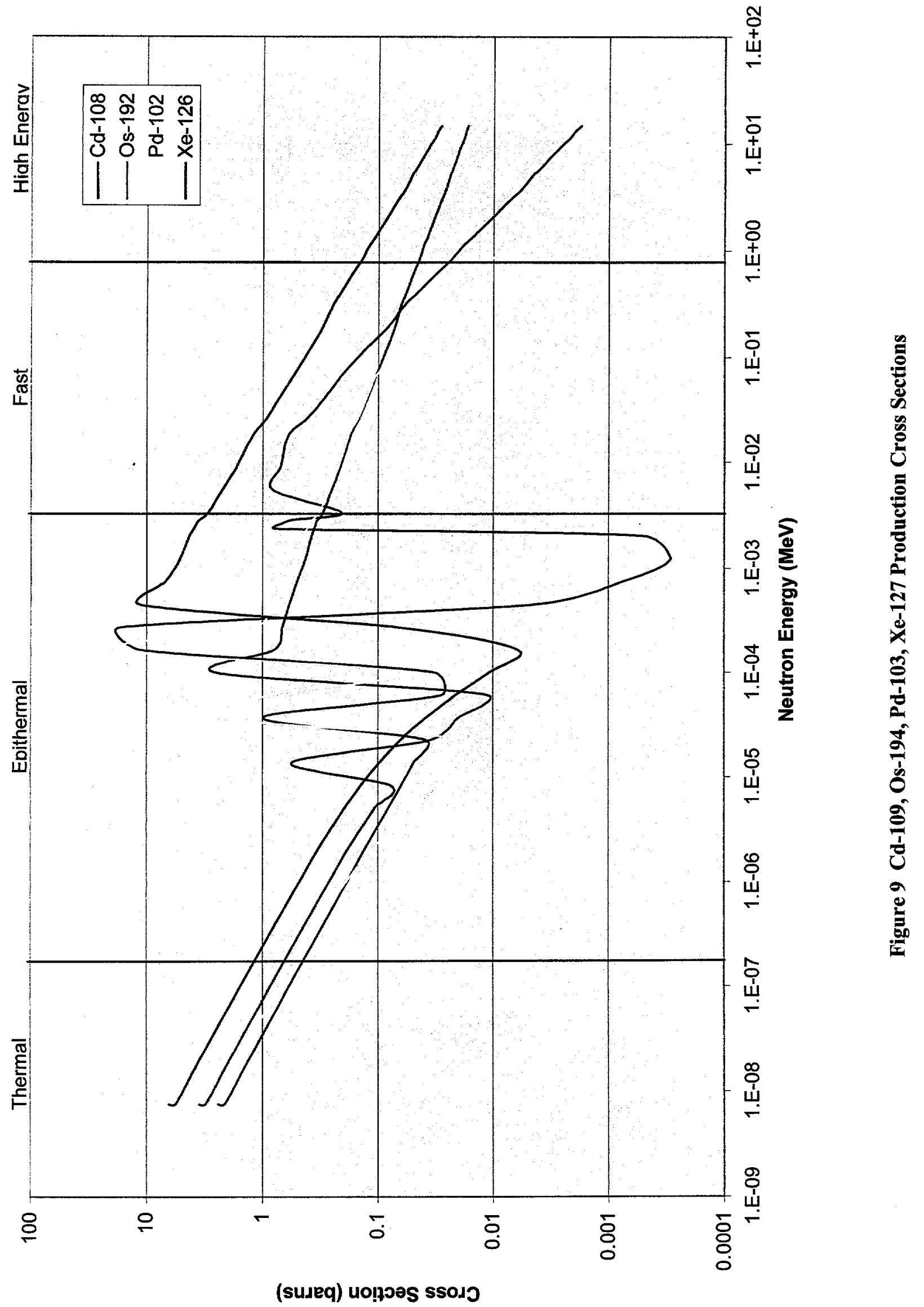




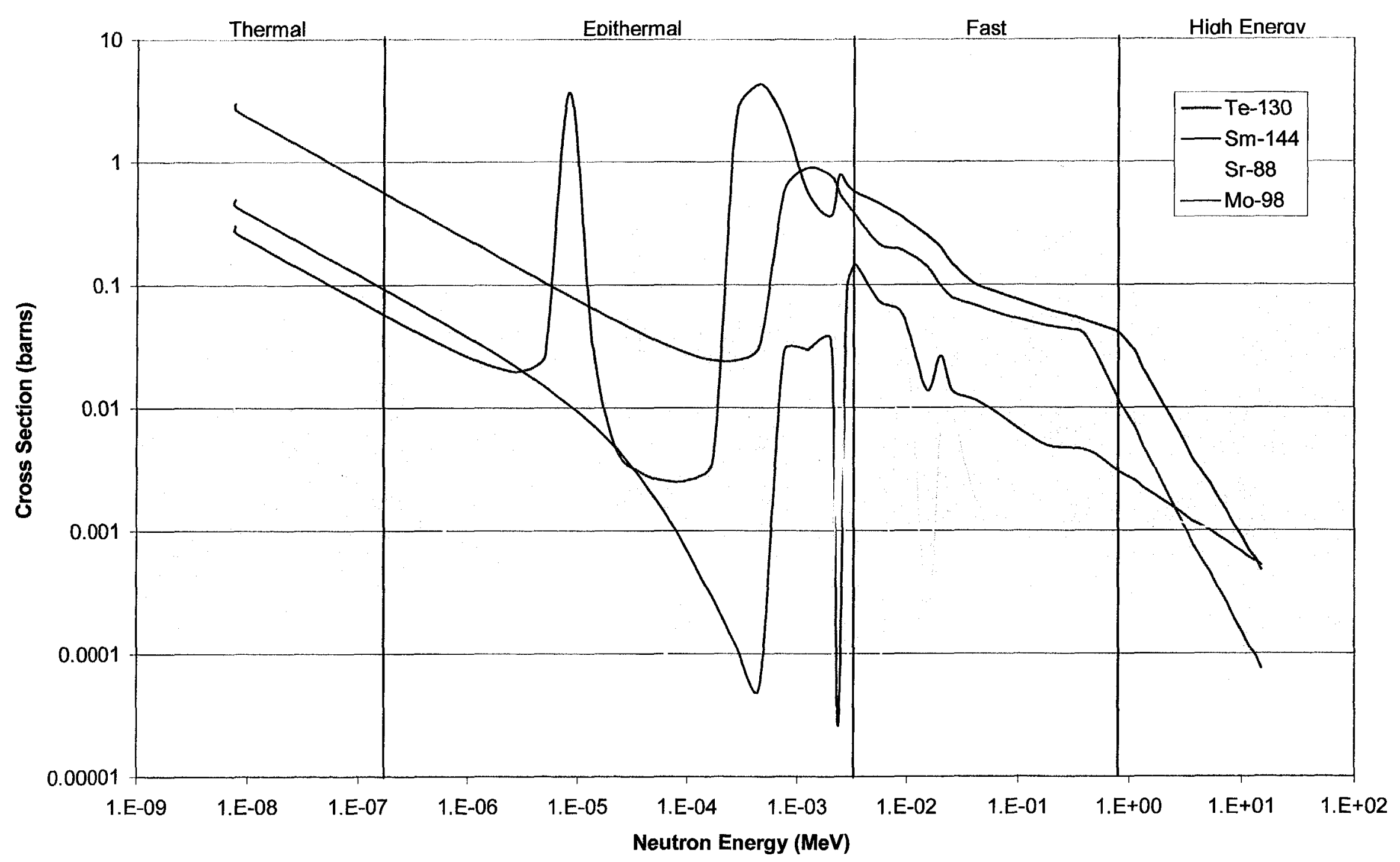

Figure 10 I-131, Sm-145, Sr-89, Mo-99 Production Cross Sections 


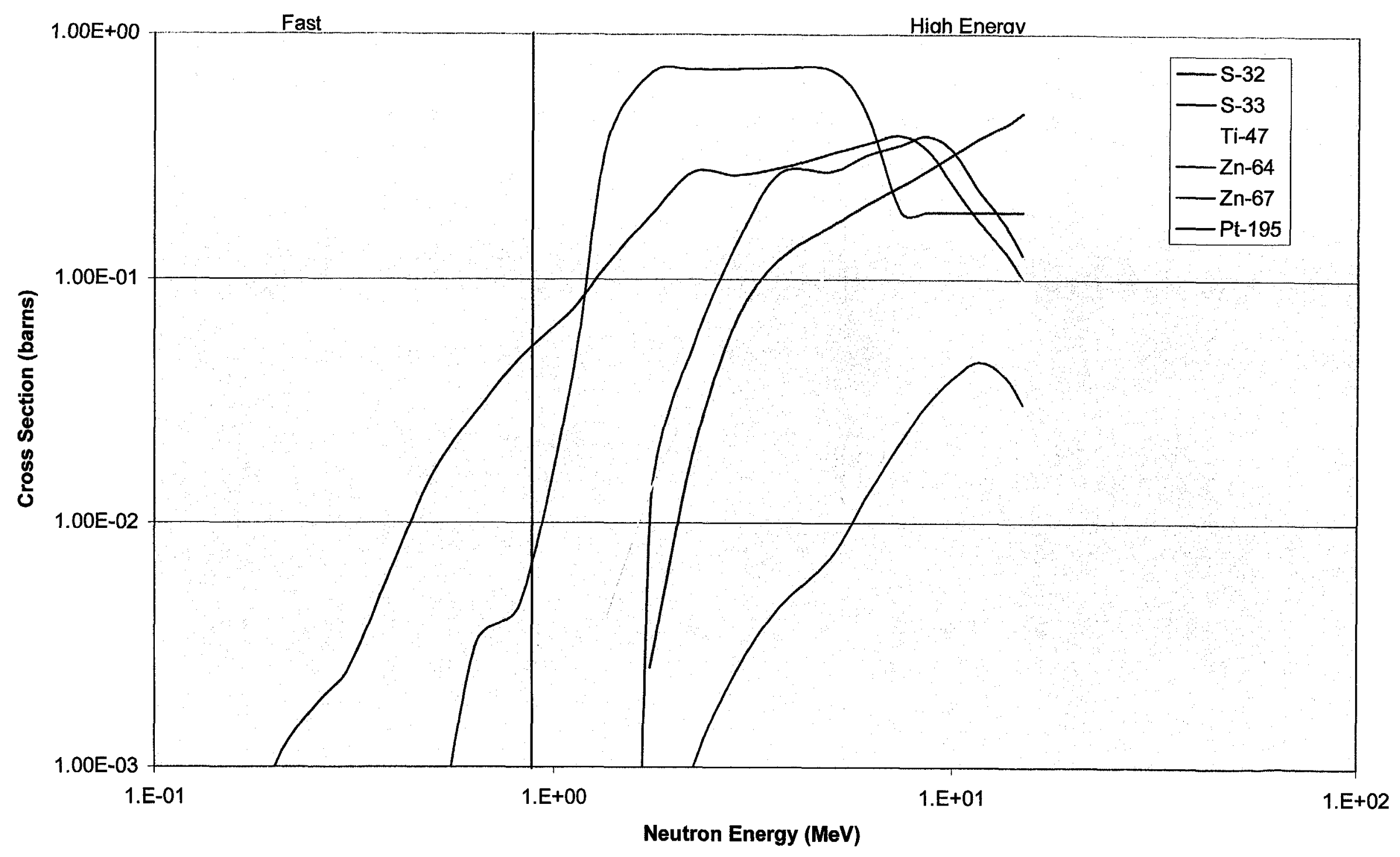

Figure 11 P-32, P-33, Sc-47, Cu-64, Cu-67, Pt-195m Production Cross Sections 


\section{Optimum Production of Reactor-Generated Medical Isotopes}

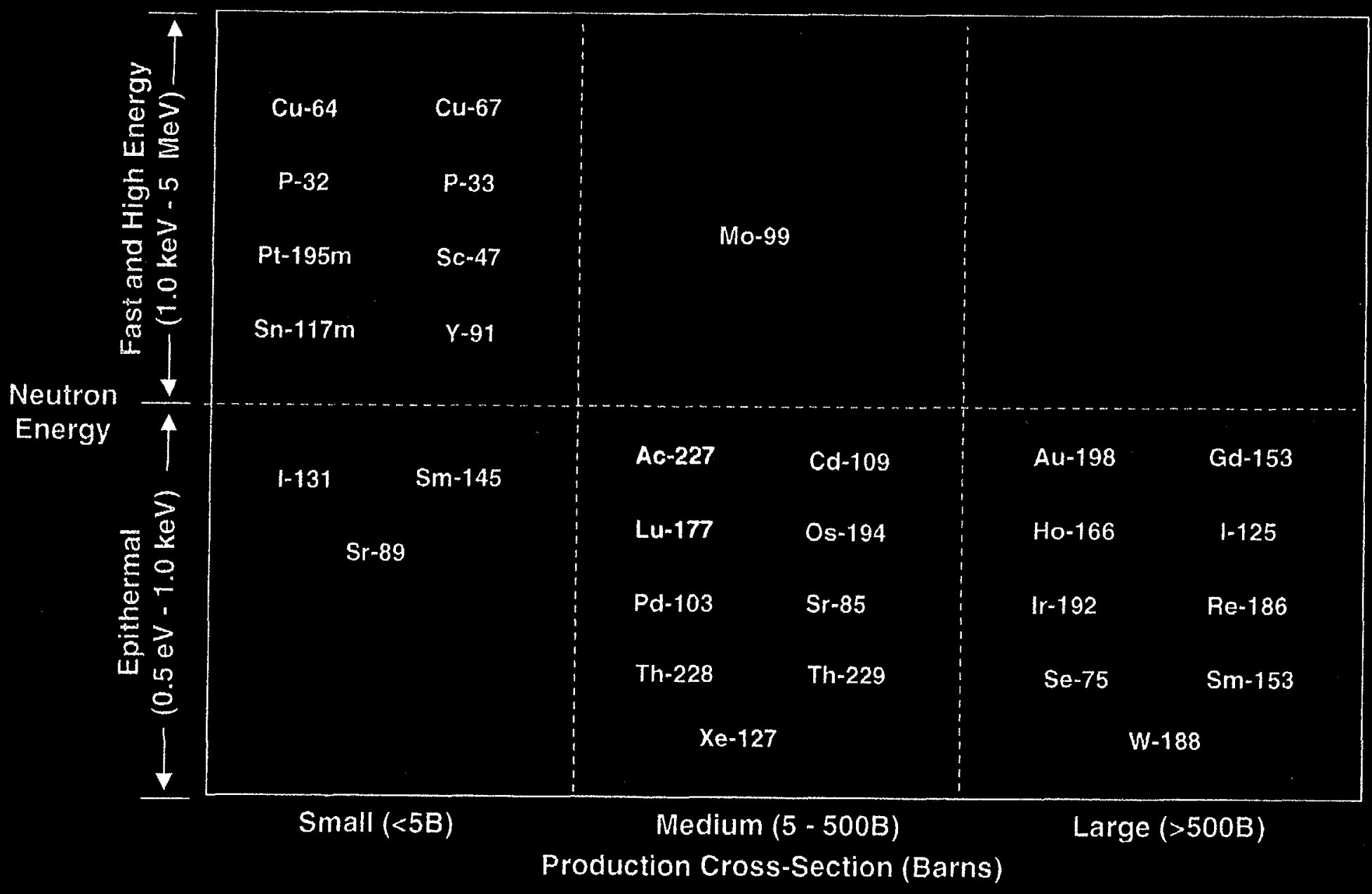




\subsection{Production Calculations}

Production calculations are performed using the CHAIN code (see Appendix C.1 for a detailed discussion of this code). This code generates isotope production data (amount in grams and Curies) based on initial mass, total flux, one-group cross section, specific activity, half-life, self-shielding factor, and power history inputs.

Table 4 presents the results of CHAIN calculations for isotope production in FFTF and HFIR. In addition to the CHAIN input variables identified in the table (irradiation time and target mass), the following input data was used:

Flux spectra

Table 2 identifies the flux spectra (core position) associated with the target vehicle identified in Table 4 (for HFIR, isotopes produced in an LIV use the PTP flux spectrum and isotopes produced in an R3 use the HT spectrum).

Cross sections One-group cross sections associated with the flux spectra mentioned above were generated using BW (see Section 3.0).

Self-shielding factors A value of 1.0 was entered for all self-shielding factors in the CHAIN input. As a result, these production values do not take self-shielding into account.

Targets used in production calculations were $100 \%$ pure as identified in Table 4. As summarized in Table 2, target vehicles and core locations were chosen based on:

- the half-lives of the product isotopes (short-lived isotopes are produced in R3 assemblies, longlived isotopes in LIVs; further explanation of which is provided in Section 5.0),

- the optimum flux spectrum (production requiring fast and high energy neutrons are produced without hydriding, isotopes with advantages in the epithermal region are produced with hydriding), and

- available core locations for isotope production.

(As discussed in Section 5.2, long-lived isotopes are produced in the HFIR PTP while short-lived isotopes are produced in the HFIR HT.) Irradiation times were selected based on the half-lives of the product isotopes. Target masses were chosen to be consistent with production calculations in Isotope Production at the Hanford Site in Richland, Washington (Pacific Northwest National Laboratory June 1999).

It should be noted that target masses listed in Table 4 represent $20 \%$ of the projected U.S. demand for each isotope (Pacific Northwest National Laboratory June 1999). Sufficient volume exists in FFTF for targets of such size; however, HFIR volume is not sufficient to accommodate the full mass of some of these targets. 
Table 4 Isotope Production Results

\begin{tabular}{|c|c|c|c|c|c|c|}
\hline \multirow{2}{*}{$\begin{array}{l}\text { Product } \\
\text { Isotope }\end{array}$} & \multirow{2}{*}{$\begin{array}{c}\text { Target } \\
\text { Material }\end{array}$} & \multirow{2}{*}{$\begin{array}{l}\text { Target } \\
\text { Vehicle }\end{array}$} & \multirow{2}{*}{$\begin{array}{l}\text { Irradiation } \\
\text { Time (days) }\end{array}$} & \multirow{2}{*}{$\begin{array}{c}\text { Target } \\
\text { Mass }(\mathrm{g})\end{array}$} & \multicolumn{2}{|c|}{ Product Activity (Ci) } \\
\hline & & & & & FFTF & HFIR \\
\hline Ac-227 & $\mathrm{Ra}-226$ & LIV-H & 200 & $3.3 E+01$ & $8.5 \mathrm{E}+01$ & $4.3 \mathrm{E}+01$ \\
\hline Cd-109 & $\mathrm{Cd}-108$ & LIV-H & 600 & $1.0 \mathrm{E}+03$ & $1.2 \mathrm{E}+04$ & $4.7 \mathrm{E}+03$ \\
\hline $\mathrm{Cu}-64$ & $\mathrm{Zn}-64$ & $\mathrm{R} 3$ & 2 & $1.1 \mathrm{E}+01$ & $7.5 \mathrm{E}+00$ & $1.1 \mathrm{E}+01$ \\
\hline $\mathrm{Cu}-67$ & $\mathrm{Zn}-67$ & R3 & 10 & $9.3 \mathrm{E}+01$ & $2.9 \mathrm{E}+00$ & $4.1 E+00$ \\
\hline $\mathrm{Ho}-166$ & $\mathrm{Ho}-165$ & $\mathrm{R} 3-\mathrm{H}$ & 5 & $1.3 \mathrm{E}-01$ & $9.1 E+01$ & $1.2 \mathrm{E}+03$ \\
\hline $\mathrm{I}-131$ & $\mathrm{Te}-130$ & $\mathrm{R} 3-\mathrm{H}$ & 25 & $1.4 \mathrm{E}+02$ & $4.3 \mathrm{E}+02$ & $5.5 \mathrm{E}+03$ \\
\hline Ir-192 & Ir-191 & LIV & 300 & $1.5 \mathrm{E}+04$ & $8.2 \mathrm{E}+06$ & $7.9 \mathrm{E}+06$ \\
\hline Mo-99 & Mo-98 & R3-H & 10 & $2.1 \mathrm{E}+00$ & $1.0 \mathrm{E}+02$ & $2.3 \mathrm{E}+02$ \\
\hline Os-194 & Os-192 & LIV & 600 & $2.3 \mathrm{E}+05$ & $3.1 \mathrm{E}+01$ & $4.0 \mathrm{E}+03$ \\
\hline P-32 & $\mathrm{S}-32$ & R3 & 50 & $2.0 \mathrm{E}+01$ & $5.5 \mathrm{E}+01$ & $7.8 \mathrm{E}+01$ \\
\hline P-33 & $S-33$ & LIV & 100 & $7.1 \mathrm{E}+00$ & $4.6 \mathrm{E}+01$ & $3.0 \mathrm{E}+02$ \\
\hline $\mathrm{Pd}-103$ & $\mathrm{Pd}-102$ & LIV & 100 & $5.4 \mathrm{E}+01$ & $1.6 \mathrm{E}+03$ & $2.4 \mathrm{E}+04$ \\
\hline $\mathrm{Pt}-195 \mathrm{~m}$ & Pt-195 & $\mathrm{R} 3$ & 25 & $5.0 \mathrm{E}+01$ & $6.5 E+01$ & $1.9 \mathrm{E}+02$ \\
\hline $\mathrm{Re}-186$ & $\mathrm{Re}-185$ & R3-H & 25 & $1.5 \mathrm{E}+01$ & $1.3 \mathrm{E}+04$ & $1.1 \mathrm{E}+05$ \\
\hline $\mathrm{Sc}-47$ & $\mathrm{Ti}-47$ & R3 & 10 & $7.2 \mathrm{E}+01$ & $5.7 E+01$ & $1.4 \mathrm{E}+02$ \\
\hline Se-75 & Se-74 & LIV-H & 300 & $3.0 \mathrm{E}-01$ & $4.4 \mathrm{E}+02$ & $1.3 \mathrm{E}+03$ \\
\hline Sm-145 & Sm-144 & LIV-H & 300 & $1.1 \mathrm{E}+01$ & $4.3 \mathrm{E}+01$ & $1.5 \mathrm{E}+02$ \\
\hline Sm-153 & $\mathrm{Sm}-152$ & $\mathrm{R} 3-\mathrm{H}$ & 10 & $8.3 \mathrm{E}-03$ & $3.1 E+01$ & $3.0 \mathrm{E}+02$ \\
\hline $\mathrm{Sr}-89$ & $\mathrm{Sr}-88$ & LIV-H & 200 & $2.5 \mathrm{E}+02$ & $9.8 \mathrm{E}+01$ & $5.3 E+02$ \\
\hline Th-228 & $\mathrm{Ra}-226$ & LIV-H & 300 & $3.3 \mathrm{E}+01$ & $5.0 \mathrm{E}+02$ & $1.9 \mathrm{E}+03$ \\
\hline Th-229 & $\mathrm{Ra}-226$ & LIV-H & 600 & $3.3 \mathrm{E}+01$ & $5.9 \mathrm{E}-02$ & $2.4 \mathrm{E}-01$ \\
\hline W-188 & W-186 & LIV-H & 300 & $3.0 \mathrm{E}+04$ & $6.2 \mathrm{E}+04$ & $1.3 \mathrm{E}+06$ \\
\hline $\mathrm{Xe}-127$ & $\mathrm{Xe}-126$ & LIV & 100 & $1.2 \mathrm{E}+00$ & $7.5 \mathrm{E}+01$ & $7.4 \mathrm{E}+02$ \\
\hline
\end{tabular}

In assessing the differences between production data in this report and Isotope Production at the Hanford Site in Richland, Washington (Pacific Northwest National Laboratory June 1999), it should be noted that:

- product quantities are given in $\mathrm{Ci}$ rather than $\mathrm{Ci}$ of product per gram of target,

- all R3 assemblies were assumed to be in row 4 and all LIVs were assumed to be in row 6, and

- irradiation times were changed to optimize production based on product half-lives. 


\subsection{Target Volume Data}

Target volumes for FFTF and HFIR calculated in this section are used to compare total isotope production capabilities in Section 6.0.

\subsection{FFTF Target Volumes}

\subsubsection{FFTF LIV Target Volume}

Long-lived isotopes are produced in FFTF using Long-term Irradiation Vehicles (LIV). These are assemblies that are placed in the reactor core for one or more reactor operating cycles (typically 100 days per cycle).

Based on prior isotope production experiments, a usable volume of $8,564 \mathrm{~cm}^{3} /$ assembly $^{(a)}$ was used for LIVs. For the purposes of comparing total isotope production in Section 6.0, it is assumed that 9 FFTF core locations will be available for isotope production. The total target.volume for LIVs is therefore $9 \times 8,564=77,100 \mathrm{~cm}^{3}$.

Production of certain isotopes is enhanced by tailoring the neutron flux to take advantage of high resonance neutron capture cross sections at particular neutron energies. This requires using materials that moderate (slow down) the neutron flux, a process known as hydriding. Introduction of moderator materials reduces the volume available for target material. While the volume required for moderator material will vary depending on the isotopes produced in an assembly, a conservative estimate is that half the volume will be required for moderator material ${ }^{(a)}$. Thus, for long-lived isotopes produced using hydriding (LIV-H), the total target volume is $0.5 \times 9 \times 8,564=38,500 \mathrm{~cm}^{3}$.

\subsubsection{FFTF Rapid Retrieval Target Volume}

Short-lived isotopes are produced in FFTF using Rapid Radioisotope Retrieval (R3) vehicles. These vehicles allow the insertion and removal of target capsules while the reactor is at power.

Based on prior design work for R3 assemblies, the target volume available is $24 \mathrm{~cm}^{3}$ per vehicle ${ }^{(a)}$. This volume will also be available for isotopes produced with hydriding since the hydride pins are outside the target tube. For the purposes of comparing total isotope production in Section 6.0 , it is assumed that 3 $\mathrm{R} 3$ assemblies will be available for isotope production. The total target volume for R3 and R3-H is therefore $3 \times 24=72 \mathrm{~cm}^{3}$.

(a) Klos, DB (FFTF Program Deputy Director). phone conversation, June, 1999. 


\subsection{HFIR Target Volumes}

\subsubsection{HFIR LIV Target Volume}

For the purposes of this report, it was assumed that production of long-lived isotopes would be accomplished in the optimal location, the peripheral target positions (PTP) in the central flux trap (Figure 3).

A typical PTP target pin is shown in Figure 13. Irradiation capsules used in these pins are typically $1.27 \mathrm{~cm}$ in diameter with an overall target length of $50.8 \mathrm{~cm}$ (Mirzadeh et al. 1992). Target volume is therefore:

$$
\pi\left(\frac{1.27}{2}\right)^{2}(50.8)=64.4 \mathrm{~cm}^{3}
$$
$386 \mathrm{~cm}^{3}$.

Since there are six PTP positions in the flux trap (Figure 3), the total target volume is $6 \times 64.4=$

\subsubsection{HFIR HT Target Volume}

There is one hydraulic tube (HT) in the central flux trap (Figure 3) that can be used to produce short-lived isotopes. The hydraulic tube is designed to allow the insertion and removal of target capsules while the reactor is at power.

A typical hydraulic tube capsule assembly is shown in Figure 14. As seen in the figure, each capsule has a sample length of $2-3 / 16$ in. with a diameter of 0.255 in. Target volume is therefore:

$$
\pi\left(\frac{0.255}{2} \times 2.54\right)^{2}\left(2 \frac{3}{16} \times 2.54\right)=1.83 \mathrm{~cm}^{3}
$$

Since only seven of the nine capsules in a string are used for target materials (Mirzadeh et al. 1992), the total HT target volume is $7 \times 1.83=12.8 \mathrm{~cm}^{3}$. 


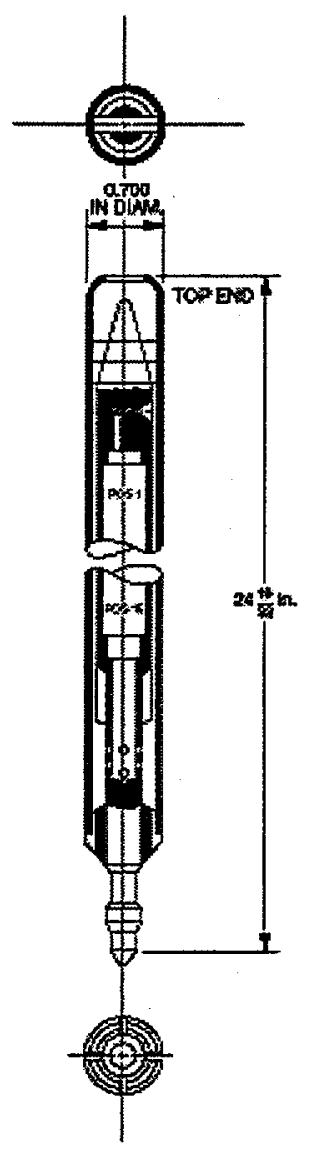

Figure 13 HFIR PTP Pin

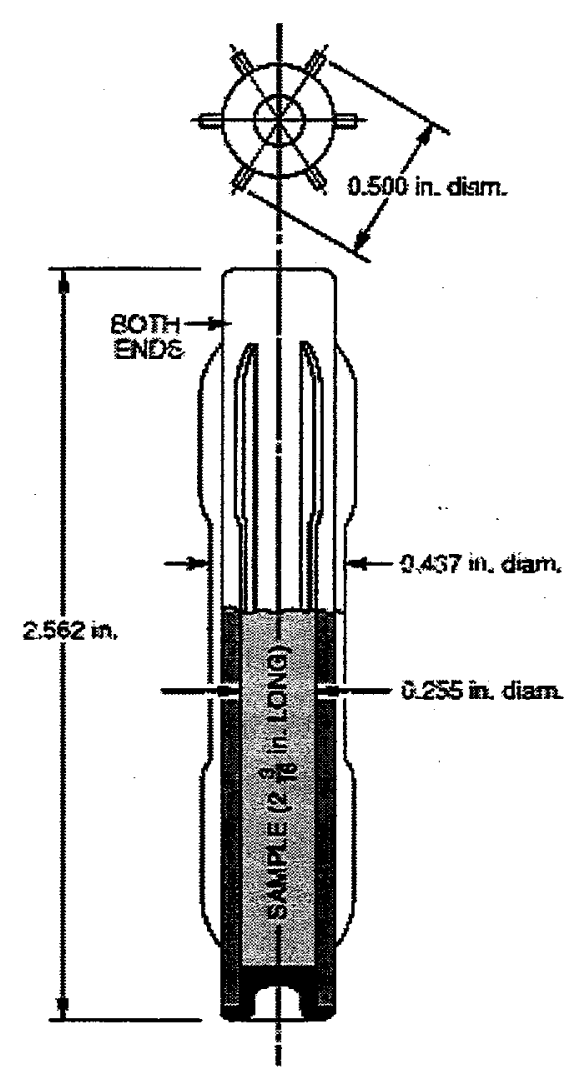

Figure 14 HFIR HT Capsule 


\subsection{Results}

Table 5 presents a summary of the isotope production capabilities of FFTF and HFIR. The two columns labeled Product Activity (Ci) are the results for FFTF and HFIR obtained in Section 4.0. The Production Ratio (FFTF/HFIR) was calculated by dividing FFTF product activity by HFIR product activity. The two columns labeled Target Volume $\left(\mathrm{cm}^{3}\right)$ were derived in Section 5.0. The Volume Ratio (FFTF/HFIR) was calculated by dividing FFTF target volume by HFIR target volume. The column labeled FFTF Advantage was obtained by multiplying the production ratio by the volume ratio.

Table 5 FFTF-HFIR Isotope Production Comparison

\begin{tabular}{|c|c|c|c|c|c|c|c|}
\hline \multirow{2}{*}{$\begin{array}{l}\text { Product } \\
\text { Isotope }\end{array}$} & \multicolumn{2}{|c|}{$\begin{array}{l}\text { Product Activity } \\
\text { (Ci) }\end{array}$} & \multirow{2}{*}{$\begin{array}{c}\text { Production } \\
\text { Ratio } \\
\text { (FFTF/HFIR) }\end{array}$} & \multicolumn{2}{|c|}{$\begin{array}{l}\text { Target Volume } \\
\left(\mathrm{cm}^{3}\right)\end{array}$} & \multirow{2}{*}{$\begin{array}{c}\text { Volume } \\
\text { Ratio } \\
\text { (FFTF/HFIR) }\end{array}$} & \multirow{2}{*}{$\begin{array}{l}\text { FFTF Advantage } \\
\text { (Prod. Ratio x } \\
\text { Vol. Ratio) }\end{array}$} \\
\hline & FFTF & HFIR & & FFTF & HFIR & & \\
\hline Ac- 227 & $8.5 E+01$ & $4.3 E+01$ & 2.0 & 38500 & 386 & 99.7 & 197 \\
\hline Cd-109 & $1.2 \mathrm{E}+04$ & $4.7 \mathrm{E}+03$ & 2.6 & 38500 & 386 & 99.7 & 255 \\
\hline $\mathrm{Cu}-64$ & $7.5 \mathrm{E}+00$ & $1.1 \mathrm{E}+01$ & 0.7 & 72 & 12.8 & 5.6 & 3.8 \\
\hline $\mathrm{Cu}-67$ & $2.9 \mathrm{E}+00$ & $4.1 \mathrm{E}+00$ & 0.7 & 72 & 12.8 & 5.6 & 4.0 \\
\hline Ho-166 & $9.1 \mathrm{E}+01$ & $1.2 \mathrm{E}+03$ & 0.1 & 72 & 12.8 & 5.6 & 0.4 \\
\hline $\mathrm{I}-131$ & $4.3 \mathrm{E}+02$ & $5.5 \mathrm{E}+03$ & 0.1 & 72 & 12.8 & 5.6 & 0.4 \\
\hline $\mathrm{Ir}-192$ & $8.2 \mathrm{E}+06$ & $7.9 \mathrm{E}+06$ & 1.0 & 77100 & 386 & 200 & 207 \\
\hline Mo-99 & $1.0 \mathrm{E}+02$ & $2.3 \mathrm{E}+02$ & 0.4 & 72 & 12.8 & 5.6 & 2.4 \\
\hline Os-194 & $3.1 \mathrm{E}+01$ & $4.0 \mathrm{E}+03$ & 0.0 & 77100 & 386 & 200 & 1.5 \\
\hline $\mathrm{P}-32$ & $5.5 \mathrm{E}+01$ & $7.8 \mathrm{E}+01$ & 0.7 & 72 & 12.8 & 5.6 & 4.0 \\
\hline P-33 & $4.6 \mathrm{E}+01$ & $3.0 \mathrm{E}+02$ & 0.2 & 77100 & 386 & 200 & 30.6 \\
\hline Pd-103 & $1.6 \mathrm{E}+03$ & $2.4 \mathrm{E}+04$ & 0.1 & 77100 & 386 & 200 & 13.3 \\
\hline Pt-195m & $6.5 \mathrm{E}+01$ & $1.9 \mathrm{E}+02$ & 0.3 & 72 & 12.8 & 5.6 & 1.9 \\
\hline $\operatorname{Re}-186$ & $1.3 \mathrm{E}+04$ & $1.1 \mathrm{E}+05$ & 0.1 & 72 & 12.8 & 5.6 & 0.7 \\
\hline Sc-47 & $5.7 \mathrm{E}+01$ & $1.4 \mathrm{E}+02$ & 0.4 & 72 & 12.8 & 5.6 & 2.3 \\
\hline $\mathrm{Se}-75$ & $4.4 \mathrm{E}+02$ & $1.3 E+03$ & 0.3 & 38500 & 386 & 99.7 & 33.8 \\
\hline Sm-145 & $4.3 \mathrm{E}+01$ & $1.5 \mathrm{E}+02$ & 0.3 & 38500 & 386 & 99.7 & 28.6 \\
\hline Sm-153 & $3.1 \mathrm{E}+01$ & $3.0 \mathrm{E}+02$ & 0.1 & 72 & 12.8 & 5.6 & 0.6 \\
\hline Sr-89 & $9.8 \mathrm{E}+01$ & $5.3 E+02$ & 0.2 & 38500 & 386 & 99.7 & 18.4 \\
\hline Th-228 & $5.0 \mathrm{E}+02$ & $1.9 \mathrm{E}+03$ & 0.3 & 38500 & 386 & 99.7 & 26.2 \\
\hline Th-229 & $5.9 \mathrm{E}-02$ & $2.4 \mathrm{E}-01$ & 0.2 & 38500 & 386 & 99.7 & 24.5 \\
\hline W-188 & $6.2 \mathrm{E}+04$ & $1.3 \mathrm{E}+06$ & 0.0 & 38500 & 386 & 99.7 & 4.8 \\
\hline $\mathrm{Xe}-127$ & $7.5 \mathrm{E}+01$ & $7.4 E+02$ & 0.1 & 77100 & 386 & 200 & 20.2 \\
\hline
\end{tabular}

Production ratios mostly favor HFIR (i.e., the ratio is typically $<1$ ). The reasons for this were discussed in Section 2.3. For example, isotope production requiring epithermal neutrons (e.g., Ho-166, I131, Os-194) is favored in HFIR due to its higher fluxes in that region as a result of FFTF operation at $100 \mathrm{MW}$ rather than $400 \mathrm{MW}$. Isotope production requiring fast or high energy neutrons (e.g., Cu-64, $\mathrm{Cu}-67, \mathrm{P}-32, \mathrm{P}-33$ ) is favored in HFIR also due to the lower fluxes associated with $100 \mathrm{MW}$ operation of FFTF and because of the reduction of fast and high energy neutrons associated with overall core moderation for the production of Pu-238. In some cases, FFTF has a production advantage only because of substantial burnout of the product isotope in HFIR (e.g., Ac-227 - in FFTF, production of this isotope increases beyond 100 days irradiation while in HFIR, production decreases beyond 100 days). 
Higher production in FFTF can be achieved by placing target vehicles in areas with more favorable neutronic conditions. As identified in Section 2.3, long-lived isotope production was calculated for row 6. Greater production would be possible in locations closer to the reactor center. Likewise, short-lived isotope production was calculated for row 4. Greater production would be possible in an R3 in row 2.

Volume ratios favor FFTF due to larger volumes of the irradiation vehicles and the higher number of irradiation locations available (see Section 5.0).

Typically, production in FFTF is favored (FFTF Advantage column $>1$ ) because the volume advantage overcomes the production disadvantage. The fact that some isotopes (Ho-166, I-131, Re-186, and Sm-153; all of which have substantial production in the epithermal region) are more favorably produced in HFIR reemphasizes the importance of judicious placement of target vehicles and flux tailoring (see Section 2.3) to compensate for the detrimental effects of FFTF operation at $100 \mathrm{MW}$. Also, the low advantage ratios for isotopes produced in the fast and high energy range (e.g., Cu-64, Cu-67, P32 , Pt-195m) highlights the importance of placing R3 assemblies in regions of high flux that are minimally affected by moderation for the production of Pu- 238 . 


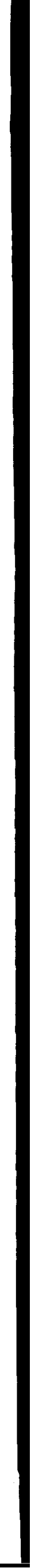




\subsection{Conclusion}

Both FFTF and HFIR can produce significant quantities of medical isotopes. This fact is extremely important in light of the need for a reliable source of isotopes for use in medicine. Research and clinical applications require a continuous supply of isotopes to satisfactorily complete investigations and provide for the treatment of patients in a timely manner. No one reactor can meet this requirement due to routine shutdowns for maintenance and refueling. Such shutdowns interrupt the steady supply of short-lived isotopes. It is therefore beneficial, if not absolutely necessary, to have multiple sources of medical isotopes. With FFTF and HFIR capable of efficient production of isotopes that are not easily produced in conventional thermal reactors, the Department of Energy has the opportunity to provide needed isotopes in a coordinated manner that satisfies the needs of the medical community.

Flux spectra in both reactors are favorable for the production of many medical isotopes that require epithermal, fast, and high energy neutrons. Neutrons of these energies are not available in appreciable quantities in typical light water reactors and as such, FFTF and HFIR offer distinct advantages over most other reactors for the production of certain isotopes.

HFIR PTP and HT positions have a much higher thermal flux than any of the FFTF core locations studied as would be expected since HFIR is a water-cooled reactor while FFTF is a sodium-cooled reactor. Interestingly, however, both HFIR positions have substantially higher epithermal fluxes than FFTF positions and the HFIR PTP has a substantial fast and high energy flux compared with FFTF. Such phenomena should not be exceptionally surprising since HFIR was designed to provide a very high flux in the central region of the reactor, i.e., the flux trap. Thus, even with both reactors operating at similar power levels, HFIR should be expected to have higher flux levels in the high flux region than FFTF which is a more homogeneous reactor.

In addition to the higher flux levels achieved by the design of HFIR there are other factors that reduce FFTF flux levels with respect to HFIR. There is a substantial "flux degradation" associated with operation of FFTF at $100 \mathrm{MW}$ with a Pu-238 mission. Obviously, the change from $400 \mathrm{MW}$ to $100 \mathrm{MW}$ operation will reduce the flux. Also, the $100 \mathrm{MW}$ flux spectra were generated assuming a Pu-238 mission. Production of Pu-238 requires significant hydriding and this also affects the overall flux spectrum. These two effects result in lower total fluxes and a softer (slower) neutron spectrum than prior FFTF experience.

More favorable flux spectra for FFTF than those used in this report can be achieved in two ways. The degree of hydriding should be optimized in assemblies producing isotopes that have targets with large cross sections in the epithermal region. This report used a generic target vehicle design that had two rows of yttrium hydride pins surrounding the target pins; other designs that tailor the flux to take advantage of high neutron capture resonance peaks of individual targets would result in increased isotope production. Also, core locations should be selected for target assemblies that have the highest available flux. This report used one row 4 location to calculate all R3 production data and one row 6 location to calculate all LIV production data. Placing target assemblies in rows closer to the core centerline would increase total flux and investigating optimal position within rows (e.g., positions not in close proximity to $\mathrm{Pu}-238$ production assemblies) would identify locations with higher fluxes and more favorable flux spectra. 
Production ratios (see Table 5) mostly favor HFIR (i.e., the ratio of FFTF/HFIR production is typically $<1$ ). The reasons for this are primarily due to flux spectra as discussed above. On the other hand, volume ratios favor FFTF due to larger volumes of the irradiation vehicles and the higher number of irradiation locations available.

When production and volume data are considered simultaneously, FFTF typically has higher overall production capabilities because the volume advantage overcomes the production disadvantage. The fact that some isotopes (Ho-166, I-131, Re-186, and Sm-153, all of which have substantial production in the epithermal region) are more favorably produced in HFIR reemphasizes the importance of judicious placement of target vehicles and flux tailoring to compensate for the "flux degradation" mentioned above. Also, the low advantage ratios for isotopes produced in the fast and high energy range (e.g., $\mathrm{Cu}-64, \mathrm{Cu}-67, \mathrm{P}-32$, Pt-195m) highlights the importance of placing R3 assemblies in regions of high flux that are minimally affected by moderation for the production of Pu- 238 .

The above discussion identifies significant neutronic effects that should be taken into account when core locations are allocated for isotope production. If isotope production is relegated to outer rows that are in close proximity to Pu-238 targets, the degradation in the total flux and the neutron spectrum will significantly impact production capabilities. Further, the degradation in flux levels highlights the importance of flux tailoring to optimize isotope production (i.e., to get the most benefit from the neutrons available). Finally, resumption of FFTF operation at $400 \mathrm{MW}$ would provide tremendous advantages for the production of substantial quantities of isotopes.

It should be noted that target masses used in this report represent $20 \%$ of the projected U.S. demand for each isotope (Pacific Northwest National Laboratory June 1999). Sufficient volume exists in FFTF for targets of such size; however, HFIR volume is not sufficient to accommodate the full mass of some of these targets. 


\subsection{References}

Briesmeister JF, ed. March 1997. MCNP - A General Monte Carlo N-Particle Transport Code, Version 4B. LA-12625-M, Los Alamos National Laboratory, Los Alamos, New Mexico.

Browne E, RB Firestone, and VS Shirley, ed. 1986. Table of Radioactive Isotopes. John Wiley \& Sons, Inc., New York, New York.

McLane V, CL Dunford, and PF Rose. 1988. Neutron Cross Sections Volume 2 Neutron Cross Section Curves. Academic Press, Inc., San Diego, California.

Mirzadeh S, RE Schenter, AP Callahan, and FF Knapp. November 1992. Production Capabilities in U.S. Nuclear Reactors for Medical Radioisotopes. ORNL/TM-12010, Oak Ridge National Laboratory, Oak Ridge, Tennessee.

Mughabghab SF, M Divadeenam, and NE Holden. 1984. Neutron Cross Sections Volume 1 Neutron Resonance Parameters and Thermal Cross Sections Parts $A(Z=1-60)$ and $B(Z=61-100)$. Academic Press, Inc., San Diego, California.

Pacific Northwest National Laboratory. November 1997. Medical Isotope Production at the Fast Flux Test Facility. PNNL-SA-29502, Richland, Washington.

Pacific Northwest National Laboratory. June 1999. Isotope Production at the Hanford Site in Richland, Washington. PNNL-12228, Richland, Washington.

Parrington JR, HD Knox, SL Breneman, EM Baum, and F Feiner. 1996. Nuclides and Isotopes Fifteenth Edition Chart of the Nuclides. General Electric Co. and KAPL Inc., San Jose, California.

Schenter RE. November 1990. Comparison of Medical Isotope Production in Fast and Thermal Reactor Systems. WHC-SA-0956-FP, Westinghouse Hanford Company, Richland, Washington. 



\section{Appendix A - Flux Spectra}

\section{A.1 MKFLX Multi-Group Flux Generation Program}

\section{A.1.1 MKLFX Flux Input File}

MKFLX is an unpublished Fortran program developed by the Westinghouse Hanford Company to produce multi-group fluxes for use in cross section calculations based on multi-group cross section information. It does this by applying generic reactor flux distributions to a smaller number of group fluxes input by the user.

A typical input text file is presented in Figure A.1. The first row is an 80 character title field (in this case it identifies that the fluxes are for the HFIR-PTP and are based on 85MW axial average values).

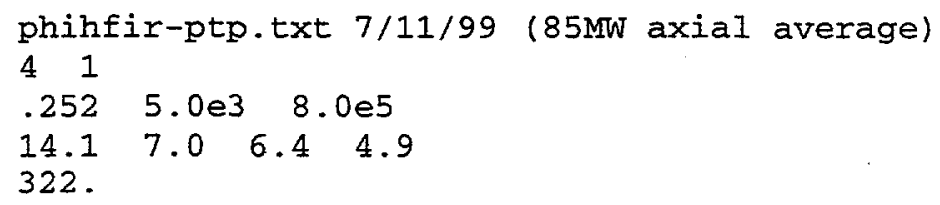

Figure A.1 MKFLX Input File

The first entry in the second line identifies the number of flux groups for which values will be provided to MKFLX. The second entry is either 1 or 2 and determines whether an exponent in the equation for flux calculations is 1.0 or 1.5. All MKFLX calculations on file have used 1 for this parameter.

The third line contains the upper energies (in eV) of the n- 1 input groups. MKFLX sets the lower energy of the lowest input group to $5 \mathrm{E}-3 \mathrm{eV}$ and the upper energy of the highest input group to 1.67E7 $\mathrm{eV}$.

Line 4 contains the input group fluxes in $\mathrm{n} / \mathrm{cm}^{2}-\sec \times 10^{-14}$.

Line 5 is an average temperature in $\mathrm{K}$ that is used as a correction for thermal neutron energy in a MKFLX subroutine.

\section{A.1.2 Running MKLFX}

Figure A.2 is a batch file used to run the MKFLX program (note that the line numbers are for explanatory purposes only and are not to be included in the actual batch file). The second line copies the MKLFX code into the current directory. The third line copies the file enu58 into the current directorythis file defines the 58 energy groups for which MKFLX will generate flux data. The fourth line specifies the location of the flux input file (c:Imkflx99linputlin_hfirptp.txt, Figure A.1, in this example). The fifth 
line executes the code and the sixth line prints data generated during the running of the program in a DOS window opened by the run batch file.

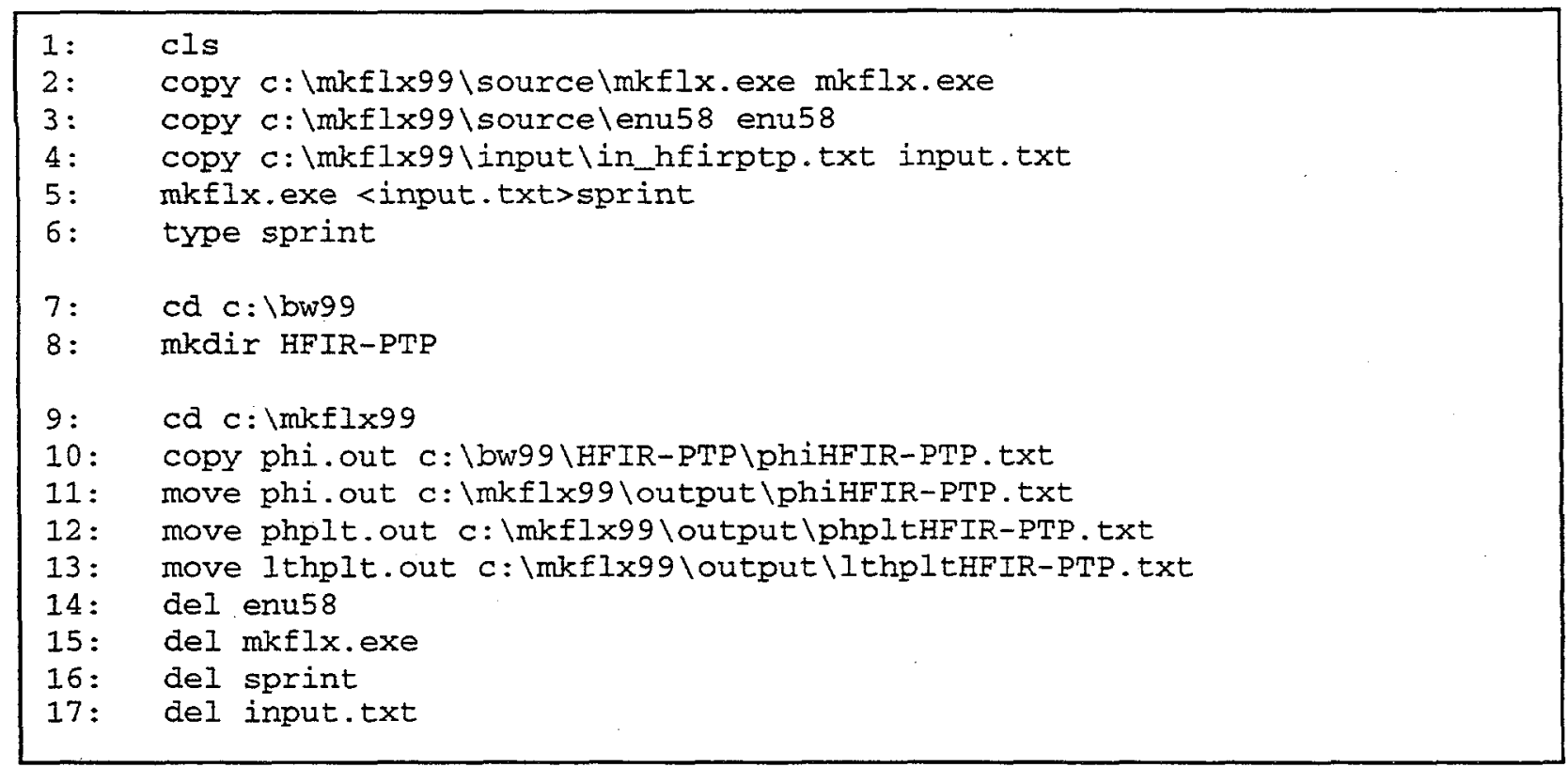

Figure A.2 MKFLX Run Batch File

The seventh line changes the directory to the location of the BW files and the eighth line creates a subdirectory for the core location for which a multi-group flux is being generated. This creates a subdirectory where the generated multi-group flux will be placed for use in calculating one-group cross sections (see Appendix B).

Line 9 returns to the MKFLX directory. Line 10 copies the multi-group flux output into the BW subdirectory that had just been created. Lines $11-13$ move the three generated flux files into an output subdirectory and gives them names that identify the core location of the flux spectrum.

The remaining lines clean up the run directory following execution of the code.

\section{A.1.3 MKLFX Output File}

Figure A.3 presents a representative portion of a MKFLX output file (for brevity, all 58 group fluxes are not shown). The first line is the 80 character title field from the input file.

The first entry in the second line identifies the number of flux groups in the output (MKFLX is currently configured to generate a 58-group output). The second, third, and fourth entries are parameters that are established in the MKFLX program; these parameters are used by the BW program's calculation of one-group cross sections (see Appendix B). 


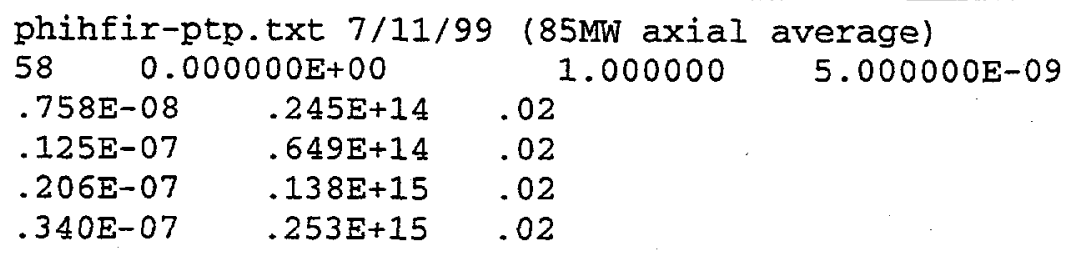

Figure A.3 MKFLX Output File

The remaining lines in the output file are the data for the 58 groups. The first number is the upper energy of the group (in $\mathrm{MeV}$ ), the second number is the group flux (in $\mathrm{n} / \mathrm{cm}^{2}-\mathrm{sec}$ ) and the third number is the uncertainty that is set in the MKFLX program.

This output file is used as the input for the BW program to calculate one-group cross sections (see Section 3 and Appendix B).

\section{A.2 Flux Data Tables}

Table A.1 FFTF Non-Hydrided Flux Data (100 MW)

\begin{tabular}{|c|c|c|c|c|c|c|}
\hline \multirow{2}{*}{$\begin{array}{l}\text { Flux Group } \\
\text { Upper Energy } \\
(\mathrm{MeV})\end{array}$} & \multicolumn{6}{|c|}{ Core Position } \\
\hline & $\begin{array}{c}1202^{(\mathrm{a})} \\
\left(\mathrm{n} / \mathrm{cm}^{2}-\mathrm{s}\right)\end{array}$ & $\begin{array}{c}1406^{(\mathrm{a})} \\
\left(\mathrm{n} / \mathrm{cm}^{2}-\mathrm{s}\right)\end{array}$ & $\begin{array}{c}3406^{(2)} \\
\left(\mathrm{n} / \mathrm{cm}^{2}-\mathrm{s}\right)\end{array}$ & $\begin{array}{c}2610^{(\mathrm{a})} \\
\left(\mathrm{n} / \mathrm{cm}^{2}-\mathrm{s}\right)\end{array}$ & $\begin{array}{c}3610^{(2)} \\
\left(\mathrm{n} / \mathrm{cm}^{2}-\mathrm{s}\right)\end{array}$ & $\begin{array}{c}-607 / 8 / 9^{(b)} \\
\left(n / \mathrm{cm}^{2}-\mathrm{s}\right)\end{array}$ \\
\hline $7.58 \mathrm{E}-09$ & $0.00 \mathrm{E}+00$ & $0.00 \mathrm{E}+00$ & $0.00 \mathrm{E}+00$ & $2.83 E+10$ & $2.07 \mathrm{E}+10$ & $1.63 E+10$ \\
\hline $1.25 \mathrm{E}-08$ & $0.00 \mathrm{E}+00$ & $0.00 \mathrm{E}+00$ & $0.00 \mathrm{E}+00$ & $3.73 \mathrm{E}+10$ & $0.00 \mathrm{E}+00$ & $5.67 E+10$ \\
\hline $2.06 \mathrm{E}-08$ & $0.00 \mathrm{E}+00$ & $0.00 \mathrm{E}+00$ & $0.00 \mathrm{E}+00$ & $0.00 \mathrm{E}+00$ & $2.88 E+10$ & $9.04 \mathrm{E}+10$ \\
\hline $3.40 \mathrm{E}-08$ & $0.00 \mathrm{E}+00$ & $0.00 \mathrm{E}+00$ & $0.00 \mathrm{E}+00$ & $1.81 \mathrm{E}+10$ & $7.34 \mathrm{E}+10$ & $1.59 \mathrm{E}+11$ \\
\hline 5.60E-08 & $0.00 \mathrm{E}+00$ & $0.00 \mathrm{E}+00$ & $0.00 \mathrm{E}+00$ & $1.28 \mathrm{E}+11$ & $9.92 \mathrm{E}+10$ & $4.71 \mathrm{E}+11$ \\
\hline $9.24 \mathrm{E}-08$ & $0.00 \mathrm{E}+00$ & $0.00 \mathrm{E}+00$ & $0.00 \mathrm{E}+00$ & $2.11 \mathrm{E}+11$ & $1.59 \mathrm{E}+11$ & $9.65 \mathrm{E}+11$ \\
\hline $1.52 \mathrm{E}-07$ & $0.00 \mathrm{E}+00$ & $0.00 \mathrm{E}+00$ & $0.00 \mathrm{E}+00$ & $5.65 \mathrm{E}+11$ & $4.91 \mathrm{E}+11$ & $1.60 \mathrm{E}+12$ \\
\hline $2.51 \mathrm{E}-07$ & $0.00 \mathrm{E}+00$ & $0.00 \mathrm{E}+00$ & $0.00 \mathrm{E}+00$ & $6.77 \mathrm{E}+11$ & $6.45 \mathrm{E}+11$ & $1.95 \mathrm{E}+12$ \\
\hline $4.14 \mathrm{E}-07$ & $0.00 E+00$ & $0.00 \mathrm{E}+00$ & $0.00 \mathrm{E}+00$ & $8.42 \mathrm{E}+11$ & $5.44 \mathrm{E}+11$ & $1.52 \mathrm{E}+12$ \\
\hline $6.83 \mathrm{E}-07$ & $0.00 \mathrm{E}+00$ & $0.00 \mathrm{E}+00$ & $0.00 \mathrm{E}+00$ & $1.00 \mathrm{E}+12$ & $5.01 \mathrm{E}+11$ & $1.50 \mathrm{E}+12$ \\
\hline $1.13 \mathrm{E}-06$ & $0.00 \mathrm{E}+00$ & $0.00 \mathrm{E}+00$ & $0.00 \mathrm{E}+00$ & $1.13 \mathrm{E}+12$ & $6.49 \mathrm{E}+11$ & $1.84 \mathrm{E}+12$ \\
\hline $1.86 \mathrm{E}-06$ & $0.00 \mathrm{E}+00$ & $0.00 \mathrm{E}+00$ & $9.52 \mathrm{E}+10$ & $1.36 \mathrm{E}+12$ & $8.53 \mathrm{E}+11$ & $1.98 \mathrm{E}+12$ \\
\hline $3.06 \mathrm{E}-06$ & $3.85 \mathrm{E}+10$ & $3.60 \mathrm{E}+10$ & $1.23 E+10$ & $1.61 \mathrm{E}+12$ & $1.87 \mathrm{E}+12$ & $1.98 \mathrm{E}+12$ \\
\hline $5.04 \mathrm{E}-06$ & $0.00 \mathrm{E}+00$ & $0.00 \mathrm{E}+00$ & $0.00 \mathrm{E}+00$ & $1.65 \mathrm{E}+12$ & $1.03 E+12$ & $2.00 \mathrm{E}+12$ \\
\hline $8.31 \mathrm{E}-06$ & $7.49 \mathrm{E}+09$ & $1.34 \mathrm{E}+10$ & $0.00 \mathrm{E}+00$ & $1.66 \mathrm{E}+12$ & $1.04 \mathrm{E}+12$ & $2.35 \mathrm{E}+12$ \\
\hline $1.37 \mathrm{E}-05$ & $0.00 \mathrm{E}+00$ & $1.37 \mathrm{E}+10$ & $0.00 \mathrm{E}+00$ & $1.25 E+12$ & $1.26 \mathrm{E}+12$ & $2.74 E+12$ \\
\hline $2.26 \mathrm{E}-05$ & $1.08 \mathrm{E}+11$ & $2.22 \mathrm{E}+11$ & $0.00 \mathrm{E}+00$ & $1.68 \mathrm{E}+12$ & $1.76 E+12$ & $2.77 \mathrm{E}+12$ \\
\hline $3.72 \mathrm{E}-05$ & $9.31 E+10$ & $1.07 \mathrm{E}+10$ & $2.85 E+09$ & $2.19 \mathrm{E}+12$ & $1.59 \mathrm{E}+12$ & $3.31 \mathrm{E}+12$ \\
\hline $6.14 \mathrm{E}-05$ & $2.49 E+11$ & $1.25 \mathrm{E}+11$ & $4.46 \mathrm{E}+10$ & $2.01 E+12$ & $1.98 \mathrm{E}+12$ & $3.53 \mathrm{E}+12$ \\
\hline
\end{tabular}




\begin{tabular}{|c|c|c|c|c|c|c|}
\hline \multirow{2}{*}{$\begin{array}{c}\text { Flux Group } \\
\text { Upper Energy } \\
(\mathrm{MeV})\end{array}$} & \multicolumn{6}{|c|}{ Core Position } \\
\hline & $\begin{array}{c}1202^{(2)} \\
\left(\mathrm{n} / \mathrm{cm}^{2}-\mathrm{s}\right)\end{array}$ & $\begin{array}{c}1406^{(a)} \\
\left(n / \mathrm{cm}^{2}-\mathrm{s}\right)\end{array}$ & $\begin{array}{c}3406^{(a)} \\
\left(\mathrm{n} / \mathrm{cm}^{2}-\mathrm{s}\right)\end{array}$ & $\begin{array}{c}2610^{(a)} \\
\left(n / \mathrm{cm}^{2}-\mathrm{s}\right)\end{array}$ & $\begin{array}{c}\begin{array}{c}3610^{(\mathbf{a})} \\
\left(\mathrm{n} / \mathrm{cm}^{2}-\mathrm{s}\right)\end{array}\end{array}$ & $\begin{array}{l}-607 / 8 / 9^{(\mathbf{b})} \\
\left(\mathrm{n} / \mathrm{cm}^{2}-\mathrm{s}\right)\end{array}$ \\
\hline $1.01 \mathrm{E}-04$ & $6.18 \mathrm{E}+11$ & $3.45 \mathrm{E}+11$ & $5.09 \mathrm{E}+11$ & $2.30 \mathrm{E}+12$ & $2.63 \mathrm{E}+12$ & $4.13 \mathrm{E}+12$ \\
\hline $1.67 \mathrm{E}-04$ & $9.71 \mathrm{E}+11$ & $7.92 \mathrm{E}+11$ & $1.02 \mathrm{E}+12$ & $4.65 \mathrm{E}+12$ & $3.45 \mathrm{E}+12$ & $5.02 \mathrm{E}+12$ \\
\hline $2.75 \mathrm{E}-04$ & $1.61 \mathrm{E}+12$ & $1.73 \mathrm{E}+12$ & $2.36 \mathrm{E}+12$ & $5.54 \mathrm{E}+12$ & $4.66 \mathrm{E}+12$ & $5.65 \mathrm{E}+12$ \\
\hline $4.54 \mathrm{E}-04$ & $3.20 \mathrm{E}+12$ & $3.28 \mathrm{E}+12$ & $2.84 \mathrm{E}+12$ & $5.67 \mathrm{E}+12$ & $5.07 \mathrm{E}+12$ & $6.71 E+12$ \\
\hline $7.49 \mathrm{E}-04$ & $8.85 \mathrm{E}+12$ & $7.27 \mathrm{E}+12$ & $7.41 \mathrm{E}+12$ & $8.45 \mathrm{E}+12$ & $7.48 \mathrm{E}+12$ & $8.53 E+12$ \\
\hline $1.23 \mathrm{E}-03$ & $1.41 E+13$ & $1.09 \mathrm{E}+13$ & $1.09 \mathrm{E}+13$ & $1.03 \mathrm{E}+13$ & $1.04 \mathrm{E}+13$ & $1.07 \mathrm{E}+13$ \\
\hline 2.03E-03 & $2.22 \mathrm{E}+13$ & $1.99 \mathrm{E}+13$ & $1.97 \mathrm{E}+13$ & $1.57 \mathrm{E}+13$ & $1.34 \mathrm{E}+13$ & $1.29 \mathrm{E}+13$ \\
\hline $2.40 \mathrm{E}-03$ & $3.90 \mathrm{E}+12$ & $3.25 \mathrm{E}+12$ & $3.23 \mathrm{E}+12$ & $2.81 \mathrm{E}+12$ & $2.49 \mathrm{E}+12$ & $3.45 E+12$ \\
\hline $2.84 \mathrm{E}-03$ & $1.06 \mathrm{E}+12$ & $8.28 \mathrm{E}+11$ & $8.89 \mathrm{E}+11$ & $6.67 \mathrm{E}+11$ & $5.52 \mathrm{E}+11$ & $1.45 \mathrm{E}+12$ \\
\hline $3.35 \mathrm{E}-03$ & $1.18 \mathrm{E}+12$ & $9.40 \mathrm{E}+11$ & $1.06 \mathrm{E}+12$ & $7.60 \mathrm{E}+11$ & $6.23 \mathrm{E}+11$ & $1.72 \mathrm{E}+12$ \\
\hline $5.53 \mathrm{E}-03$ & $1.76 \mathrm{E}+13$ & $1.49 \mathrm{E}+13$ & $1.47 \mathrm{E}+13$ & $9.87 E+12$ & $8.11 \mathrm{E}+12$ & $1.22 \mathrm{E}+13$ \\
\hline $9.12 \mathrm{E}-03$ & $2.52 \mathrm{E}+13$ & $2.46 \mathrm{E}+13$ & $2.36 \mathrm{E}+13$ & $1.37 \mathrm{E}+13$ & $1.12 \mathrm{E}+13$ & $1.57 \mathrm{E}+13$ \\
\hline $1.50 \mathrm{E}-02$ & $4.58 \mathrm{E}+13$ & $4.05 \mathrm{E}+13$ & $3.99 \mathrm{E}+13$ & $2.12 \mathrm{E}+13$ & $2.02 \mathrm{E}+13$ & $2.14 \mathrm{E}+13$ \\
\hline $1.99 \mathrm{E}-02$ & $2.76 \mathrm{E}+13$ & $2.49 E+13$ & $2.47 \mathrm{E}+13$ & $1.26 \mathrm{E}+13$ & $1.08 \mathrm{E}+13$ & $1.47 \mathrm{E}+13$ \\
\hline $2.55 \mathrm{E}-02$ & $4.44 \mathrm{E}+13$ & $3.59 \mathrm{E}+13$ & $3.65 \mathrm{E}+13$ & $2.06 \mathrm{E}+13$ & $1.65 \mathrm{E}+13$ & $1.54 \mathrm{E}+13$ \\
\hline 4.09E-02 & $6.11 \mathrm{E}+13$ & $5.20 \mathrm{E}+13$ & $4.61 \mathrm{E}+13$ & $2.93 \mathrm{E}+13$ & $2.24 \mathrm{E}+13$ & $2.72 \mathrm{E}+13$ \\
\hline $6.74 \mathrm{E}-02$ & $9.34 \mathrm{E}+13$ & $7.75 \mathrm{E}+13$ & $7.13 \mathrm{E}+13$ & $3.90 \mathrm{E}+13$ & $3.78 \mathrm{E}+13$ & $3.51 \mathrm{E}+13$ \\
\hline $1.11 \mathrm{E}-01$ & $1.11 \mathrm{E}+14$ & $9.29 \mathrm{E}+13$ & $9.22 \mathrm{E}+13$ & $4.66 \mathrm{E}+13$ & $4.33 \mathrm{E}+13$ & $4.33 \mathrm{E}+13$ \\
\hline $1.83 \mathrm{E}-01$ & $1.52 \mathrm{E}+14$ & $1.16 \mathrm{E}+14$ & $1.19 \mathrm{E}+14$ & $6.56 \mathrm{E}+13$ & $5.19 E+13$ & $5.29 \mathrm{E}+13$ \\
\hline $3.02 \mathrm{E}-01$ & $1.43 \mathrm{E}+14$ & $1.08 \mathrm{E}+14$ & $1.14 \mathrm{E}+14$ & $6.03 \mathrm{E}+13$ & $5.01 E+13$ & $3.75 \mathrm{E}+13$ \\
\hline $3.88 \mathrm{E}-01$ & $7.86 \mathrm{E}+13$ & $6.08 \mathrm{E}+13$ & $5.54 \mathrm{E}+13$ & $3.27 \mathrm{E}+13$ & $2.64 \mathrm{E}+13$ & $2.12 \mathrm{E}+13$ \\
\hline $4.98 \mathrm{E}-01$ & $6.28 \mathrm{E}+13$ & $5.06 \mathrm{E}+13$ & $4.82 \mathrm{E}+13$ & $2.80 \mathrm{E}+13$ & $2.29 \mathrm{E}+13$ & $2.05 \mathrm{E}+13$ \\
\hline 6.39E-01 & $8.08 \mathrm{E}+13$ & $6.77 \mathrm{E}+13$ & $6.26 \mathrm{E}+13$ & $3.84 \mathrm{E}+13$ & $3.01 E+13$ & $2.15 \mathrm{E}+13$ \\
\hline $8.21 \mathrm{E}-01$ & $5.74 \mathrm{E}+13$ & $4.74 \mathrm{E}+13$ & $4.75 \mathrm{E}+13$ & $2.66 \mathrm{E}+13$ & $1.91 E+13$ & $1.83 \mathrm{E}+13$ \\
\hline $1.11 \mathrm{E}+00$ & $4.90 \mathrm{E}+13$ & $4.00 \mathrm{E}+13$ & $4.05 \mathrm{E}+13$ & $2.31 \mathrm{E}+13$ & $1.94 \mathrm{E}+13$ & $1.70 \mathrm{E}+13$ \\
\hline $1.35 \mathrm{E}+00$ & $3.28 \mathrm{E}+13$ & $2.61 \mathrm{E}+13$ & $2.60 \mathrm{E}+13$ & $1.48 \mathrm{E}+13$ & $1.22 \mathrm{E}+13$ & $1.24 \mathrm{E}+13$ \\
\hline $1.74 \mathrm{E}+00$ & $3.65 \mathrm{E}+13$ & $3.05 E+13$ & $3.08 \mathrm{E}+13$ & $1.42 \mathrm{E}+13$ & $1.05 \mathrm{E}+13$ & $1.20 \mathrm{E}+13$ \\
\hline $2.23 \mathrm{E}+00$ & $2.27 \mathrm{E}+13$ & $2.31 \mathrm{E}+13$ & $2.14 \mathrm{E}+13$ & $1.36 \mathrm{E}+13$ & $1.19 \mathrm{E}+13$ & $9.16 \mathrm{E}+12$ \\
\hline $2.87 \mathrm{E}+00$ & $2.25 \mathrm{E}+13$ & $1.93 \mathrm{E}+13$ & $1.86 \mathrm{E}+13$ & $8.95 \mathrm{E}+12$ & $8.36 \mathrm{E}+12$ & $7.37 \mathrm{E}+12$ \\
\hline $3.68 \mathrm{E}+00$ & $1.28 \mathrm{E}+13$ & $1.25 \mathrm{E}+13$ & $1.05 \mathrm{E}+13$ & $5.27 \mathrm{E}+12$ & $4.01 \mathrm{E}+12$ & $4.02 \mathrm{E}+12$ \\
\hline $4.97 \mathrm{E}+00$ & $8.75 \mathrm{E}+12$ & $8.31 \mathrm{E}+12$ & $6.92 \mathrm{E}+12$ & $3.97 \mathrm{E}+12$ & $3.04 \mathrm{E}+12$ & $3.06 \mathrm{E}+12$ \\
\hline $6.07 \mathrm{E}+00$ & $3.48 \mathrm{E}+12$ & $2.32 \mathrm{E}+12$ & $2.67 \mathrm{E}+12$ & $1.97 \mathrm{E}+12$ & $1.24 \mathrm{E}+12$ & $1.32 \mathrm{E}+12$ \\
\hline $7.41 \mathrm{E}+00$ & $1.52 \mathrm{E}+12$ & $1.36 \mathrm{E}+12$ & $1.50 \mathrm{E}+12$ & $7.62 \mathrm{E}+11$ & $6.41 \mathrm{E}+11$ & $5.11 \mathrm{E}+11$ \\
\hline $8.61 \mathrm{E}+00$ & $6.45 \mathrm{E}+11$ & $4.47 \mathrm{E}+11$ & $5.19 \mathrm{E}+11$ & $2.35 \mathrm{E}+11$ & $1.91 \mathrm{E}+11$ & $1.83 \mathrm{E}+11$ \\
\hline $1.00 \mathrm{E}+01$ & $1.77 \mathrm{E}+11$ & $2.08 \mathrm{E}+11$ & $8.90 \mathrm{E}+10$ & $5.13 \mathrm{E}+10$ & $8.09 \mathrm{E}+10$ & $8.05 \mathrm{E}+10$ \\
\hline $1.16 \mathrm{E}+01$ & $7.24 \mathrm{E}+10$ & $1.25 \mathrm{E}+11$ & $8.26 \mathrm{E}+10$ & $5.85 \mathrm{E}+10$ & $2.31 \mathrm{E}+10$ & $3.87 \mathrm{E}+10$ \\
\hline $1.35 \mathrm{E}+01$ & $1.47 \mathrm{E}+10$ & $6.22 \mathrm{E}+10$ & $6.96 \mathrm{E}+10$ & $6.79 \mathrm{E}+10$ & $1.32 \mathrm{E}+10$ & $6.02 E+09$ \\
\hline $1.49 \mathrm{E}+01$ & $3.51 \mathrm{E}+10$ & $0.00 \mathrm{E}+00$ & $5.67 \mathrm{E}+09$ & $0.00 \mathrm{E}+00$ & $3.07 \mathrm{E}+10$ & $1.65 \mathrm{E}+08$ \\
\hline $1.69 \mathrm{E}+01$ & $2.84 \mathrm{E}+09$ & $0.00 \mathrm{E}+00$ & $0.00 \mathrm{E}+00$ & $0.00 \mathrm{E}+00$ & $0.00 \mathrm{E}+00$ & $2.47 \mathrm{E}+09$ \\
\hline Total & $1.25 \mathrm{E}+15$ & $1.03 \mathrm{E}+15$ & $1.01 \mathrm{E}+15$ & $6.06 \mathrm{E}+14$ & $5.08 \mathrm{E}+14$ & $5.15 \mathrm{E}+14$ \\
\hline $\begin{array}{l}\text { (a) } 100 \mathrm{MW} \\
\text { (b) } 100 \mathrm{MW}\end{array}$ & $\begin{array}{l}\text { reraged o } \\
\text { eraged o }\end{array}$ & $9.4 "$ & & & & \\
\hline
\end{tabular}


Table A.2 FFTF Hydrided Flux Data (400 MW)

\begin{tabular}{|c|c|c|c|c|c|}
\hline \multirow{2}{*}{$\begin{array}{c}\text { Flux Group } \\
\text { Upper Energy } \\
(\mathrm{MeV})\end{array}$} & \multicolumn{5}{|c|}{ Core Position } \\
\hline & $\begin{array}{c}1202(\mathrm{YH} / \mathrm{inc} / \mathrm{W}) \\
\left(\mathrm{n} / \mathrm{cm}^{2}-\mathrm{s}\right)\end{array}$ & $\begin{array}{c}\text { 1406(YH/inc/W }) \\
\left(\mathrm{n} / \mathrm{cm}^{2}-\mathrm{s}\right)\end{array}$ & $\begin{array}{c}\text { 3406(YH/inc/W) } \\
\left(\mathrm{n} / \mathrm{cm}^{2}-\mathrm{s}\right)\end{array}$ & $\begin{array}{c}2610(Y H / i n c / W) \\
\left(n / \mathrm{cm}^{2}-\mathrm{s}\right)\end{array}$ & $\begin{array}{l}3610(Y H) \\
\left(n / \mathrm{cm}^{2}-\mathrm{s}\right)\end{array}$ \\
\hline $7.5800 \mathrm{E}-09$ & $0.00000 \mathrm{E}+00$ & $0.00000 \mathrm{E}+00$ & $0.00000 \mathrm{E}+00$ & $0.00000 \mathrm{E}+00$ & $0.00000 \mathrm{E}+00$ \\
\hline $1.2500 \mathrm{E}-08$ & $0.00000 \mathrm{E}+00$ & $0.00000 \mathrm{E}+00$ & $0.00000 \mathrm{E}+00$ & $0.00000 \mathrm{E}+00$ & $0.00000 \mathrm{E}+00$ \\
\hline $2.0600 \mathrm{E}-08$ & $0.00000 \mathrm{E}+00$ & $0.00000 \mathrm{E}+00$ & $3.73278 \mathrm{E}+12$ & $0.00000 \mathrm{E}+00$ & $9.66346 \mathrm{E}+12$ \\
\hline $3.4000 \mathrm{E}-08$ & $0.00000 \mathrm{E}+00$ & $0.00000 \mathrm{E}+00$ & $8.59744 E+12$ & $2.28698 \mathrm{E}+12$ & $6.07737 \mathrm{E}+12$ \\
\hline $5.6000 \mathrm{E}-08$ & $9.33774 \mathrm{E}+12$ & $2.77635 \mathrm{E}+12$ & $6.77061 \mathrm{E}+12$ & $8.73244 \mathrm{E}+11$ & $1.80260 \mathrm{E}+13$ \\
\hline $9.2400 \mathrm{E}-08$ & $1.80016 \mathrm{E}+13$ & $1.06107 \mathrm{E}+13$ & $1.07323 \mathrm{E}+13$ & $6.06693 \mathrm{E}+12$ & $7.89033 \mathrm{E}+13$ \\
\hline $1.5200 \mathrm{E}-07$ & $1.93623 \mathrm{E}+13$ & $2.18154 \mathrm{E}+13$ & $1.23485 \mathrm{E}+13$ & $8.30027 \mathrm{E}+12$ & $6.90543 \mathrm{E}+13$ \\
\hline $2.5100 \mathrm{E}-07$ & $1.26580 \mathrm{E}+13$ & $1.21222 \mathrm{E}+13$ & $1.43369 \mathrm{E}+13$ & $1.65112 E+13$ & $6.57496 E+13$ \\
\hline $4.1400 \mathrm{E}-07$ & $1.65026 \mathrm{E}+13$ & $1.60214 \mathrm{E}+13$ & $2.21842 \mathrm{E}+13$ & $1.37774 \mathrm{E}+13$ & $5.96133 \mathrm{E}+13$ \\
\hline $6.8300 \mathrm{E}-07$ & $1.10141 \mathrm{E}+13$ & $7.58467 \mathrm{E}+12$ & $2.75564 \mathrm{E}+13$ & $1.51445 \mathrm{E}+13$ & $3.71364 \mathrm{E}+13$ \\
\hline $1.1300 \mathrm{E}-06$ & $1.27888 \mathrm{E}+13$ & $1.71983 \mathrm{E}+13$ & $2.24520 \mathrm{E}+13$ & $2.40020 \mathrm{E}+13$ & $3.29737 \mathrm{E}+13$ \\
\hline $1.8600 \mathrm{E}-06$ & $3.01201 E+13$ & $2.39354 \mathrm{E}+13$ & $1.55478 \mathrm{E}+13$ & $9.59978 \mathrm{E}+12$ & $2.36592 \mathrm{E}+13$ \\
\hline $3.0600 \mathrm{E}-06$ & $3.32858 \mathrm{E}+13$ & $2.01706 \mathrm{E}+13$ & $1.85341 \mathrm{E}+13$ & $2.07258 \mathrm{E}+13$ & $3.10519 \mathrm{E}+13$ \\
\hline $5.0400 \mathrm{E}-06$ & $4.09985 E+13$ & $2.84787 \mathrm{E}+13$ & $1.55688 \mathrm{E}+13$ & $1.26446 \mathrm{E}+13$ & $2.41564 \mathrm{E}+13$ \\
\hline $8.3100 \mathrm{E}-06$ & $5.07950 \mathrm{E}+13$ & $2.65540 \mathrm{E}+13$ & $2.56743 \mathrm{E}+13$ & $3.45303 \mathrm{E}+13$ & $3.35183 \mathrm{E}+13$ \\
\hline $1.3700 \mathrm{E}-05$ & $3.84309 \mathrm{E}+13$ & $2.18317 \mathrm{E}+13$ & $3.96341 \mathrm{E}+13$ & $2.40237 E+13$ & $2.53071 \mathrm{E}+13$ \\
\hline $2.2600 \mathrm{E}-05$ & $6.38760 \mathrm{E}+13$ & $4.86038 \mathrm{E}+13$ & $5.58337 \mathrm{E}+13$ & $5.70840 \mathrm{E}+13$ & $3.02183 \mathrm{E}+13$ \\
\hline $3.7200 \mathrm{E}-05$ & $7.62695 \mathrm{E}+13$ & $4.38667 \mathrm{E}+13$ & $3.84224 \mathrm{E}+13$ & $3.71902 \mathrm{E}+13$ & $4.26646 \mathrm{E}+13$ \\
\hline $6.1400 \mathrm{E}-05$ & $4.96128 \mathrm{E}+13$ & $4.35280 \mathrm{E}+13$ & $4.69741 \mathrm{E}+13$ & $2.32617 \mathrm{E}+13$ & $3.70279 E+13$ \\
\hline $1.0100 \mathrm{E}-04$ & $7.49417 \mathrm{E}+13$ & $5.49115 \mathrm{E}+13$ & $6.22161 \mathrm{E}+13$ & $4.42267 \mathrm{E}+13$ & $4.07001 \mathrm{E}+13$ \\
\hline $1.6700 \mathrm{E}-04$ & $8.79193 \mathrm{E}+13$ & $4.97546 \mathrm{E}+13$ & $6.88664 \mathrm{E}+13$ & $3.98517 \mathrm{E}+13$ & $4.50830 \mathrm{E}+13$ \\
\hline $2.7500 \mathrm{E}-04$ & $9.32453 E+13$ & $7.29464 \mathrm{E}+13$ & $8.61611 \mathrm{E}+13$ & $4.28635 \mathrm{E}+13$ & $5.82991 \mathrm{E}+13$ \\
\hline $4.5400 \mathrm{E}-04$ & $1.15099 \mathrm{E}+14$ & $7.54100 \mathrm{E}+13$ & $7.53215 \mathrm{E}+13$ & $4.84884 \mathrm{E}+13$ & $4.94713 E+13$ \\
\hline $7.4900 \mathrm{E}-04$ & $1.02375 \mathrm{E}+14$ & $5.69764 \mathrm{E}+13$ & $9.96571 \mathrm{E}+13$ & $7.63626 \mathrm{E}+13$ & $5.20669 \mathrm{E}+13$ \\
\hline $1.2300 \mathrm{E}-03$ & $1.62775 \mathrm{E}+14$ & $9.58273 \mathrm{E}+13$ & $8.80222 \mathrm{E}+13$ & $9.10997 \mathrm{E}+13$ & $4.47632 \mathrm{E}+13$ \\
\hline $2.0300 \mathrm{E}-03$ & $2.36233 \mathrm{E}+14$ & $1.37347 \mathrm{E}+14$ & $1.28794 \mathrm{E}+14$ & $9.94439 \mathrm{E}+13$ & $7.59316 \mathrm{E}+13$ \\
\hline $2.4000 \mathrm{E}-03$ & $1.01969 \mathrm{E}+14$ & $4.66528 \mathrm{E}+13$ & $3.40606 \mathrm{E}+13$ & $4.43807 \mathrm{E}+13$ & $2.46021 \mathrm{E}+13$ \\
\hline $2.8400 \mathrm{E}-03$ & $3.68416 \mathrm{E}+13$ & $1.44811 \mathrm{E}+13$ & $3.29015 \mathrm{E}+13$ & $2.16590 \mathrm{E}+13$ & $2.93365 \mathrm{E}+12$ \\
\hline $3.3500 \mathrm{E}-03$ & $2.83198 \mathrm{E}+13$ & $1.46619 \mathrm{E}+13$ & $1.20679 \mathrm{E}+13$ & $1.65542 \mathrm{E}+13$ & $8.53752 \mathrm{E}+12$ \\
\hline $5.5300 \mathrm{E}-03$ & $2.22051 \mathrm{E}+14$ & $1.41500 \mathrm{E}+14$ & $1.53816 \mathrm{E}+14$ & $7.05106 \mathrm{E}+13$ & $6.53972 \mathrm{E}+13$ \\
\hline $9.1200 \mathrm{E}-03$ & $2.12362 \mathrm{E}+14$ & $1.65753 \mathrm{E}+14$ & $1.50847 \mathrm{E}+14$ & $9.30542 \mathrm{E}+13$ & $3.31863 \mathrm{E}+13$ \\
\hline $1.5000 \mathrm{E}-02$ & $2.51465 \mathrm{E}+14$ & $1.99971 \mathrm{E}+14$ & $2.13730 \mathrm{E}+14$ & $1.03554 \mathrm{E}+14$ & $7.07143 \mathrm{E}+13$ \\
\hline $1.9900 \mathrm{E}-02$ & $1.36015 \mathrm{E}+14$ & $8.75661 \mathrm{E}+13$ & $7.73172 \mathrm{E}+13$ & $7.26804 \mathrm{E}+13$ & $3.33402 \mathrm{E}+13$ \\
\hline $2.5500 \mathrm{E}-02$ & $1.39118 \mathrm{E}+14$ & $1.29726 \mathrm{E}+14$ & $1.25811 \mathrm{E}+14$ & $7.91565 \mathrm{E}+13$ & $3.92007 \mathrm{E}+13$ \\
\hline $4.0900 \mathrm{E}-02$ & $2.61526 \mathrm{E}+14$ & $1.67353 \mathrm{E}+14$ & $2.11420 \mathrm{E}+14$ & $1.06061 \mathrm{E}+14$ & $7.20504 \mathrm{E}+13$ \\
\hline $6.7400 \mathrm{E}-02$ & $3.81949 \mathrm{E}+14$ & $2.42112 \mathrm{E}+14$ & $2.38188 \mathrm{E}+14$ & $1.49724 \mathrm{E}+14$ & $8.22076 \mathrm{E}+13$ \\
\hline $1.1100 \mathrm{E}-01$ & $4.16535 \mathrm{E}+14$ & $3.14415 \mathrm{E}+14$ & $2.67989 \mathrm{E}+14$ & $1.55333 \mathrm{E}+14$ & $8.75648 \mathrm{E}+13$ \\
\hline $1.8300 \mathrm{E}-01$ & $5.00381 \mathrm{E}+14$ & $3.37928 \mathrm{E}+14$ & $3.25391 \mathrm{E}+14$ & $2.10508 \mathrm{E}+14$ & $8.77381 \mathrm{E}+13$ \\
\hline $3.0200 \mathrm{E}-01$ & $4.44768 \mathrm{E}+14$ & $3.34660 \mathrm{E}+14$ & $4.21317 \mathrm{E}+14$ & $1.92186 \mathrm{E}+14$ & $1.19892 \mathrm{E}+14$ \\
\hline $3.8800 \mathrm{E}-01$ & $2.40103 E+14$ & $1.93174 \mathrm{E}+14$ & $2.11430 \mathrm{E}+14$ & $9.41996 \mathrm{E}+13$ & $4.97214 \mathrm{E}+13$ \\
\hline $4.9800 \mathrm{E}-01$ & $2.06925 \mathrm{E}+14$ & $1.61389 \mathrm{E}+14$ & $1.87467 \mathrm{E}+14$ & $9.98636 \mathrm{E}+13$ & $5.51747 \mathrm{E}+13$ \\
\hline
\end{tabular}




\begin{tabular}{|c|c|c|c|c|c|}
\hline \multirow{2}{*}{$\begin{array}{c}\text { Flux Group } \\
\text { Upper Energy } \\
(\mathrm{MeV})\end{array}$} & \multicolumn{5}{|c|}{ Core Position } \\
\hline & $\begin{array}{c}1202(\mathrm{YH} / \mathrm{inc} / \mathrm{W}) \\
\left(\mathrm{n} / \mathrm{cm}^{2}-\mathrm{s}\right)\end{array}$ & $\begin{array}{c}1406(Y H / i n c / W) \\
\left(n / \mathrm{cm}^{2}-s\right)\end{array}$ & $\begin{array}{c}3406(Y H / i n c / W) \\
\left(n / \mathrm{cm}^{2}-\mathrm{s}\right)\end{array}$ & $\begin{array}{c}2610(\text { YH/inc/W }) \\
\left(\mathrm{n}^{\prime} / \mathrm{cm}^{2}-\mathrm{s}\right)\end{array}$ & $\begin{array}{l}3610(\mathrm{YH}) \\
\left(\mathrm{n} / \mathrm{cm}^{2}-\mathrm{s}\right)\end{array}$ \\
\hline $6.3900 \mathrm{E}-01$ & $2.71792 \mathrm{E}+14$ & $2.16961 \mathrm{E}+14$ & $2.19005 \mathrm{E}+14$ & $1.16767 \mathrm{E}+14$ & $7.11231 \mathrm{E}+13$ \\
\hline $8.2100 \mathrm{E}-01$ & $2.42151 E+14$ & $1.68567 \mathrm{E}+14$ & $1.30608 \mathrm{E}+14$ & $8.82871 \mathrm{E}+13$ & $3.92520 \mathrm{E}+13$ \\
\hline $1.1100 \mathrm{E}+00$ & $2.04488 \mathrm{E}+14$ & $1.43344 \mathrm{E}+14$ & $1.48940 \mathrm{E}+14$ & $7.35437 \mathrm{E}+13$ & $6.38371 \mathrm{E}+13$ \\
\hline $1.3500 \mathrm{E}+00$ & $1.36275 \mathrm{E}+14$ & $7.90336 \mathrm{E}+13$ & $1.17797 \mathrm{E}+14$ & $3.78181 \mathrm{E}+13$ & $5.90703 \mathrm{E}+13$ \\
\hline $1.7400 \mathrm{E}+00$ & $1.33562 \mathrm{E}+14$ & $1.05785 \mathrm{E}+14$ & $1.00070 \mathrm{E}+14$ & $7.61161 \mathrm{E}+13$ & $5.79870 \mathrm{E}+13$ \\
\hline $2.2300 \mathrm{E}+00$ & $5.70818 \mathrm{E}+13$ & $7.60383 \mathrm{E}+13$ & $6.59843 \mathrm{E}+13$ & $4.24752 \mathrm{E}+13$ & $3.40236 \mathrm{E}+13$ \\
\hline $2.8700 \mathrm{E}+00$ & $8.92101 \mathrm{E}+13$ & $5.10321 \mathrm{E}+13$ & $4.23680 \mathrm{E}+13$ & $5.14765 \mathrm{E}+13$ & $2.39774 \mathrm{E}+13$ \\
\hline $3.6800 \mathrm{E}+00$ & $5.26374 \mathrm{E}+13$ & $3.54031 E+13$ & $2.95022 \mathrm{E}+13$ & $1.41733 \mathrm{E}+13$ & $1.71869 \mathrm{E}+13$ \\
\hline $4.9700 E+00$ & $3.88554 \mathrm{E}+13$ & $4.13201 \mathrm{E}+13$ & $3.21824 \mathrm{E}+13$ & $2.66037 \mathrm{E}+13$ & $1.13089 \mathrm{E}+13$ \\
\hline $6.0700 \mathrm{E}+00$ & $1.48227 \mathrm{E}+13$ & $1.90306 \mathrm{E}+13$ & $1.45121 \mathrm{E}+13$ & $5.56413 \mathrm{E}+12$ & $1.66472 \mathrm{E}+12$ \\
\hline $7.4100 \mathrm{E}+00$ & $4.38310 \mathrm{E}+12$ & $3.34346 \mathrm{E}+12$ & $6.89123 \mathrm{E}+12$ & $2.86864 \mathrm{E}+12$ & $1.61435 \mathrm{E}+12$ \\
\hline $8.6100 \mathrm{E}+00$ & $1.21108 \mathrm{E}+12$ & $1.41951 \mathrm{E}+12$ & $2.45611 \mathrm{E}+12$ & $1.15927 \mathrm{E}+12$ & $6.00330 \mathrm{E}+11$ \\
\hline $1.0000 \mathrm{E}+01$ & $4.08178 \mathrm{E}+11$ & $4.08424 \mathrm{E}+11$ & $3.91995 \mathrm{E}+11$ & $2.72794 \mathrm{E}+11$ & $8.82811 \mathrm{E}+11$ \\
\hline $1.1600 \mathrm{E}+01$ & $0.00000 \mathrm{E}+00$ & $4.38520 \mathrm{E}+11$ & $0.00000 \mathrm{E}+00$ & $3.99688 \mathrm{E}+11$ & $1.37175 \mathrm{E}+11$ \\
\hline $1.3500 \mathrm{E}+01$ & $1.22332 \mathrm{E}+11$ & $0.00000 \mathrm{E}+00$ & $0.00000 \mathrm{E}+00$ & $0.00000 \mathrm{E}+00$ & $0.00000 \mathrm{E}+00$ \\
\hline $1.4900 \mathrm{E}+01$ & $0.00000 \mathrm{E}+00$ & $0.00000 \mathrm{E}+00$ & $0.00000 \mathrm{E}+00$ & $0.00000 \mathrm{E}+00$ & $0.00000 \mathrm{E}+00$ \\
\hline $1.6900 \mathrm{E}+01$ & $0.00000 \mathrm{E}+00$ & $0.00000 \mathrm{E}+00$ & $0.00000 \mathrm{E}+00$ & $0.00000 \mathrm{E}+00$ & $0.00000 \mathrm{E}+00$ \\
\hline Total & $6.18297 \mathrm{E}+15$ & $4.38174 \mathrm{E}+15$ & $4.56840 \mathrm{E}+15$ & $2.79531 \mathrm{E}+15$ & $2.20604 \mathrm{E}+15$ \\
\hline
\end{tabular}

Table A.3 HFIR PTP Four-Group Flux

\begin{tabular}{|c|c|c|c|c|c|}
\hline \multirow{2}{*}{$\begin{array}{c}\text { Power } \\
\text { Level }\end{array}$} & $\begin{array}{c}\text { Thermal } \\
(\mathbf{0 - 0 . 2 5 e V})\end{array}$ & $\begin{array}{c}\text { Epithermal } \\
(\mathbf{0 . 2 5 e V - 5 k e V )}\end{array}$ & $\begin{array}{c}\text { Fast } \\
(\mathbf{5 k e V - 0 . 8 M e V})\end{array}$ & $\begin{array}{c}\text { High Energy } \\
(\mathbf{0 . 8 M e V - 1 6 M e V})\end{array}$ & Total \\
\hline $100 \mathrm{MW}$ & 16.6 & 8.2 & 7.5 & 5.8 & 38.1 \\
\hline $85 \mathrm{MW}$ & 14.1 & 7.0 & 6.4 & 4.9 & 32.4 \\
\hline
\end{tabular}

Table A.4 HFIR HT Four-Group Flux

\begin{tabular}{|c|c|c|c|c|c|}
\hline & \multicolumn{5}{|c|}{ Group Flux $\left(\mathbf{1 0}^{\mathbf{1 4}} \mathbf{n} / \mathrm{cm}^{2}-\mathbf{s}\right)$} \\
\cline { 2 - 6 } & $\begin{array}{c}\text { Thermal } \\
(\mathbf{0 - 0 . 2 5 e V})\end{array}$ & $\begin{array}{c}\text { Epithermal } \\
(\mathbf{0 . 2 5 e V - 5 k e V})\end{array}$ & $\begin{array}{c}\text { Fast } \\
(\mathbf{5 k e V - 0 . 8 M e V})\end{array}$ & $\begin{array}{c}\text { High Energy } \\
(\mathbf{0 . 8 M e V - 1 6 M e V})\end{array}$ & Total \\
\hline PTP & 14.1 & 7.0 & 6.4 & 4.9 & 32.4 \\
\hline $\begin{array}{c}\text { Conversion } \\
\text { Factor }\end{array}$ & 1.12 & 0.94 & 0.22 & 0.22 & \\
\hline HT & 15.8 & 6.6 & 1.4 & 1.1 & 24.9 \\
\hline
\end{tabular}


Table A.5 HFIR Flux Data

\begin{tabular}{|c|c|c|}
\hline $\begin{array}{c}\text { Flux Group } \\
\text { Upper Energy } \\
(\mathrm{MeV})\end{array}$ & $\begin{array}{l}\text { PTP Flux } \\
\left(\mathbf{n} / \mathrm{cm}^{2}-\mathrm{s}\right)\end{array}$ & $\begin{array}{l}\text { HT Flux } \\
\left(n / \mathrm{cm}^{2}-\mathrm{s}\right)\end{array}$ \\
\hline $0.758 \mathrm{E}-08$ & $0.245 \mathrm{E}+14$ & $0.275 E+14$ \\
\hline $0.125 \mathrm{E}-07$ & $0.649 \mathrm{E}+14$ & $0.727 \mathrm{E}+14$ \\
\hline $0.206 \mathrm{E}-07$ & $0.138 \mathrm{E}+15$ & $0.155 \mathrm{E}+15$ \\
\hline $0.340 \mathrm{E}-07$ & $0.253 E+15$ & $0.284 \mathrm{E}+15$ \\
\hline $0.560 \mathrm{E}-07$ & $0.359 \mathrm{E}+15$ & $0.402 \mathrm{E}+15$ \\
\hline $0.924 \mathrm{E}-07$ & $0.342 \mathrm{E}+15$ & $0.384 \mathrm{E}+15$ \\
\hline $0.152 \mathrm{E}-06$ & $0.172 \mathrm{E}+15$ & $0.193 \mathrm{E}+15$ \\
\hline $0.251 \mathrm{E}-06$ & $0.332 \mathrm{E}+14$ & $0.372 \mathrm{E}+14$ \\
\hline $0.414 \mathrm{E}-06$ & $0.354 \mathrm{E}+14$ & $0.334 \mathrm{E}+14$ \\
\hline $0.683 \mathrm{E}-06$ & $0.354 \mathrm{E}+14$ & $0.334 \mathrm{E}+14$ \\
\hline $0.113 \mathrm{E}-05$ & $0.356 \mathrm{E}+14$ & $0.336 \mathrm{E}+14$ \\
\hline $0.186 \mathrm{E}-05$ & $0.353 \mathrm{E}+14$ & $0.332 E+14$ \\
\hline $0.306 \mathrm{E}-05$ & $0.352 \mathrm{E}+14$ & $0.332 \mathrm{E}+14$ \\
\hline $0.504 \mathrm{E}-05$ & $0.353 \mathrm{E}+14$ & $0.333 E+14$ \\
\hline $0.831 \mathrm{E}-05$ & $0.354 \mathrm{E}+14$ & $0.334 \mathrm{E}+14$ \\
\hline $0.137 \mathrm{E}-04$ & $0.354 \mathrm{E}+14$ & $0.333 \mathrm{E}+14$ \\
\hline $0.226 \mathrm{E}-04$ & $0.354 \mathrm{E}+14$ & $0.334 \mathrm{E}+14$ \\
\hline $0.372 \mathrm{E}-04$ & $0.353 \mathrm{E}+14$ & $0.332 \mathrm{E}+14$ \\
\hline $0.614 \mathrm{E}-04$ & $0.354 \mathrm{E}+14$ & $0.334 \mathrm{E}+14$ \\
\hline $0.110 \mathrm{E}-03$ & $0.412 \mathrm{E}+14$ & $0.389 \mathrm{E}+14$ \\
\hline $0.167 \mathrm{E}-03$ & $0.295 \mathrm{E}+14$ & $0.278 \mathrm{E}+14$ \\
\hline $0.275 \mathrm{E}-03$ & $0.353 \mathrm{E}+14$ & $0.333 E+14$ \\
\hline $0.454 \mathrm{E}-03$ & $0.355 \mathrm{E}+14$ & $0.334 \mathrm{E}+14$ \\
\hline $0.749 \mathrm{E}-03$ & $0.354 \mathrm{E}+14$ & $0.334 \mathrm{E}+14$ \\
\hline $0.123 \mathrm{E}-02$ & $0.351 \mathrm{E}+14$ & $0.331 \mathrm{E}+14$ \\
\hline $0.203 \mathrm{E}-02$ & $0.354 \mathrm{E}+14$ & $0.334 \mathrm{E}+14$ \\
\hline $0.240 \mathrm{E}-02$ & $0.118 \mathrm{E}+14$ & $0.112 \mathrm{E}+14$ \\
\hline $0.284 \mathrm{E}-02$ & $0.119 \mathrm{E}+14$ & $0.112 \mathrm{E}+14$ \\
\hline $0.335 \mathrm{E}-02$ & $0.117 \mathrm{E}+14$ & $0.110 \mathrm{E}+14$ \\
\hline $0.553 \mathrm{E}-02$ & $0.632 \mathrm{E}+14$ & $0.138 \mathrm{E}+14$ \\
\hline $0.912 \mathrm{E}-02$ & $0.631 \mathrm{E}+14$ & $0.138 \mathrm{E}+14$ \\
\hline $0.150 \mathrm{E}-01$ & $0.627 \mathrm{E}+14$ & $0.137 \mathrm{E}+14$ \\
\hline $0.199 \mathrm{E}-01$ & $0.356 E+14$ & $0.780 \mathrm{E}+13$ \\
\hline $0.255 \mathrm{E}-01$ & $0.313 E+14$ & $0.684 \mathrm{E}+13$ \\
\hline $0.409 \mathrm{E}-01$ & $0.596 \mathrm{E}+14$ & $0.130 \mathrm{E}+14$ \\
\hline $0.674 \mathrm{E}-01$ & $0.630 \mathrm{E}+14$ & $0.138 \mathrm{E}+14$ \\
\hline $0.111 E+00$ & $0.629 \mathrm{E}+14$ & $0.138 \mathrm{E}+14$ \\
\hline $0.183 E+00$ & $0.630 \mathrm{E}+14$ & $0.138 \mathrm{E}+14$ \\
\hline $0.302 E+00$ & $0.632 E+14$ & $0.138 \mathrm{E}+14$ \\
\hline $0.388 \mathrm{E}+00$ & $0.316 E+14$ & $0.691 \mathrm{E}+13$ \\
\hline
\end{tabular}




\begin{tabular}{|c|c|c|}
\hline $\begin{array}{c}\text { Flux Group } \\
\text { Upper Energy } \\
(\mathbf{M e V})\end{array}$ & $\begin{array}{c}\text { PTP Flux } \\
\left(\mathbf{n} / \mathbf{c m}^{2}-\mathbf{s}\right)\end{array}$ & $\begin{array}{c}\text { HT Flux } \\
\left(\mathbf{n} / \mathbf{c m}^{2}-\mathbf{s}\right)\end{array}$ \\
\hline $0.498 \mathrm{E}+00$ & $0.315 \mathrm{E}+14$ & $0.689 \mathrm{E}+13$ \\
\hline $0.639 \mathrm{E}+00$ & $0.314 \mathrm{E}+14$ & $0.688 \mathrm{E}+13$ \\
\hline $0.821 \mathrm{E}+00$ & $0.415 \mathrm{E}+14$ & $0.931 \mathrm{E}+13$ \\
\hline $0.111 \mathrm{E}+01$ & $0.642 \mathrm{E}+14$ & $0.144 \mathrm{E}+14$ \\
\hline $0.135 \mathrm{E}+01$ & $0.500 \mathrm{E}+14$ & $0.112 \mathrm{E}+14$ \\
\hline $0.174 \mathrm{E}+01$ & $0.727 \mathrm{E}+14$ & $0.163 \mathrm{E}+14$ \\
\hline $0.223 \mathrm{E}+01$ & $0.753 \mathrm{E}+14$ & $0.169 \mathrm{E}+14$ \\
\hline $0.287 \mathrm{E}+01$ & $0.737 \mathrm{E}+14$ & $0.165 \mathrm{E}+14$ \\
\hline $0.368 \mathrm{E}+01$ & $0.616 \mathrm{E}+14$ & $0.138 \mathrm{E}+14$ \\
\hline $0.497 \mathrm{E}+01$ & $0.514 \mathrm{E}+14$ & $0.115 \mathrm{E}+14$ \\
\hline $0.607 \mathrm{E}+01$ & $0.194 \mathrm{E}+14$ & $0.435 \mathrm{E}+13$ \\
\hline $0.741 \mathrm{E}+01$ & $0.100 \mathrm{E}+14$ & $0.225 \mathrm{E}+13$ \\
\hline $0.861 \mathrm{E}+01$ & $0.350 \mathrm{E}+13$ & $0.785 \mathrm{E}+12$ \\
\hline $0.100 \mathrm{E}+02$ & $0.154 \mathrm{E}+13$ & $0.345 \mathrm{E}+12$ \\
\hline $0.116 \mathrm{E}+02$ & $0.564 \mathrm{E}+12$ & $0.127 \mathrm{E}+12$ \\
\hline $0.135 \mathrm{E}+02$ & $0.172 \mathrm{E}+12$ & $0.387 \mathrm{E}+11$ \\
\hline $0.149 \mathrm{E}+02$ & $0.322 \mathrm{E}+11$ & $0.723 \mathrm{E}+10$ \\
\hline $0.169 \mathrm{E}+02$ & $0.121 \mathrm{E}+11$ & $0.272 \mathrm{E}+10$ \\
\hline Total & $3.25 \mathrm{E}+15$ & $2.45 \mathrm{E}+15$ \\
\hline & & \\
\hline
\end{tabular}




\section{Appendix B - Cross Section Generation}

\section{B.1 BW One-Group Cross Section Generation Program}

BW is an unpublished Fortran program developed by the Westinghouse Hanford Company to produce one-group cross sections for use in isotope production calculations. One-group cross sections are derived using multi-group flux input, and resonance parameters and/or cross section curves.

The program determines cross sections for each of the energy groups in the multi-group flux input based on Breit-Wigner calculations and any cross section data points entered by the user. These cross sections can then be multiplied by the group fluxes to determine multi-group reaction rates. The sum of the group reaction rates is then divided by the sum of the group fluxes to produce the one-group cross section. Details of this process will be presented in Section B.1.2.

\section{B.1.1 Flux Input Files}

Multi-group flux input files are required to be in the format shown in Figure B.1 (note that this is the flux output file from the MKFLX program discussed in Appendix A).

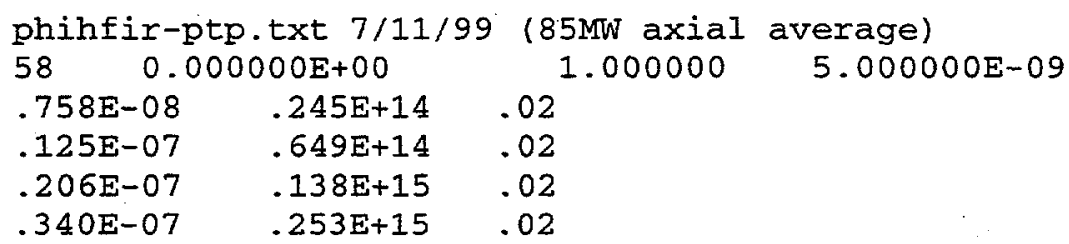

Figure B.1 BW Flux Input File

The first line is an 80 character title field that is used to identify the reactor and core location for the particular flux profile (in this case it is the flux profile of the HFIR PTP based on 85MW operation and representing axial average values).

The first entry in the second line identifies the number of energy groups for which flux information will be provided in subsequent lines. As noted in Appendix A, MKFLX is currently configured to generate a 58-group output. Flux profiles containing other than 58 groups can be used, but the number of lines of data following the second line must agree with the value entered here.

The second entry in the second line (variable esf in the BW program) identifies the structure of the energy group data in the subsequent lines. A value of 1.0 indicates that the energies are the lower end of a group, while a value of 0.0 indicates that the energies are the upper end of a group.

The third entry in the second line (variable uncerfl in the BW program) identifies whether or not there will be uncertainty data associated with the flux values. An entry of 1.0 indicates that there is 
uncertainty data (subsequent lines will have three entries), while an entry of 0.0 indicates that there is no uncertainty data (subsequent lines will have two entries).

The final entry in the second line identifies the width (in $\mathrm{MeV}$ ) of the lowest energy group if esf = 0.0 or it identifies the width of the highest energy group if esf $=1.0$.

All subsequent lines are the data for the number of groups identified by the first entry of line two (for brevity, all 58 groups of this input file are not shown in Figure B.1). The first number is the upper energy of the group (if esf $=0.0$ ) or the lower energy of the group (if esf $=1.0$ ) in $\mathrm{MeV}$. The second number is the group flux in $\mathrm{n} / \mathrm{cm}^{2}$-sec. The third number is the uncertainty in the flux, unless uncerfl = 0.0 in which case there are only two entries per line (i.e., no uncertainty data is presented).

MKFLX output files take into account these formatting requirements and as such can be used directly as input files for BW. However, flux data for FFTF core locations are usually received as MCNP output files and $\mathrm{BW}$ input files must be created in accordance with the formatting requirements.

\section{B.1.2 Resonance Parameter Input Files}

Figure B.2 is a typical resonance parameter input file for BW, in this case for tungsten-186 (note that the line numbers are for explanatory purposes only and are not to be included in the actual input file).

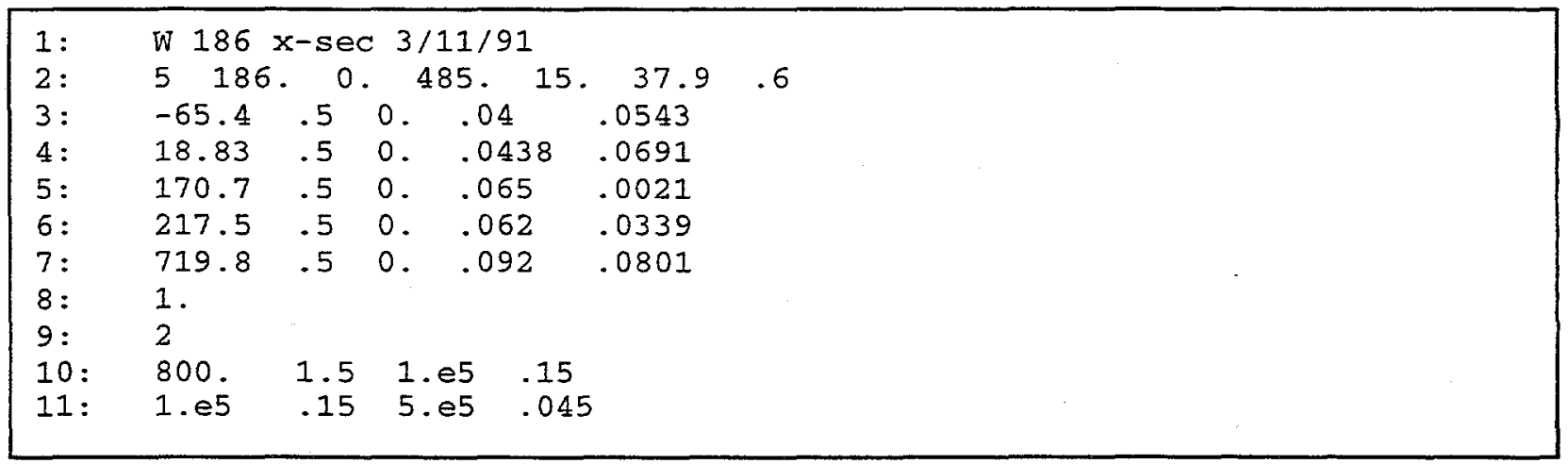

Figure B.2 BW Resonance Parameter Input File

Line 1 is a 40 character title field used to identify the isotope and can also be used to identify the date the input was created and the reaction being evaluated (this is usually an $n, \gamma$ reaction, but inputs can also be created for $n, p$ and other reactions using cross section curves and resonance parameters).

Line 2 provides the following information:

- The first entry (5) identifies the number of resonance parameter entries that will follow. In the example, the " 5 " indicates that there will be five sets of resonance parameters (these are entered in lines 3 through 7). This entry is an integer; all subsequent entries in line 2 are real numbers.

- The second entry (186.) is the atomic weight (the atomic number has been typically entered). 
- The third entry (0.) is the spin of the nucleus; this can be found in Neutron Cross Sections, Volume 1 (Mughabghab 1984), identified as $I^{\pi}$.

- The fourth and fifth entries (485. and 15.) are the radiative capture resonance integral and its uncertainty (in barns), identified as $\mathrm{I}_{\gamma}$ in Neutron Cross Sections, Volume 1 (Mughabghab 1984).

- The sixth and seventh entries (37.9 and .6) are the thermal capture cross section and its uncertainty (in barns), identified as $\sigma_{\gamma}$ in Neutron Cross Sections, Volume 1 (Mughabghab 1984). The total thermal cross section should be entered; i.e., the sum of the cross sections to all states.

The values for resonance integrals and thermal cross sections are not used in BW calculations; they are merely printed in the output file and can be compared with resonance integrals and thermal cross sections calculated by BW.

Lines 3 through 7 contain resolved resonance region data obtained from Neutron Cross Sections, Volume 1 (Mughabghab 1984). In this example, 5 sets of resonance data have been entered; however, more or fewer data sets can be entered as available in the reference. The more data entered, the more accurate will be the calculations. All resonance data must be entered as real numbers.

- The first entry is the resonance energy (in $\mathrm{eV}$ ), identified in the column labeled $\mathrm{E}_{0}$.

- The second entry is the spin of the resonance state, identified in the column labeled $\mathbf{J}$.

- The third entry is the orbital angular momentum of the incoming neutron, identified in the column labeled $\ell$.

- The fourth entry is the radiative width (in $\mathrm{eV}$ ), identified in the column labeled $\Gamma_{\gamma}$. Note that these values are frequently given in units of $\mathrm{meV}$ in the reference and must be converted to $\mathrm{eV}$ for the input file.

- The fifth entry depends upon the orbital angular momentum of the neutron:

- if $\ell=0$, use $\mathrm{g} \Gamma_{\mathrm{n}}{ }^{0}$, the reduced neutron width for s-wave neutrons

- if $\ell=1$, use $\mathrm{g} \Gamma_{\mathrm{n}}{ }^{1}$, the reduced neutron width for $\mathrm{p}$-wave neutrons

- if $\ell=5$, use $\mathrm{g} \Gamma_{n}$, the neutron width

- if $\ell=6$, use $\Gamma_{\mathrm{p}}$, the proton width

Again, note that these values are frequently given in units of $\mathrm{meV}$ in the reference and must be converted to $\mathrm{eV}$ for the input file. Also, the columns are occasionally multiplied by 2 (e.g., $\left.2 \mathrm{gr}_{\mathrm{n}}{ }^{9}\right)$, in which case all values must be divided by 2 for the input file. 
Line 8 is a flag that indicates whether or not unresolved resonance region data is entered. Unresolved resonance region data may be available in Neutron Cross Sections, Volume 2 (McLane et al. 1988 ) in the form of curves of cross sections as functions of incoming neutron energy. Unresolved region data is particularly important for reactions having significant cross sections for fast and high energy neutrons. A value of 1.0 indicates that unresolved region data follows, while a value of 0.0 indicates that no further data is presented.

Line 9 is an integer that identifies the number of unresolved resonance region data points that follow.

Lines 10 and 11 are the unresolved resonance region data points. Data in these lines are entered as pairs of data points. The energy of the first data point must be greater than the energy of the last data point entered in the resolved resonance region data. The first value in line 10 is the energy (in eV) of the data point and the second value is the corresponding cross section (in barns) from the cross section curve. The third value in line 10 is the energy of the second data point and the fourth value is the corresponding cross section. The first two values in line 11 are the same as the second data point of the preceding line. The third and fourth values in line 11 are the data from the third data point. This format must be followed for all subsequent data points (i.e., the first data point in each line is the same as the second data point in the preceding line).

\section{B.1.3 Running BW}

Figure B. 3 is a batch file used to run the BW program. The second line specifies the location of the resonance parameter input file (c:Ibw99linputlin_w186.txt in this example). The third line specifies the location of the flux input file (c:lbw99hfir-ptplphihfir-ptp.txt in this example). The fourth line copies the BW code into the current directory and the fifth line executes the code. The sixth line names the output and places it in an appropriate directory (c:lbw99 Lhfir-ptplw186.txt in this example). The remaining lines clean up the run directory following execution of the code.

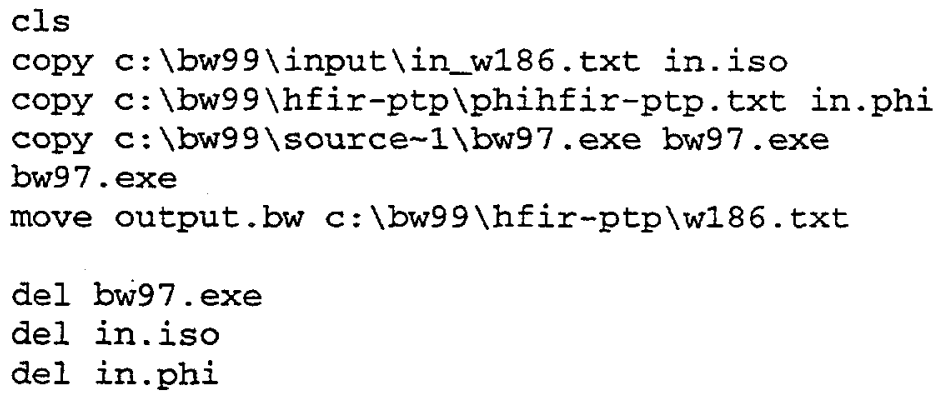

Figure B.3 BW Run Batch File 


\section{B.1.4 BW Output File}

Figure B.4 is a BW output file; in this example it is the file generated using Figures B.1, B.2, and B.3 (note that the line numbers are for explanatory purposes only and are not included in the actual output file).

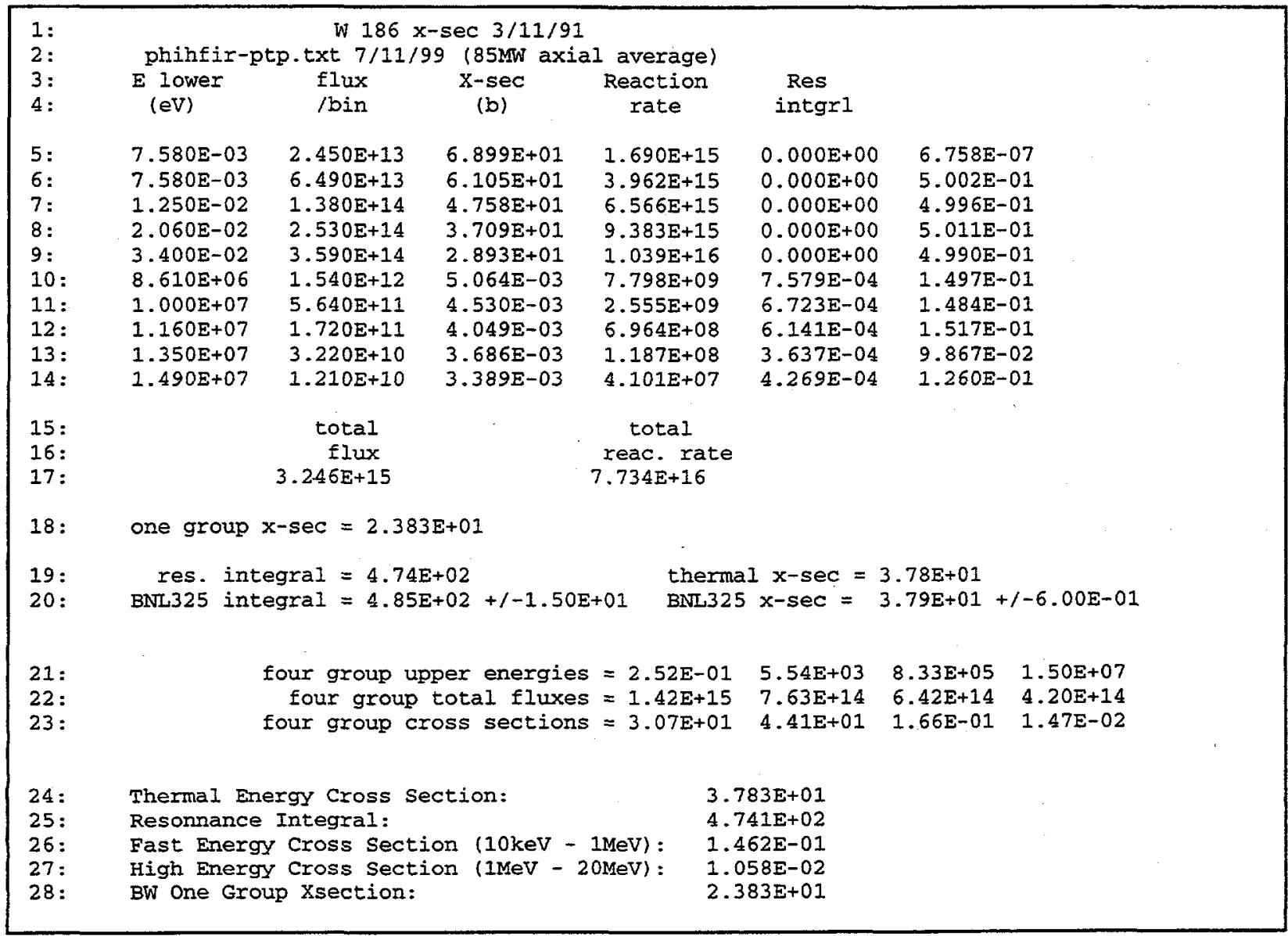

Figure B.4 BW Output File

Line 1 is the 40 character title field from the resonance parameter input file, Figure B.2.

Line 2 is the 80 character title field from the flux input file, Figure B.1.

Lines 3-4 are the column headings for the cross section calculation data printed in lines 5-14 (for brevity, only the first and last five energy groups are shown rather than all 58 groups).

- Column 1 identifies the lower energy (in $\mathrm{eV}$ ) of the group. These energy groups are determined by the flux input file, Figure B.1 (note, however, that Figure B.1 which was generated by MKFLX lists the upper energy of each group rather than the lower energy). A problem with the BW code misrepresents the lower energy of the first group. In this example, $0.758 \mathrm{E}-03$ is actually the upper energy of the first group-the lower energy should be $0.758 \mathrm{E}$ - 
$08 \mathrm{MeV}$ (the first entry in line 3 of Figure B.1, the upper energy of the lowest group) $-5.0 \mathrm{E}-09$ $\mathrm{MeV}$ (the last entry in line 2 of Figure B.1, the width of the lowest group) $=2.58 \mathrm{E}-09 \mathrm{MeV}=$ $2.58 \mathrm{E}-03 \mathrm{eV}$.

- Column 2 is the group flux (in $\mathrm{n} / \mathrm{cm}^{2}-\mathrm{sec}$ ) from the flux input file, Figure B.1.

- Column 3 is a group cross section (in barns) calculated by BW based on the resonance parameter input file, Figure B.2.

- Column 4 is the calculated group reaction rate per atom obtained by multiplying columns 2 and 3.

- Column 5 is a calculated group resonance integral (in barns).

- Column 6 is the group lethargy, $\ln \left(\mathrm{E}_{\mathrm{upper}} / \mathrm{E}_{\mathrm{lower}}\right)$, a dimensionless quantity. Note that the previously mentioned error in the lower energy limit in line 5 also produces an error in the lethargy of the first group. It should be $\ln (7.58 \mathrm{E}-03 / 2.58 \mathrm{E}-03)=1.078$.

Lines $15-17$ present the total flux and total reaction rate. Total flux is obtained by summing the group fluxes (column 2, above) and total reaction rate is obtained by summing the group reaction rates (column 4, above).

Line 18 is the calculated one-group cross section that is used by the CHAIN code for isotope production calculations (see Appendix $\mathrm{C}$ ). This value is obtained by dividing the total reaction rate by the total flux (i.e., the values presented in line 17).

Lines 19 and 20 provide comparisons between the calculated and published values of the resonance integral and thermal cross section (both in barns). The resonance integral in line 19 is the sum of the group resonance integrals (column 5, above). The thermal cross section in line 19 is a BW calculation of the cross section over the thermal energy range. The published resonance integral and thermal cross section which were entered in the resonance parameter input file (Figure B.2, line 2) are displayed in line 20. These calculated values of the resonance integral and thermal cross section should be compared to the published values to ensure that they are in reasonably close agreement. If either or both of the calculated values differ substantially from the published values, the one-group cross section will most likely produce inaccurate results when used for isotope production calculations in CHAIN. Improvements can be obtained by adding resonance parameters and/or unresolved resonance data points for other energy levels to the resonance parameter input file.

Lines $21-23$ present four-group data calculated by BW. This information can be useful in making comparisons between isotope production in different reactor environments by clearly displaying data for thermal, epithermal, fast, and high energy regions. Line 21 defines the upper energy (in eV) of the four groups. Line 22 displays the flux (in $\mathrm{n} / \mathrm{cm}^{2}-\mathrm{sec}$ ) and line 23 displays the cross section (in barns) for each group.

Line 24 displays the thermal cross section (in barns), the same value as in line 19.

Line 25 displays the resonance integral (in barns), the same value as in line 19. 
Line 26 is a calculation of a fast energy cross section (in barns) defined over a range of $10 \mathrm{keV}-1$ $\mathrm{MeV}$.

Line 27 is a calculation of a high energy cross section (in barns) defined over a range of $1 \mathrm{MeV}-$ $20 \mathrm{MeV}$.

Line 28 displays the one-group cross section (in barns), the same value as in line 18. 



\section{Appendix C - Isotope Production Calculations}

\section{C.1 CHAIN Isotope Production Calculation Program}

CHAIN is an unpublished Fortran program developed by the Westinghouse Hanford Company to calculate isotope production based on the production and removal of each isotope in the chain of isotopes of interest. For example, the chain involved in the production of tungsten-188 using a tungsten-186 target (including impurities produced) is:

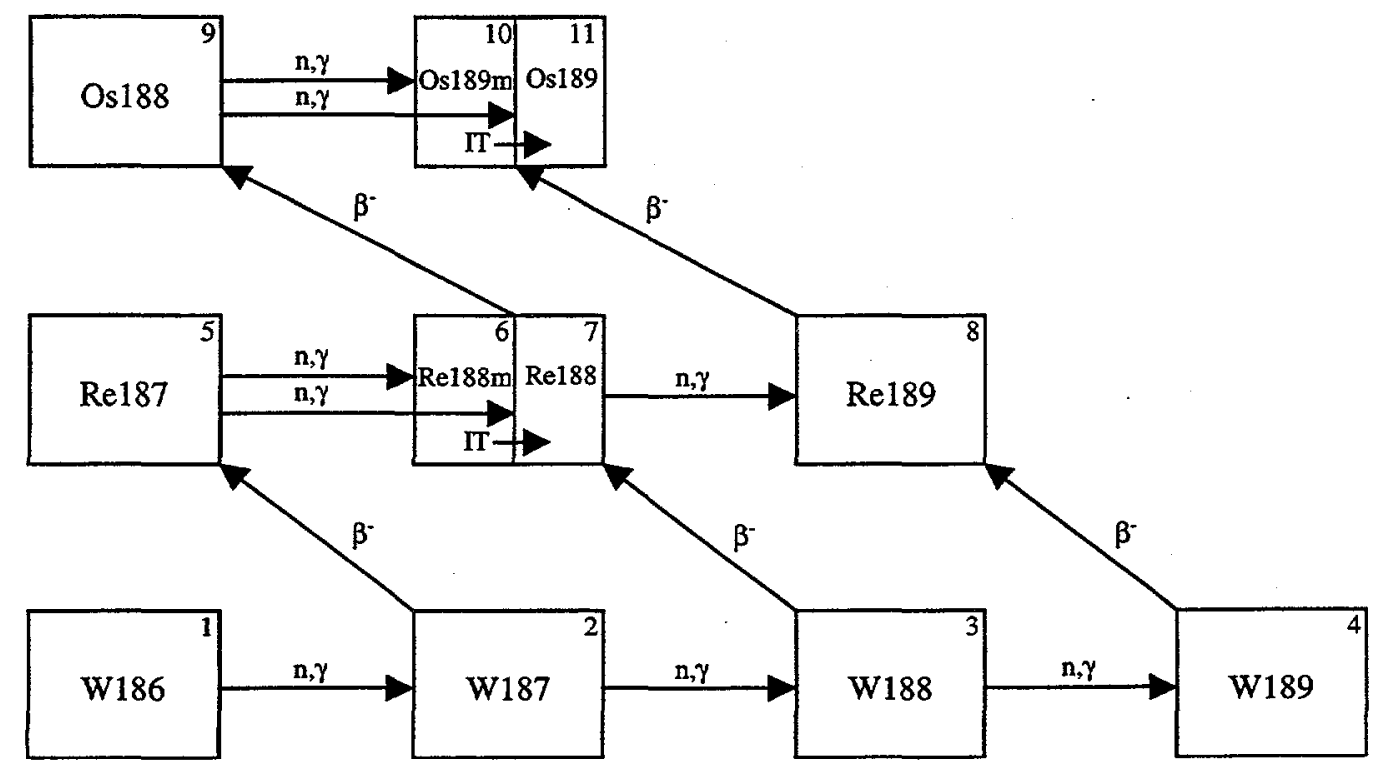

Figure C.1 W188 Production CHAIN Block Diagram

CHANN calculates production rates for isotopes along long and complex absorption and decay chains such as the one shown for $188 \mathrm{~W}$ in Figure C.1 In addition to radiative capture reactions, CHAIN can accommodate other reactions such as $\mathrm{n}, 2 \mathrm{n}$ and $\mathrm{n}, \mathrm{p}$.

The differential equation that must be solved to calculate isotope production is:

$$
\frac{d N_{i}(t)}{d t}=\sum_{j=1}^{i-1}\left[\alpha_{j i} N_{j}(t)\right]-\beta_{i} N_{i}(t) \quad i=1, L
$$

where $\alpha_{j i}$ and $\beta_{i}$ represent the "production" and "loss" coefficients, respectively. $N_{i}(t)$ is the amount of the ith isotope at time $t$ and $L$ is the total number of nuclei in the chain. The $\alpha_{\mathrm{ji}}$ coefficients are the rates of nuclide $j$ producing nuclide $i$. They are typically either the radiative capture reaction rate or the decay 
constant of nuclide $\mathrm{j}$. The $\beta_{\mathrm{i}}$ coefficients are the sum of the decay constant and the total neutron absorption rate of nuclide $i$.

The solutions to the above equations are given by the following:

$$
N_{i}(t)=\sum_{m=1}^{i} a_{i m} e^{-\beta_{m} t} \quad i=1, L
$$

where

$$
\begin{array}{ll}
\sum_{m=1}^{i} a_{i m}=N_{i}(0) & m=i \\
a_{i m}=\frac{1}{\beta_{i}-\beta_{m}} \sum_{j=m}^{i-1} \alpha_{j i} a_{j m} & m<i
\end{array}
$$

In order to obtain the $\mathrm{a}_{\mathrm{im}}$ values, a subroutine performs a sequential procedure that develops the coefficients as follows:

$$
\begin{aligned}
& a_{11}=N_{1}(0) \\
& a_{21}=\frac{1}{\beta_{2}-\beta_{1}} \alpha_{12} a_{11} \\
& \vdots \\
& a_{L 1}=\frac{1}{\beta_{L}-\beta_{1}} \sum_{m=1}^{i-1} \alpha_{m, L} a_{m, 1} \\
& a_{22}=N_{2}(0)-a_{21}
\end{aligned}
$$

It should be noted that the above solutions fail if any of the $\beta_{\mathrm{i}}$ coefficients are equal since that would produce a situation where the program divides by zero. Coefficients would be equal if isotopes had the same decay constant and cross section. This could be the case for stable isotopes which have unknown cross sections (which requires using an artificial cross section). To alleviate problems, isotopes with unknown cross sections should be assigned slightly different cross sections such as $1.01,1.02,1.03$, etc. barns.

\section{C.1.1 CHAIN Input File}

Figure C.2 is a typical input file for CHAIN, in this case for tungsten-188 production using a tungsten-186 target (note that the line numbers are for explanatory purposes only and are not included in the actual input file). This input file is associated with the production scheme shown in Figure C.1.

Line 1 is an 80 character field that identifies the product isotope and line 2 is an 80 character field that identifies the target isotope. Neither of these fields is used in the generation of output files, however. 
Line 3 is a 40 character field that identifies the irradiation location; this information is printed in CHAIN output files. This field typically identifies the reactor and core location.

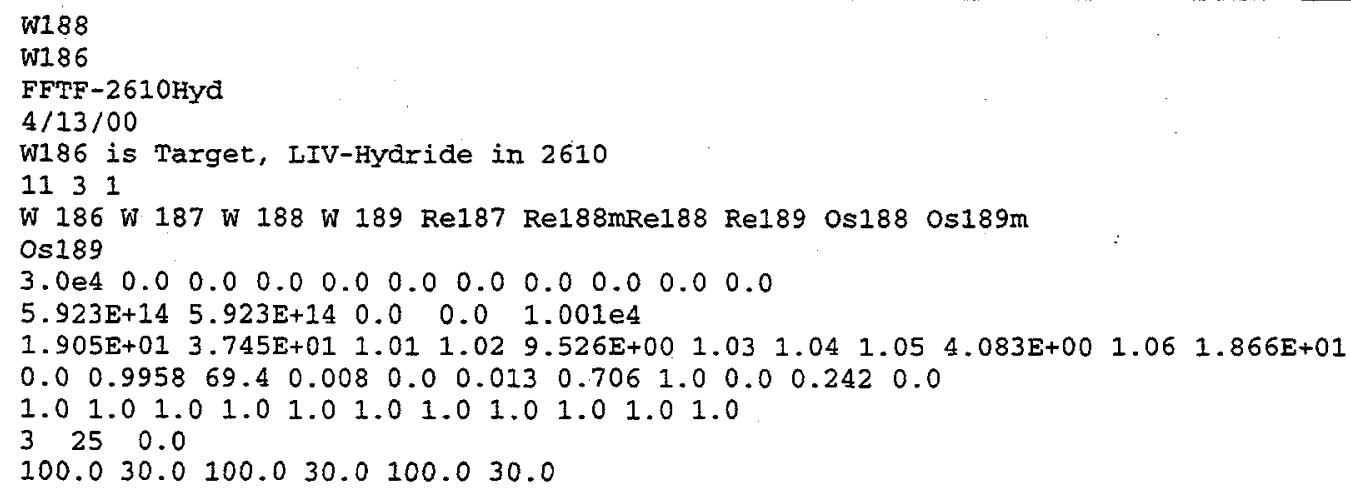

\section{Figure C.2 CHAIN Input File}

Line 4 is an 80 character field in which to enter the date that the input was developed; this information is printed in CHAIN output files.

Line 5 is an 80 character title field that is used to describe the irradiation that is being analyzed; this information is printed in CHAIN output files.

The first entry in line 6 is the number of isotopes in the chain (the example shown in Figure C.1 has 11 isotopes - metastable and ground states are different isotopes). The second entry is the number of the product isotope (the product isotope, ${ }^{188} \mathrm{~W}$, in Figure C. 1 is given the number 3). The third entry is the number of the target isotope (the target isotope, ${ }^{186} \mathrm{~W}$, in Figure C.1 is given the number 1 ). When numbering isotopes in the chain, it is a good idea to draw a figure such as C.1 and sequentially number the isotopes. This is very important since CHAIN will not work properly if a "higher numbered" isotope produces a "lower numbered" isotope. Thus, the drawing helps ensure that no production arrows point from a higher numbered box to a lower numbered box.

Lines 7 and 8 are a sequential list of the isotopes in the chain. A maximum of ten isotopes can be entered on one line. Note that the order of the listed isotopes in Figure C.2 corresponds with the numbers assigned in Figure C.1. This is very important since these labels are used to identify data in various output files.

Line 9 is a list of the initial masses (in grams) of all isotopes in the target. There must be an entry for each isotope in the chain and the order of the isotopes is the same as that entered in lines 7 and 8 . In this example, the target is $30 \mathrm{~kg}$ of pure ${ }^{186} \mathrm{~W}$.

The first and second entries in line 10 are the initial and final flux levels (in $\mathrm{n} / \mathrm{cm}^{2}-\mathrm{sec}$ ), respectively, for the irradiation. CHAIN assumes linearity between the two values over the course of irradiation. The third and fourth values provide a convenient location to enter cross sections for reactions other than $(n, \gamma)$ that are significant enough to be taken into consideration in the calculation. These reactions may be $(n, p),(n, 2 n)$, etc. This will be discussed further in Section C.1.2, CHAIN Setup File. 
The fifth entry is the maximum specific activity (i.e., the specific activity of a pure isotope, in units of $\mathrm{Ci} / \mathrm{g}$ ) of the product isotope which is listed as SpA in the Table of Radioactive Isotopes (Browne et al. 1986).

Line 11 is a list of the one-group capture cross sections (in barns) for each isotope in the chain, again entered according to the numbering scheme derived earlier. These one-group cross sections are obtained from BW (see Appendix B). Note that one-group cross sections are dependent upon irradiation location; therefore, it is important to obtain the one-group cross section values from the $\mathrm{BW}$ folder associated with the core location identified in line 3 . If a one-group cross section is unavailable, a default value of 1 barn is typically used. However, as discussed at the end of the introduction to Section C.1, using slightly different values for each unknown cross section is advisable and hence values such as 1.01 , 1.02 , etc. are used.

Line 12 is a list of the half-lives (in days) for each isotope in the chain, again entered according to the numbering scheme derived earlier. Stable isotope half-lives are entered as 0.0 days for simplicity (the CHAN Setup file, Section C.1.2, converts this value to 1E20). Half-lives are available in the Chart of the Nuclides (Parrington et al. 1996).

Line 13 is a list of the self-shielding $\mathrm{f}$ factors for each isotope in the chain, again entered according to the numbering scheme derived earlier. If it is desired to ignore self-shielding, values of 1.0 can be entered.

The first entry in line 14 identifies the number of reactor operating cycles for which the target will be irradiated. These operating cycles will be defined in line 15 . The second entry in line 14 specifies the number of data points for each period of reactor operation or shutdown. In this example, there will be 25 data points for each operating and shutdown period. NOTE: Specifying too large a number of data points may result in a failure of the program; if the program doesn't run properly, the user should try specifying fewer data points (a specific limit of data points does not exist - the upper limit depends on the number of cycles specified). The third entry acts as a starting offset (in days) for the activity (act) and mass (mass) output files. It is typically set to 0.0 , but if it were set at 10.0 , for example, the activity and mass output files would be based on an irradiation history that starts with ten days of no irradiation, followed by the defined operating cycles. This offset does not affect the isotope production rate (out) or production summary (per) output files. Further clarification on this will be provided in the following paragraph and the discussions of the various output files.

Line 15 defines the operating cycles for the target irradiation. It must agree with the number of cycles specified in the first entry of line 14. Each cycle specified in line 14 requires a time at power (in days) and a shutdown period (in days) to be entered in line 15. In this example, line 14 specifies 3 cycles and line 15 defines those cycles to be identical 100 day operating periods followed by 30 shutdown periods (the cycles do not have to be the same - the user can define them as desired). Thus, the total time for this irradiation would be 390 days. If, however, the third entry in line 14 had been 10.0 (see previous paragraph), the total irradiation time for the activity and mass output files would be 400 days and the first power cycle would have started at day 10. 


\section{C.1.2 CHAIN Setup File}

In addition to the various parameters provided in the input file (Section C.1.1), CHAIN requires a setup file to identify the production and decay pathways. Figure C. 3 is a typical setup file (note that the line numbers are for explanatory purposes only and are not included in the actual setup file). This setup file is associated with the production scheme shown in Figure C.1.

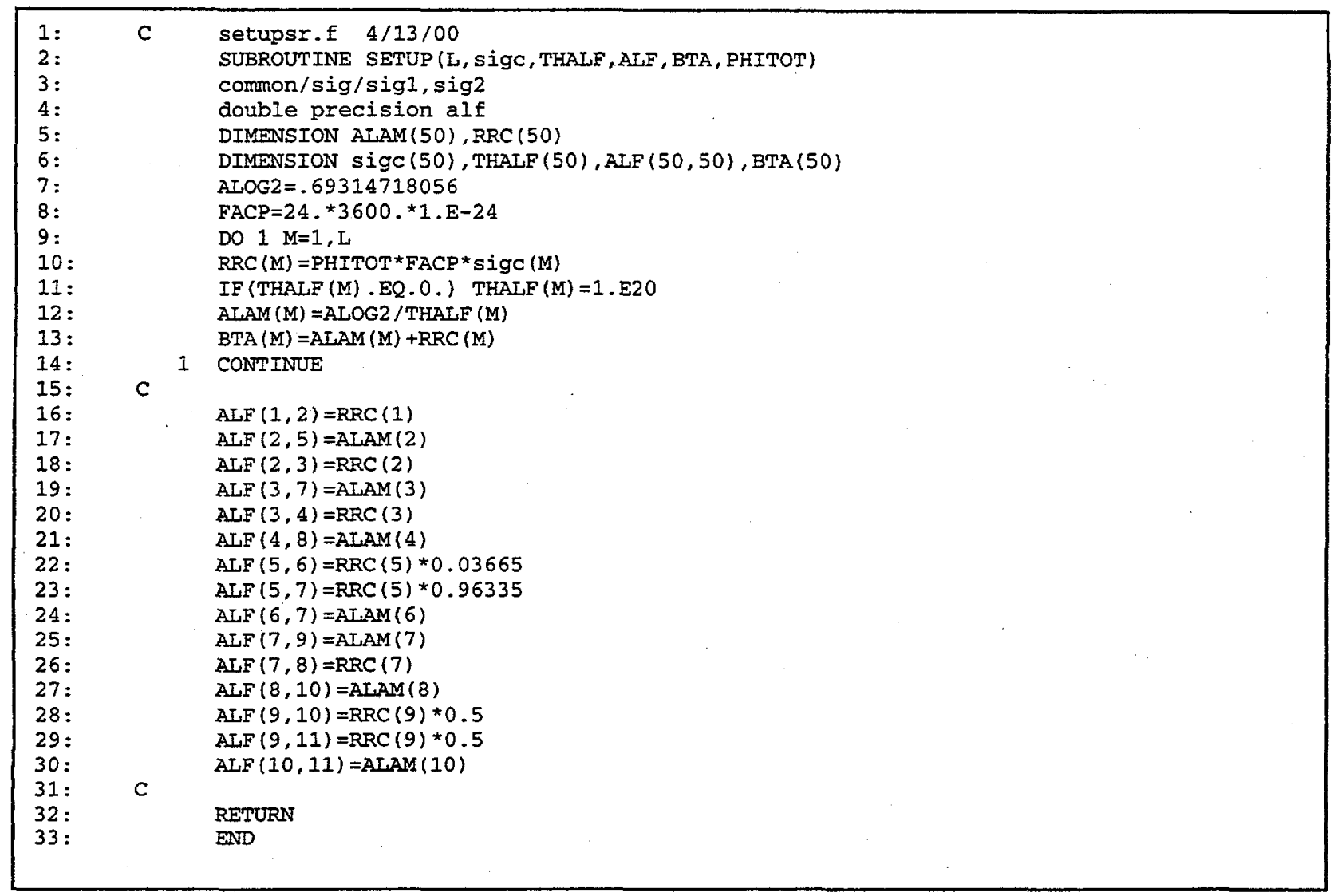

Figure C.3 CHAIN Setup File

Line 1 is a comment line that identifies this file as a Fortran subroutine and provides the date it was created or modified.

Lines 2 through 14 are standard in all setup files, defining parameter passing that occurs while CHAN is executed and creating constants that are used in reaction rate and decay calculations. These lines should be copied verbatim when creating setup files and will not be discussed in this report since they are not of interest to the user.

Lines 16 through 30 define the production and decay pathways for which CHAIN will calculate isotope production data. Numbers in these statements correspond to the isotope numbering scheme developed in Figure C.1. For all neutron capture reactions shown in Figure C.1, an entry of the form $\operatorname{ALF}(1,2)=\mathrm{RRC}(1)$ is required. The preceding example defines the neutron capture reaction rate of the 
first isotope $\left({ }^{186} \mathrm{~W}\right)$ which is transformed into the second isotope $\left({ }^{187} \mathrm{~W}\right)$. If neutron capture can also lead to the production of another energy state, the multiple states can be calculated on separate lines. For example, lines 22 and 23 define the production of the excited state and ground state of ${ }^{188} \operatorname{Re}$ from ${ }^{187} \operatorname{Re}$. The numbers 0.03665 and 0.96335 are the probabilities of production of ${ }^{188 \mathrm{~m}} \mathrm{Re}$ and ${ }^{188} \mathrm{Re}$, respectively, and are calculated based on cross sections for the reactions obtained from Neutron Cross Sections, Volume 1 (Mughabghab et al. 1984). Similarly, decay branching ratios can be entered based on data available in Table of Radioactive Isotopes (Browne et al. 1986).

For all radioactive decay pathways shown in Figure C.1, an entry of the form ALF(2,5)=ALAM(2) is required. The preceding example defines the beta decay rate of the second isotope $\left({ }^{187} \mathrm{~W}\right)$ to the fifth isotope $\left({ }^{187} \mathrm{Re}\right)$.

As mentioned in Section C.1.1, the product isotope must always have a higher number than the isotope which produces it or CHAIN will not operate properly. Thus, all ALF statements should have a pair of numbers in parentheses where the second number is greater than the first.

In addition to the radiative capture reactions shown in this example, other reactions such as $(\mathrm{n}, \mathrm{p})$ can be entered. As discussed in Section C.1.1, parameters called sig1 and sig2 in the input file are used to enter the cross sections for reactions other than radiative capture (the third and fourth values of Figure C.2 line 10). For example, the (n,p) production of ${ }^{67} \mathrm{Cu}$ from ${ }^{67} \mathrm{Zn}$ would be specified in the form of

\section{$\operatorname{ALF}(1,2)=$ SIG $1 *$ PHITOT $*$ FACP}

in the setup file, with the cross section for this reaction entered in the sig1 position of the input file.

Alternatively, cross sections for other reactions can be entered directly into the setup file rather than passing those parameters between subroutines. For example, the (n,p) cross section for ${ }^{67} \mathrm{Zn}$ mentioned above can also be entered in the setup file as

$$
\mathrm{ALF}(1,2)=1.36 \mathrm{E}-04 * \mathrm{PHITOT} * \mathrm{FACP}
$$

assuming that the one-group cross section for the reaction is $1.36 \mathrm{E}-04$ barns. This method is not recommended, however. Setup files are very versatile because they are independent of the irradiation location; i.e., the same setup file is used for production of a particular isotope in any core location. Thus, when performing production calculations for multiple core locations, the user only has to create an input file specific to each core location. However, one-group cross sections are dependent on irradiation location so if any cross sections are entered in the setup file, it becomes core location specific and must be modified in addition to the input file when calculations are performed for a different location.

\section{C.1.3 Running CHAIN}

Figure $\mathrm{C} .4$ is a batch file used to run the CHAIN program (note that the line numbers are for explanatory purposes only and are not included in the actual setup file). It is assumed that CHAIN is being run in a directory created for the particular isotope being studied; in this case, the directory C:IChain99IW188 contained the run batch file (named Run), the input file (named w188_inp01.txt), and the setup file (named setup01). The Run batch command was executed in this directory. 


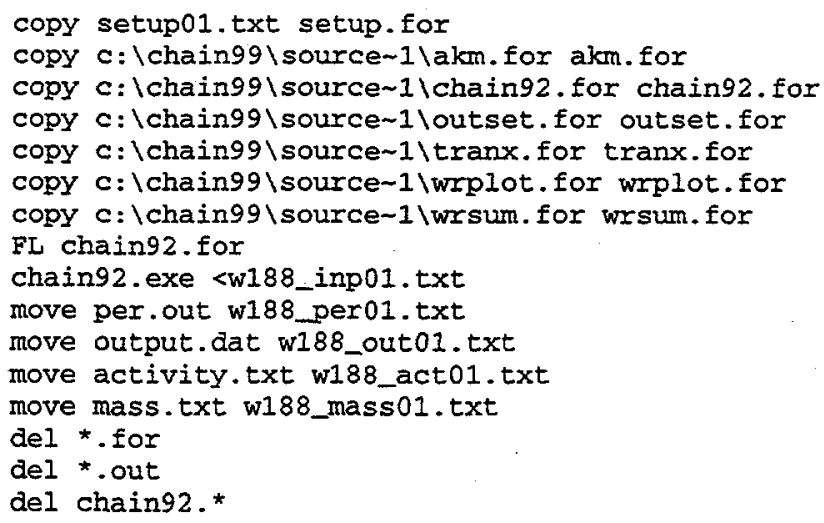

Figure C.4 CHAIN Run Batch File

Line 1 copies the setup text file (Section C.1.2) named setup01.txt into a file with the proper name for the CHANN code to recognize it as the setup file.

Lines 2 through 7 copy files from the Source Code directory into the working directory. These files, akm.for, chain92.for, outset.for, tranx.for, wrplot.for, and wrsum.for are the main executable file (chain92.for is a version of CHAIN that was modified in 1992) and supporting subroutines.

Line 8 compiles the CHAIN program. Note that Fortran is required to run CHAIN and that the compile command (FL) must be in the DOS path so that it can be found when running the batch file.

Line 9 executes CHAIN using the input text file (Section C.1.1) named w188_inp01.txt.

Lines 10 through 13 rename various CHAIN output files with names that will be more identifiable with respect to the isotope being produced, the trial number (if more than one run will be performed), and the type of output. These output files will be discussed in Section C.1.4.

Lines 14 through 16 clean up the working directory following execution of the code.

\section{C.1.4 CHAIN Output Files}

CHAIN produces four output files, an overall production summary and time breakdowns of product isotope production, isotope masses, and isotope activities.

Figure C.5 is an overall production summary (the file that the CHAIN batch file names w188_per01 in the example in Section C.1.3). Note that the line numbers are for explanatory purposes only and are not included in the output file.

Lines 1 and 2 are the title of the report. The information in the title is derived from the input file (Figure C.2).

Line 3 identifies the total irradiation time and the total elapsed time of the production run which includes the decay time associated with reactor shutdown periods. In the example discussed in Section C.1.1, there were 3 identical cycles of 100 day reactor operating periods and 30 day shutdown periods, for a total of 300 days of irradiation and 390 days overall. 
Line 4 is the total flux calculated by CHAIN based on the initial and final fluxes in the input file. The place in the CHAIN program where this output file is generated results in the total flux given in the output being equal to the final flux in the input file.

Lines 5 through 7 are the headings for the production data that follows.

Lines 8 through 18 provide a production summary. For each isotope in the chain, this output file shows the initial and final masses (in grams), its percentage of the total final mass, its final activity (in curies), and its cross section (in barns) and half-life (in days) that were entered in the input file.

Line 19 is merely a summation for the first three columns.

Line 20 identifies the specific activity of the product isotope as calculated by CHAIN.

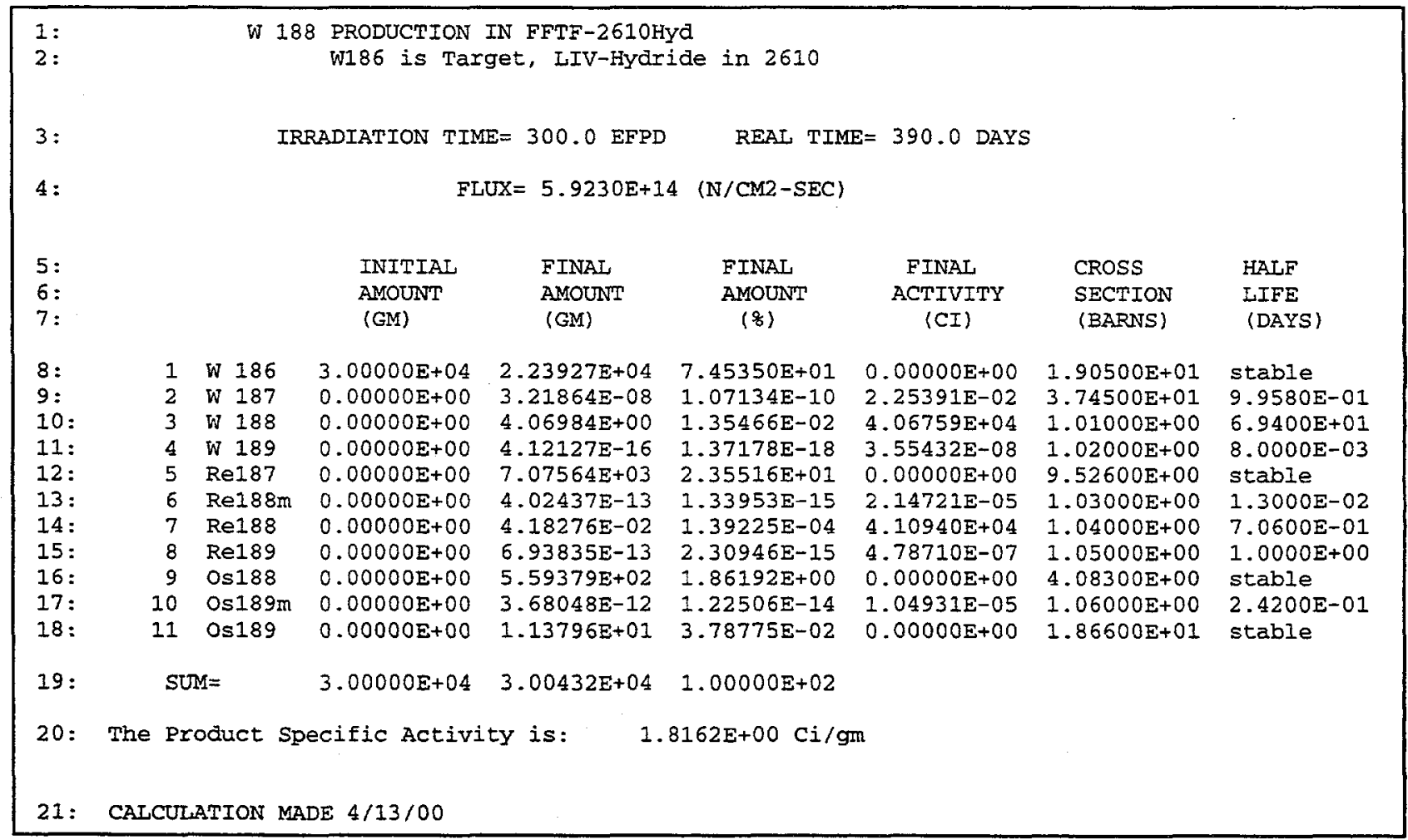

Figure C.5 CHAIN Production Summary Output File

Line 21 reproduces the date of the calculation from the input file (Figure C.2).

Figure C.6 displays the product isotope versus time (the file that the CHAIN batch file names w188_out01 in the example in Section C.1.3). Only a representative portion of this output file has been shown in Figure C.6; in the actual output file, there is no gap in data between 24 days and 382.8 days.

The title of the report is generated based on information entered in the input file (Figure C.2). 
The data presented in the table corresponds to the operating cycles and data points defined in the input file. In the example shown in Figure C.2, there were 3 cycles of 100 day operation, each followed by a 30 day shutdown period. Also, there were 25 data points defined for each period of reactor operation or shutdown. Thus, the first 100 day operating cycle is broken down into $100 / 25=4$ day increments. Similarly, the shutdown periods are broken down into $30 / 25=1.2$ day increments.

As seen in Figure C.6, product $\left({ }^{188} \mathrm{~W}\right)$ activity, amount and specific activity increase with time during reactor operation (days 0 through 24 ) and decrease as the product decays during the reactor shutdown period in days 382.8 through 390 . Also, the target mass is seen to decrease during reactor operation and remain constant during the reactor shutdown since it isn't depleted while the reactor is shutdown.

This output file is useful in plotting production/decay curves of the product isotope.

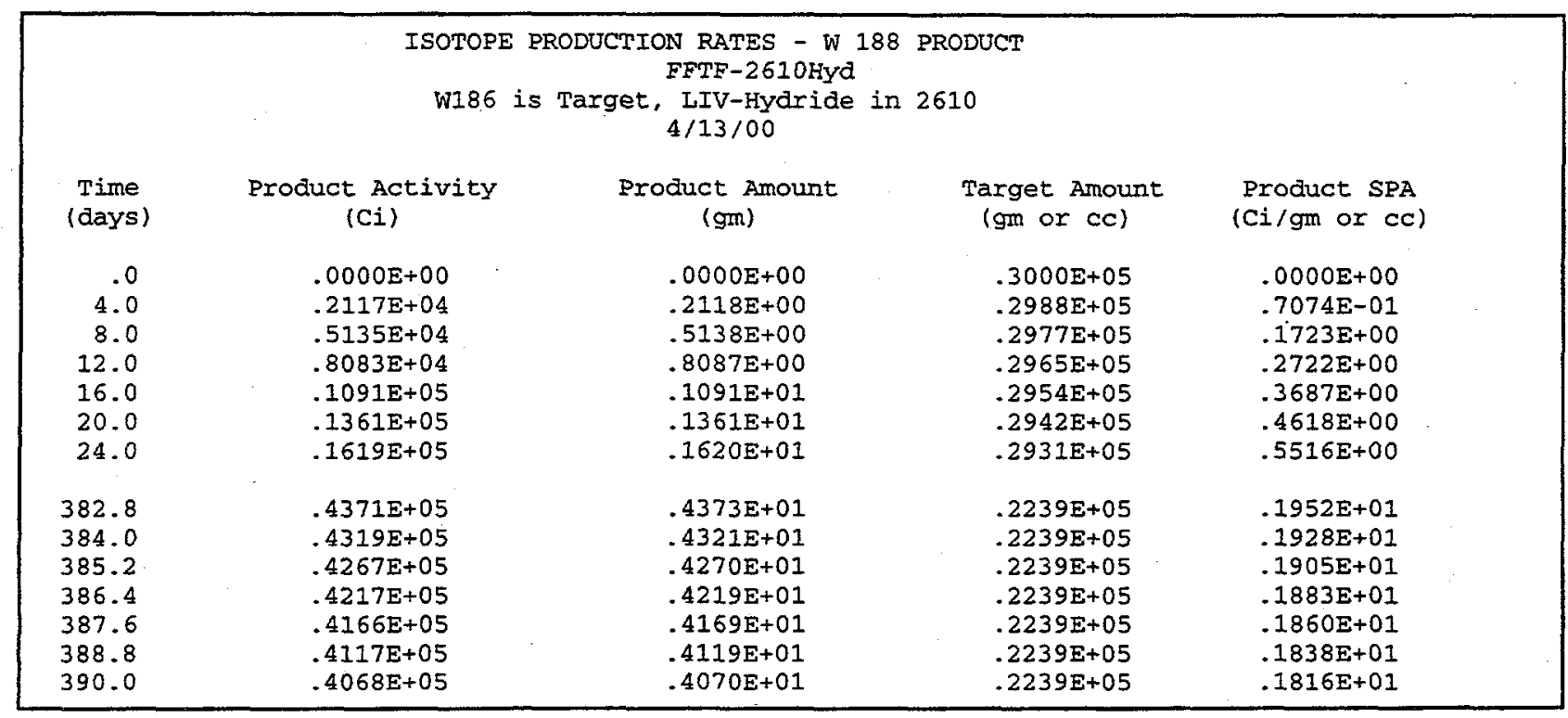

Figure C.6 CHAIN Product Isotope Production Versus Time Output File

Figures C.7 and C. 8 display the masses and activities of all isotopes in the chain versus time (the files that the CHAIN batch file names w188_mass01 and w188_act01.txt in the example in Section C.1.3). Only a representative portion of these output files has been shown in Figures C.7 and C.8; in the actual output files, there is no gap in data between 24 days and 382 days.

These output files are generated in a manner similar to the product isotope production output file; i.e., the data presented in the tables corresponds to the operating cycles and data points defined in the input file. Thus, the composition of the time scale is the same. However, as mentioned in Section C.1.1, if a starting offset was entered in the input file (third entry in Figure C.2 line 14), the data in the mass and activity output files would be offset by that amount. For example, if it were set at 10.0, the first line of data in both files would be at 14 days rather than 4 days. As mentioned previously, the production summary (Figure C.5) and product isotope production (Figure C.6) output files are not similarly affected.

These output files are useful in plotting production/decay and depletion curves of all isotopes. 


\begin{tabular}{|c|c|c|c|c|c|c|c|c|c|c|c|}
\hline $\begin{array}{l}\text { Mass (grams } \\
\text { TIME (DAYS) }\end{array}$ & W 186 & W 187 & W 188 & W 189 & $\operatorname{Re} 187$ & $\operatorname{Re} 188 \mathrm{~m}$ & $\operatorname{Re} 188$ & $\operatorname{Re} 189$ & Os188 & Os $189 \mathrm{~m}$ & 0 os189 \\
\hline $.400 \mathrm{E}+01$ & $.299 \mathrm{E}+05$ & $.394 \mathrm{E}+02$ & $.212 \mathrm{E}+00$ & $.127 \mathrm{E}-06$ & $.777 \mathrm{E}+02$ & $.260 E-04$ & $.278 E-01$ & $.104 \mathrm{E}-04$ & $.357 \mathrm{E}-01$ & $.294 \mathrm{E}-05$ & $.112 \mathrm{E}-04$ \\
\hline $.800 \mathrm{E}+01$ & $.298 \mathrm{E}+05$ & $.417 \mathrm{E}+02$ & $.514 \mathrm{E}+00$ & $.308 E-06$ & $.192 \mathrm{E}+03$ & $.644 \mathrm{E}-04$ & $.855 \mathrm{E}-01$ & $.354 \mathrm{E}-04$ & $.256 \mathrm{E}+00$ & $.162 \mathrm{E}-04$ & $.164 \mathrm{E}-03$ \\
\hline $.120 \mathrm{E}+02$ & $.297 E+05$ & $.417 \mathrm{E}+02$ & $.809 \mathrm{E}+00$ & $.485 \mathrm{E}-06$ & $.307 \mathrm{E}+03$ & $.103 E-03$ & $.146 \mathrm{E}+00$ & $.622 \mathrm{E}-04$ & $.710 \mathrm{E}+00$ & $.386 E-04$ & $.663 \mathrm{E}-03$ \\
\hline $.160 E+02$ & $.295 E+05$ & $.415 E+02$ & $.109 \mathrm{E}+01$ & $.654 \mathrm{E}-06$ & $.423 \mathrm{E}+03$ & $.142 \mathrm{E}-03$ & $.207 E+00$ & $.884 E-04$ & $.140 \mathrm{E}+01$ & $.696 \mathrm{E}-04$ & $.171 \mathrm{E}-02$ \\
\hline $.200 \mathrm{E}+02$ & $.294 \mathrm{E}+05$ & $.414 \mathrm{E}+02$ & $.136 \mathrm{E}+01$ & $.816 \mathrm{E}-06$ & $.537 \mathrm{E}+03$ & $.181 \mathrm{E}-03$ & $.267 \mathrm{E}+00$ & $.114 \mathrm{E}-03$ & $.233 \mathrm{E}+01$ & $.109 E-03$ & $.349 \mathrm{E}-02$ \\
\hline $.240 \mathrm{E}+02$ & $.293 \mathrm{E}+05$ & $.412 \mathrm{E}+02$ & $.162 \mathrm{E}+01$ & $.971 E-06$ & $.651 \mathrm{E}+03$ & $.219 E-03$ & $.326 \mathrm{E}+00$ & $.138 E-03$ & $.349 \mathrm{E}+01$ & $.157 \mathrm{E}-03$ & $.620 \mathrm{E}-02$ \\
\hline $.382 E+03$ & $.224 \mathrm{E}+05$ & $.931 \mathrm{E}-05$ & $.443 \mathrm{E}+01$ & $.448 \mathrm{E}-15$ & $.708 \mathrm{E}+04$ & $.402 \mathrm{E}-12$ & $.455 \mathrm{E}-01$ & $.217 \mathrm{E}-09$ & $.559 \mathrm{E}+03$ & $.726 \mathrm{E}-10$ & $.114 \mathrm{E}+02$ \\
\hline $.383 \mathrm{E}+03$ & $.224 E+05$ & .404 & $.437 \mathrm{E}+01$ & .44 & $.708 E+04$ & .40 & .44 & .94 & $.559 \mathrm{E}+03$ & $.336 \mathrm{E}-10$ & $.114 \mathrm{E}+02$ \\
\hline $.384 E+03$ & $.224 \mathrm{E}+05$ & $.175 \mathrm{E}-05$ & $.432 \mathrm{E}+01$ & $.438 E-15$ & $.708 \mathrm{E}+04$ & $.402 \mathrm{E}-12$ & $.444 \mathrm{E}-01$ & $.411 \mathrm{E}-10$ & $.559 \mathrm{E}+03$ & $.166 \mathrm{E}-10$ & $.114 \mathrm{E}+02$ \\
\hline $.385 E+03$ & $.224 \mathrm{E}+05$ & $.764 \mathrm{E}-06$ & $.427 \mathrm{E}+01$ & $.432 \mathrm{E}-15$ & $.708 E+04$ & $.402 \mathrm{E}-12$ & $.439 \mathrm{E}-01$ & $.179 E-10$ & $.559 \mathrm{E}+03$ & $.918 \mathrm{E}-11$ & $.114 E+02$ \\
\hline $.386 \mathrm{E}+03$ & $.224 \mathrm{E}+05$ & $.335 \mathrm{E}-06$ & $.422 \mathrm{E}+01$ & $.427 \mathrm{E}-15$ & $.708 E+04$ & $.402 \mathrm{E}-12$ & $.434 \mathrm{E}-01$ & $.783 \mathrm{E}-11$ & $.559 \mathrm{E}+03$ & $.596 \mathrm{E}-11$ & $.114 \mathrm{E}+02$ \\
\hline $.388 E+03$ & $.224 \mathrm{E}+05$ & $.148 \mathrm{E}-06$ & $.417 \mathrm{E}+01$ & $.422 \mathrm{E}-15$ & $.708 \mathrm{E}+04$ & $.402 \mathrm{E}-12$ & $.428 \mathrm{E}-01$ & $.344 \mathrm{E}-11$ & $.559 E+03$ & $.456 \mathrm{E}-11$ & $.114 \mathrm{E}+02$ \\
\hline $.389 E+03$ & $.224 \mathrm{E}+05$ & $.673 \mathrm{E}-07$ & $.412 \mathrm{E}+01$ & $.417 \mathrm{E}-15$ & $.708 E+04$ & $.402 E-12$ & $.423 \mathrm{E}-01$ & $.153 E-11$ & $.559 \mathrm{E}+03$ & $.395 E-11$ & $.114 \mathrm{E}+02$ \\
\hline $.390 \mathrm{E}+03$ & $.224 E+05$ & $.322 \mathrm{E}-07$ & $.407 \mathrm{E}+01$ & $.412 \mathrm{E}-15$ & $.708 \mathrm{E}+04$ & $.402 \mathrm{E}-12$ & $.418 \mathrm{E}-01$ & $.694 \mathrm{E}-12$ & $.559 \mathrm{E}+03$ & $.368 \mathrm{E}-11$ & $.114 \mathrm{E}+02$ \\
\hline
\end{tabular}

Figure C.7 CHAIN Isotope Masses Versus Time Output File

\begin{tabular}{|c|c|c|c|c|c|c|c|c|c|c|c|}
\hline \multicolumn{12}{|c|}{ Activity (Ci) } \\
\hline TIME (DAYS) & W 186 & W 187 & W 188 & W 189 & $\operatorname{Re} 187$ & $\operatorname{Re} 188 m$ & $\operatorname{Re} 188$ & $\operatorname{Re} 189$ & Os188 & $0 s 189 m$ & Os189 \\
\hline $.400 E+01$ & $.000 E+00$ & $.276 \mathrm{E}+08$ & $.212 \mathrm{E}+04$ & $.109 \mathrm{E}+02$ & $.000 \mathrm{E}+00$ & $.139 \mathrm{E}+04$ & $.273 E+05$ & $.716 \mathrm{E}+01$ & $.000 \mathrm{E}+00$ & $.837 E+01$ & $.000 \mathrm{E}+00$ \\
\hline $.800 E+01$ & $.000 \mathrm{E}+00$ & $.292 \mathrm{E}+08$ & $.513 E+04$ & $.265 E+02$ & $.000 \mathrm{E}+00$ & $.344 \mathrm{E}+04$ & $.840 \mathrm{E}+05$ & $.244 \mathrm{E}+02$ & $.000 \mathrm{E}+00$ & $.461 E+02$ & $.000 \mathrm{E}+00$ \\
\hline $.120 E+02$ & $.000 \mathrm{E}+00$ & $.292 E+08$ & $.808 E+04$ & $.418 \mathrm{E}+02$ & $.000 \mathrm{E}+00$ & $.552 \mathrm{E}+04$ & $.144 \mathrm{E}+06$ & $.429 E+02$ & $.000 E+00$ & $.110 E+03$ & $.000 \mathrm{E}+00$ \\
\hline $.160 \mathrm{E}+02$ & $.000 \mathrm{E}+00$ & $.291 E+08$ & $.109 E+05$ & $.564 E+02$ & $.000 \mathrm{E}+00$ & $.759 E+04$ & $.203 E+06$ & $.610 \mathrm{E}+02$ & $.000 \mathrm{E}+00$ & $.198 \mathrm{E}+03$ & $.000 \mathrm{E}+00$ \\
\hline $.200 \mathrm{E}+02$ & $.000 \mathrm{E}+00$ & $.290 \mathrm{E}+08$ & $.136 \mathrm{E}+05$ & $.704 E+02$ & $.000 \mathrm{E}+00$ & $.964 \mathrm{E}+04$ & $.262 E+06$ & $.784 \mathrm{E}+02$ & $.000 \mathrm{E}+00$ & $.311 E+03$ & $.000 \mathrm{E}+00$ \\
\hline $.240 \mathrm{E}+02$ & $.000 \mathrm{E}+00$ & $.289 E+08$ & $.162 \mathrm{E}+05$ & $.837 E+02$ & $.000 \mathrm{E}+00$ & $.117 E+05$ & $.321 \mathrm{E}+06$ & $.952 E+02$ & $.000 \mathrm{E}+00$ & $.447 E+03$ & $.000 \mathrm{E}+00$ \\
\hline $.382 \mathrm{E}+03$ & $.000 \mathrm{E}+00$ & $.652 \mathrm{E}+01$ & $.442 E+05$ & $.387 \mathrm{E}-07$ & $.000 \mathrm{E}+00$ & $.215 \mathrm{E}-04$ & $.447 E+05$ & $.149 \mathrm{E}-03$ & $.000 \mathrm{E}+00$ & $.207 E-03$ & $.000 \mathrm{E}+00$ \\
\hline $.383 E+03$ & $.000 \mathrm{E}+00$ & $.283 \mathrm{E}+01$ & $.437 \mathrm{E}+05$ & $.382 \mathrm{E}-07$ & $.000 \mathrm{E}+00$ & $.215 \mathrm{E}-04$ & $.442 E+05$ & $.651 \mathrm{E}-04$ & $.000 \mathrm{E}+00$ & $.957 \mathrm{E}-04$ & $.000 \mathrm{E}+00$ \\
\hline $.384 \mathrm{E}+03$ & $.000 \mathrm{E}+00$ & $.123 \mathrm{E}+01$ & $.432 \mathrm{E}+05$ & $.377 \mathrm{E}-07$ & $.000 \mathrm{E}+00$ & $.215 \mathrm{E}-04$ & $.436 \mathrm{E}+05$ & $.283 \mathrm{E}-04$ & $.000 \mathrm{E}+00$ & $.472 \mathrm{E}-04$ & $.000 \mathrm{E}+00$ \\
\hline $.385 \mathrm{E}+03$ & $.000 E+00$ & $.535 E+00$ & $.427 E+05$ & $.373 E-07$ & $.000 \mathrm{E}+00$ & $.215 E-04$ & $.431 E+05$ & $.124 \mathrm{E}-04$ & $.000 \mathrm{E}+00$ & $.262 \mathrm{E}-04$ & $.000 \mathrm{E}+00$ \\
\hline $.386 \mathrm{E}+03$ & $.000 \mathrm{E}+00$ & $.234 \mathrm{E}+00$ & $.422 \mathrm{E}+05$ & $.368 \mathrm{E}-07$ & $.000 \mathrm{E}+00$ & $.215 \mathrm{E}-04$ & $.426 \mathrm{E}+05$ & $.540 \mathrm{E}-05$ & $.000 \mathrm{E}+00$ & $.170 E-04$ & $.000 \mathrm{E}+00$ \\
\hline $.388 E+03$ & $.000 \mathrm{E}+00$ & $.104 \mathrm{E}+00$ & $.417 \mathrm{E}+05$ & $.364 \mathrm{E}-07$ & $.000 \mathrm{E}+00$ & $.215 \mathrm{E}-04$ & $.421 E+05$ & $.237 \mathrm{E}-05$ & $.000 \mathrm{E}+00$ & $.130 \mathrm{E}-04$ & $.000 \mathrm{E}+00$ \\
\hline $.389 E+03$ & $.000 \mathrm{E}+00$ & $.471 \mathrm{E}-01$ & $.412 E+05$ & $.360 \mathrm{E}-07$ & $.000 \mathrm{E}+00$ & $.215 \mathrm{E}-04$ & $.416 E+05$ & $.105 \mathrm{E}-05$ & $.000 \mathrm{E}+00$ & $.112 \mathrm{E}-04$ & $.000 \mathrm{E}+00$ \\
\hline $.390 E+03$ & $.000 \mathrm{E}+00$ & $.225 E-01$ & $.407 E+05$ & $.355 E-07$ & $.000 \mathrm{E}+00$ & $.215 \mathrm{E}-04$ & $.411 \mathrm{E}+05$ & $.479 \mathrm{E}-06$ & $.000 \mathrm{E}+00$ & $.105 \mathrm{E}-04$ & $.000 \mathrm{E}+00$ \\
\hline
\end{tabular}

Figure C.8 CHAIN Isotope Activities Versus Time Output File 
PNNL-13290

\section{Distribution}

No. of

Copies

\section{OFFSITE}

4 M.A. Garland

University of Maryland

Dept. of Materials \& Nuclear Engineering

College Park, MD 20742-2115

2 G.A. Pertmer

University of Maryland

Dept. of Materials \& Nuclear Engineering

College Park, MD 20742-2115

C.W. Alexander

Oak Ridge National Laboratory

P.O. Box 2008 MS6384

Oak Ridge, TN 37831-6384
No. of

Copies

ONSITE

DOE, Richland Operations Office

O.A. Farabee

N2-36

2 Fluor Daniel Hanford

D.B. Klos

N2-51

S.W. Scott

N2-57

Fluor DanieI Northwest

D.W. Wootan

B4-43

10 Pacific Northwest National Laboratory

T.S. Tenforde

P7-52

R.E. Schenter (2)

P7-25

Information Release Office (7)

Distr.1 